\title{
A Leap Forward in Iridium-NHC Catalysis: New Horizons and Mechanistic Insights
}

\author{
Manuel Iglesias, ${ }^{* a}$ Luis A. Oro*a,b
}

This review summarises the most recent advances in Ir-NHC catalysis while revisiting all the classical reactions in which this type of catalysts has proved active. The influence of the ligand system and, in particular, the impact of the NHC ligand in the activity and selectivity of the reaction has been analysed, accompanied by an examination of the great variety of catalytic cycles hitherto reported. The reaction mechanisms so far proposed are described and commented for each individual process. Moreover, some general considerations that attempt to explain influence of the NHC from a mechanistic viewpoint are presented at the end of the review. The first epigraphs are dedicated to the most widely explored reactions that use Ir-NHCs, i.e, hydrogenation and transfer hydrogenation, for which a general overview that tries to compile all the Ir-NHC catalysts hitherto reported for these processes is provided. The next sections deal with hydrogen borrowing, hydrosilylation, water splitting, dehydrogenation (of alcohols, alkanes, aminoboranes and formic acid), hydrogen isotope exchange (HIE), signal amplification by reversible exchange and $\mathrm{C}-\mathrm{H}$ bond functionalisation (silylation and borylation). The last section compiles a series of reactions somewhat less explored for Ir-NHC catalysts that include the hydroalkynylation of imines, hydroamination, diboration of olefins, hydrolysis and methanolysis of silanes, arylation of aldehydes with boronic acids, addition of aroyl chlorides to alkynes, visible light driven reactions, isomerisation of alkenes, asymmetric intramolecular allylic amination and reactions that employ heterometallic catalysts containing at least one Ir-NHC unit.

\section{Introduction}

Iridium catalysts have been notably successful in the chemoselective and enantioselective hydrogenation of $\mathrm{C}=\mathrm{N}$ and non-functionalised $\mathrm{C}=\mathrm{C}$ bonds, which are reactions of remarkable importance for the fine chemical industry. Prominent iridium catalysts have been reported during the last two decades, ${ }^{1}$ including noteworthy examples that have seen industrial application: (i) Crabtree's catalyst, namely $\left[\operatorname{Ir}(\mathrm{cod})\left(\mathrm{PCy}_{3}\right) \mathrm{py}_{\mathrm{PF}} \mathrm{P}_{6}(\mathrm{cod}=1,5\right.$-cyclooctadiene $),{ }^{2}$ is one of the most active catalysts for the hydrogenation of hindered $\mathrm{C}=\mathrm{C}$ bonds; (ii) The enantioselective catalysts developed by Pfaltz and co-workers for the asymmetric hydrogenation of unfunctionalysed $\mathrm{C}=\mathrm{C}$ bonds. ${ }^{3}$ Other remarkable Ir catalysed processes of industrial relevance are (iii) the carbonylation of methanol by the anion $\left[\operatorname{Ir}(\mathrm{CO})_{2} \mathrm{I}_{2}\right]^{-}$(Cativa process) ${ }^{4}$ and (iv) the synthesis of (S)-metolachor-achieved by means of a key step that involves the Ir-xyliphos-catalyzed enantioselective hydrogenation of an aromatic imine. ${ }^{5}$

The use of $\mathrm{N}$-heterocyclic carbenes (NHCs) as ancillary ligands in catalysis has experienced a dramatic increase since the seminal work by Arduengo's and Herrmann's groups. The former reported on the isolation and characterisation of the first stable and isolable carbene, ${ }^{6}$ while the latter disclosed the first example of the use of an ancillary NHC ligand in homogeneous catalysis. $^{7}$ Initially seen as analogues of the ubiquitous phosphine ligands, NHCs have shown remarkable capabilities that distinguish them from phosphines: (i) NHCs are usually stronger $\sigma$-donors that often lead to more robust metal-ligand bonds. This results in more electron rich metal centres and sturdier catalysts. (ii) The umbrella-shaped structure of NHCs, with the wingtip groups pointing toward the metal centre, contrasts sharply with the cone-shaped arrangement of phosphines, where the substituents at the phosphorus atom are oriented away from the metallic core. Consequently, NHC ligands may offer a greater steric protection of the metal centre, thus stabilising unsaturated intermediates of the catalytic cycle. ${ }^{8}$

The Grubbs' second-generation catalyst for olefin metathesis and the PEPPSI ${ }^{\mathrm{TM}}$ catalyst developed by Organ et al. for crosscoupling reactions are noteworthy examples that show the impact of NHC ligands in the catalytic performance of organometallic complexes. ${ }^{9}$ The widespread use of NHCs as spectator ligands for transition metal complexes has boosted the development of new iridium catalysts; proof of this is the increasing number of publications that deal with the application of Ir-NHC complexes in homogeneous catalysis during the last decade, and the ever growing diversity of processes that these species are able to catalyse. In fact, more papers on Ir-NHC catalysis have been published in the last 7 years than in the previous 20 , since the isolation of the first NHC. ${ }^{6}$ The successful use of Ir-NHC complexes in new processes, different from the largely explored hydrogenation reactions, has powerfully emerged in recent years. Especially remarkable is their contribution to the development of reactions such as water oxidation, dehydrogenation, $\mathrm{C}-\mathrm{H}$ functionalisation, signal amplification by reversible exchange (SABRE), deuteration, visible-light-driven reactions, or borrowing hydrogen process.

In this review, we aim to classify and comprehensively analyse these contributions, including mechanistic insights and providing a critical examination of the role played by the NHC ligand on the catalytic processes under study. Several accounts that deal with the catalytic application of $\mathrm{NHCs}^{10}$ and group 9 NHC complexes ${ }^{11,12}$ have been published. However, a detailed revision that includes the most recent advances in this fastdeveloping field feels indispensable, especially taking under account the amount of outstanding contributions, particularly on novel processes, that have been unveiled in the last five years.

\section{Hydrogenation reactions}


Early work on Ir-NHC catalysed hydrogenation reactions by Nolan et al. studied the effect that exchanging the $\mathrm{PC}_{3}$ ligand in Crabtree's catalyst $(1),\left[\operatorname{Ir}(\operatorname{cod})\left(\mathrm{PCy}_{3}\right) \mathrm{Py}_{\mathrm{P}} \mathrm{PF}_{6},(\operatorname{cod}=1,5-\right.$ cyclooctadiene) by SIMes (1,3-Bis(2,4,6-trimethylphenyl)-4,5dihydroimidazol-2-ylidene) would have in the catalytic activity of the process (Figure 1). ${ }^{13}$ The nature of the ligands accompanying 1,5-cyclooctadiene in the coordination sphere is crucial for the stability and activity of this type of hydrogenation catalyst, since the latter acts as a sacrificial ligand that is hydrogenated to generate the unsaturated active species. A higher activity for the reduction of alkenes with [ $\operatorname{Ir}(\mathrm{cod})\left(\mathrm{SIMes}_{\mathrm{N}} \mathrm{py} \mathrm{PF}_{6}(\mathbf{2})\right.$ was observed at $50^{\circ} \mathrm{C}$ and under $4 \mathrm{~atm}$ of $\mathrm{H}_{2}$ when compared to Crabtree's catalyst, although the latter proved to perform better at room temperature and atmospheric pressure. This behaviour was explained on the grounds of the greater steric bulk of the NHC ligand, which confers a higher stability to the catalyst, but also hampers its reactivity when operating under mild conditions. This agrees with the results reported by Cavell's group on expanded-ring $\mathrm{NHC}(e \mathrm{NHC})$ rhodium complexes, namely $[\mathrm{Rh}(\mathrm{Cl})(\mathrm{cod})(e \mathrm{NHC})] \mathrm{PF}_{6}$, where more hindered $\mathrm{NHC}^{\prime}$ s lead to higher catalytic activities due to a better stabilisation of the active species. ${ }^{14}$ In this context, iridium complexes featuring 6and 7-membered NHC ligands have shown good activities in the hydrogenation of non-hindered alkenes under mild conditions. ${ }^{15}$ Further modifications of Crabtree's catalyst by Buriak and co-workers entailed the substitution of the pyridine ligand by phosphanes, and the use less hindered NHCs than the SIMes employed by Nolan, with $\left[\operatorname{Ir}(\operatorname{cod})(\mathrm{SIMe}) \mathrm{P}\left({ }^{n} \mathrm{Bu}\right)_{3}\right] \mathrm{PF}_{6}$ (3) being the most active catalyst of the series. ${ }^{16}$ This resulted in better activities at room temperature and atmospheric pressure than $\mathbf{2}$, and close to those obtained by $\mathbf{1}$, which illustrates well the difficulties to achieve an appropriate balance between activity and stability of the catalyst. ${ }^{17}$ Optimisation of the $\mathrm{NHC} /$ phosphine ligand couple and the counteranion led to the development of catalyst $\mathbf{4}$, which selectively hydrogenates the $\mathrm{C}=\mathrm{C}$ bond of a wide range of $\alpha, \beta$-unsaturated carbonyl compounds, showing higher activities than Crabtree's catalyst for this process in a variety of solvents. The related catalyst $\mathbf{5}^{18}$ proved effective for the hydrogenation of a range of $\mathrm{N}$ heterocyclic compounds in the presence of catalytic amounts $\mathrm{PPh}_{3}$ under mild conditions. Stoichiometric experiments suggest that the dihydrogen dihydride complex formed upon 1,5cyclooctadiene hydrogenation is stabilised by the coordination of a second $\mathrm{PPh}_{3}$ ligand. Remarkably, theoretical studies support an outer-sphere mechanism for this reaction. The migratory insertion of the $\mathrm{C}=\mathrm{N}$ bond into a metal-hydride, according to a classical inner-sphere mechanism, is not energetically affordable under the experimental conditions. As an alternative, an outer sphere-mechanism was proposed in which the substrate undergoes a series of protonation reactions and hydride transfers from a coordinated dihydrogen molecule and a hydride ligand, respectively (Scheme 1).

Other noteworthy variation on Crabtree's catalyst is the neutral complex 6, [(WCA-NHC) Ir(cod)], which presents an IDipp (1,3bis-(2,6-diisopropylphenyl)imidazol-2-ylidene) ligand bearing a borate moiety $\left(-B\left(C_{6} F_{5}\right)_{3}\right)$ at the backbone. The resulting zwitterionic complex can be described as an anionic NHC ligand tethered to an $[\operatorname{lr}(\operatorname{cod})]^{+}$fragment, with the vacant coordination site being stabilised by a short contact interaction with the ipsocarbon of the diisopropylphenyl group, which causes the NHC to tilt toward the metal centre (Figure 1). This complex showed remarkable activity in the hydrogenation of hindered alkenes in non-polar solvents and even in neat alkenes. This has been attributed to its enhanced solubility when compared with related cationic catalysts, which is conferred by its neutral nature. ${ }^{19}$ The seminal work by Pfaltz ${ }^{20,3 a}$ on P-N chelate ligands for Ir-catalysed hydrogenations paved the way to Ir-complexes featuring heteroditopyc NHC ligands. This type of complexes has been especially successful in the asymmetric version of this reaction, ${ }^{21}$ with the chiral NHC-oxazolyl Ir-complexes developed by Burgess et al. being particularly remarkable (e.g. complex 7 , Figure 2).

Structurally, these complexes are very similar to the cationic $[\operatorname{Ir}(\mathrm{P}-\mathrm{N})(\mathrm{cod})]^{+}$catalysts previously described by Pfaltz, as they present a 1,5-cyclooctadiene ligand trans to the P-N chelate, both being coordinated to an iridium(I) centre (Figure 2). ${ }^{22}$ Other notable examples of complexes featuring ditopic NHC-N ligands that showed good activities and enantiomeric excesses (ee's) for the hydrogenation of alkenes are $\mathbf{8}$ and $\mathbf{9}$ (Figure 2).

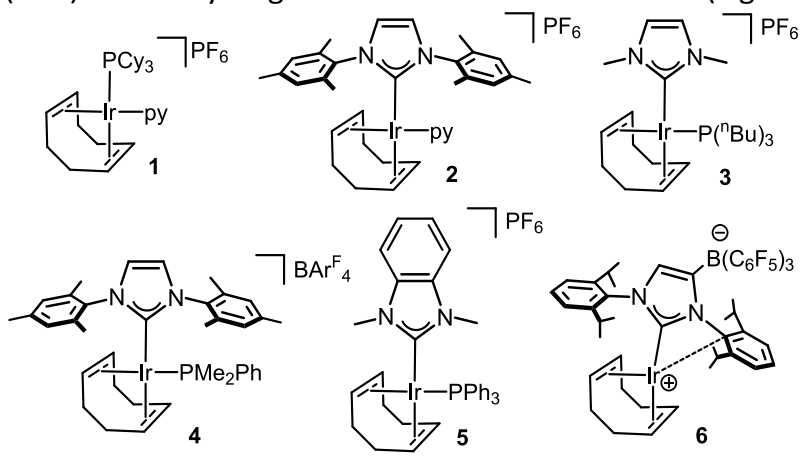

Figure 1 Cationic hydrogenation catalysts based on the $[\operatorname{Ir}(\operatorname{cod})(\mathrm{NHC})(\mathrm{L})]^{+}$scaffold. 


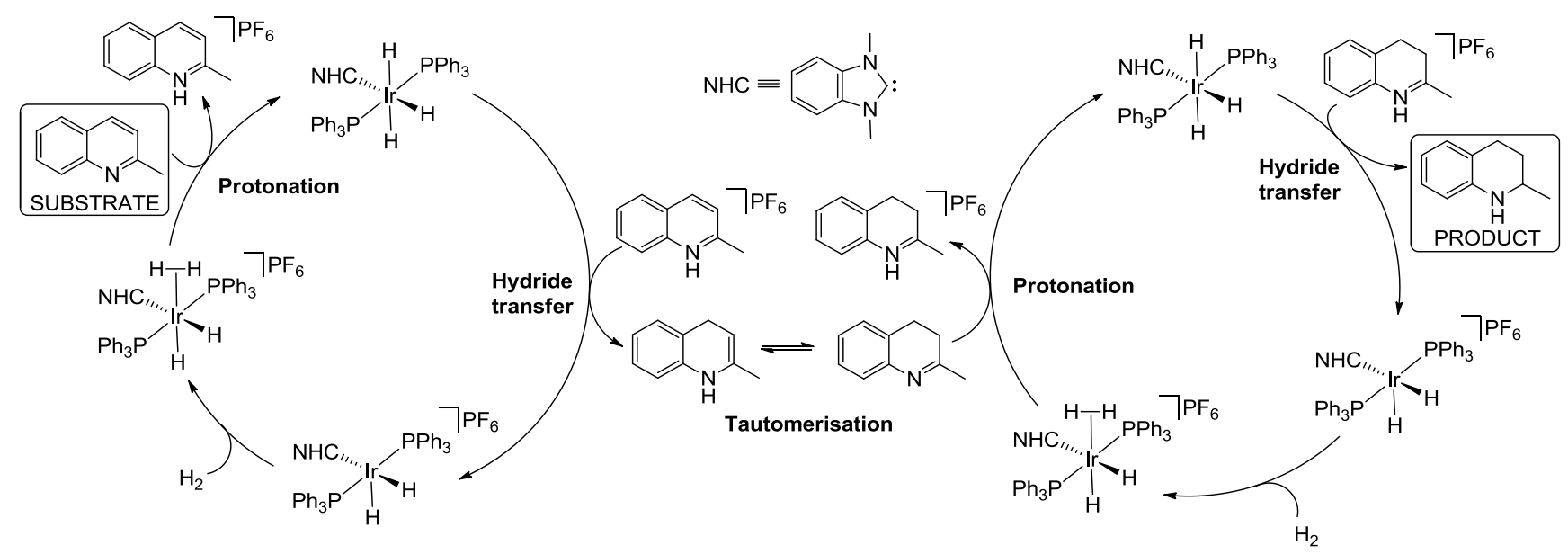

Scheme 1 Outer-Sphere mechanism for the hydrogenation of N-Heterocyclic compounds. ${ }^{18}$

The former features a pyridine based wingtip group at the $\mathrm{NHC},{ }^{23}$ while the latter presents a thiazole moiety at the wingtip group. ${ }^{24} \operatorname{Ir}(\mathrm{NHC}-\mathrm{N})$ complex 10,25 however, showed somewhat lower ee's. The related NHC-P catalyst $\mathbf{1 1}$, showed a significantly lower chiral induction compared to the previously described NHC-N based catalysts. ${ }^{26}$

Monodentate NHCs containing chiral backbones have also been studied as ligands for asymmetric hydrogenation, but, in general, modest optical inductions were obtained for their corresponding iridium catalysts $12,{ }^{27} 13,{ }^{28} 14,,^{28} 15^{29}$ and $16^{30}$ (Figure 3).

NHC-N Ir complexes presenting a coordinated $\mathrm{NH}_{2}$ moiety (17 and 18 , Figure 4 ) are able to reduce unsaturated polar bonds ${ }^{31}$ via an outer-sphere mechanism assisted by an external base, namely isopropoxide, where metal-ligand cooperation ${ }^{32}$ plays a key role (Scheme 2 ).
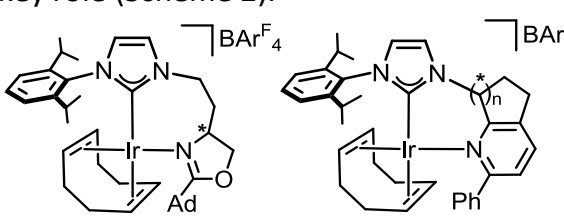

8

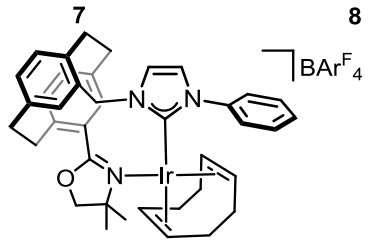

10

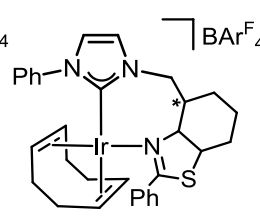

9

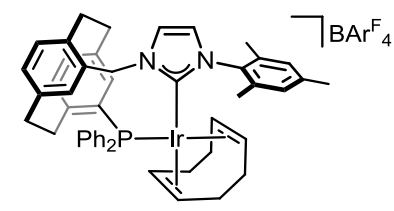

11
Figure 2 Chiral cationic hydrogenation catalysts based on the $[\operatorname{Ir}(\operatorname{cod})(\mathrm{NHC}-\mathrm{N})]^{+}$scaffold

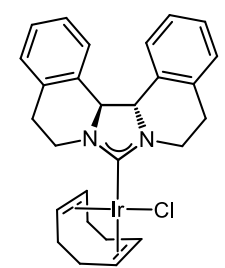

12

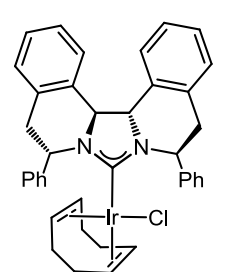

13

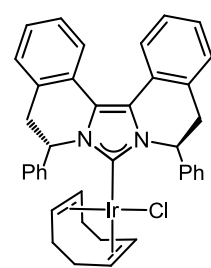

14

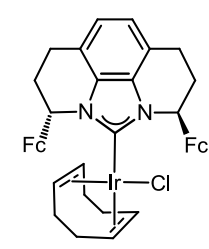

15

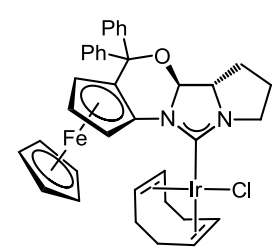

Figure 3 Chiral neutral hydrogenation catalysts based on the $[\mathrm{Ir}(\mathrm{Cl})(\mathrm{cod})(\mathrm{NHC})]$ scaffold.

Iridium(III) complexes bearing a chelating NHC-C ligand (19 and 20, Figure 4) have proved effective catalysts for the hydrogenation of imines under low hydrogen pressure, possibly operating as well by an outer-sphere mechanism that requires metal-ligand cooperation to achieve the heterolytic cleavage of the $\mathrm{H}_{2}$ molecule. ${ }^{33}$

Interesting types of Ir-NHC catalysed hydrogenation reactionsespecially when aiming at the development of green and sustainable processes-are those that allow performing the reaction in aqueous media. For this purpose, the design of water-soluble and water-stable catalysts is required. Several examples of water-soluble Ir-NHC catalysts for hydrogenation have been described in the literature. For instance, complex 21, decorated with a sulfonate moiety, catalyses the reduction of acetophenone in an aqueous solution of sodium hydroxide. ${ }^{34}$ Complex 22, which features an NHC ligand and a water-soluble phosphine, namely $[\operatorname{Ir}(\mathrm{cod})(\mathrm{NHC})(\mathrm{PTA})] \mathrm{Cl}$, (PTA $=1,3,5$-Triaza-7- 


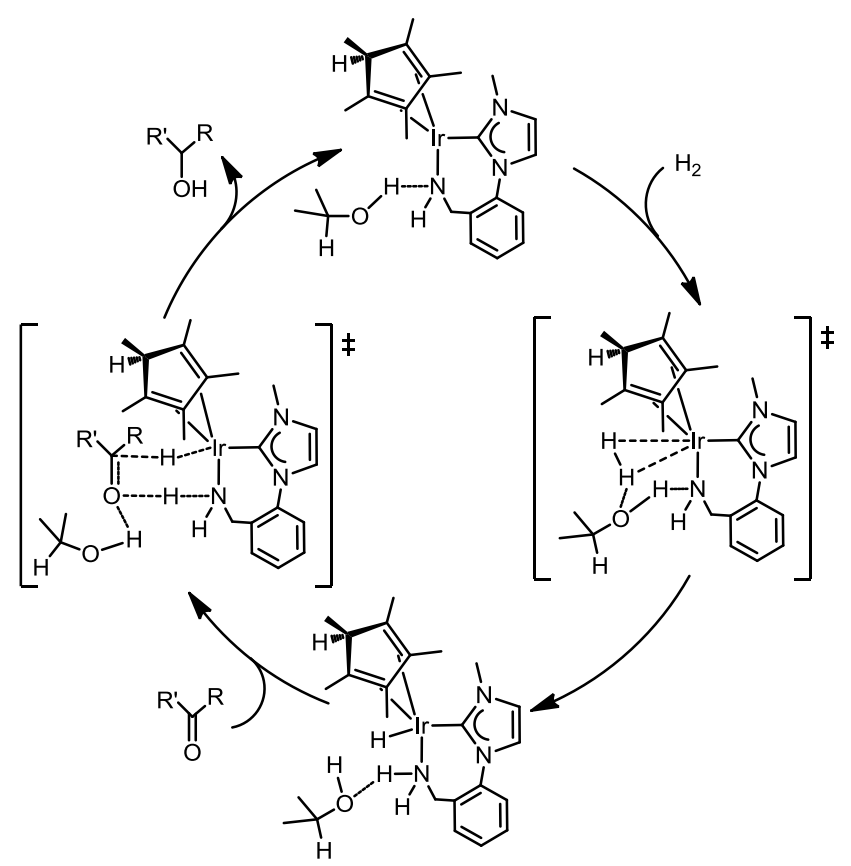

Scheme 2 External base assisted outer-sphere mechanism for the hydrogenation of carbonyl compounds. ${ }^{31 \mathrm{~b}}$

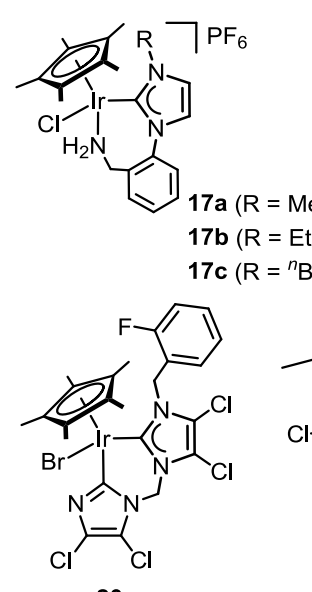

20
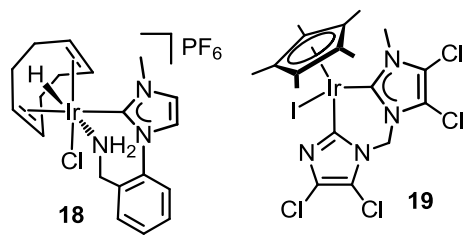

19

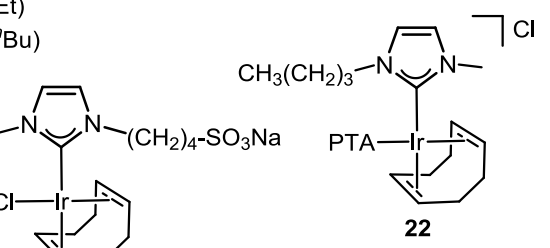

21

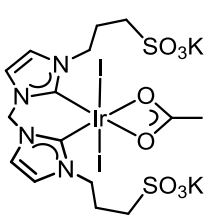

23

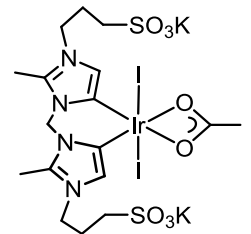

24
Figure 4 Water-soluble Ir-NHC catalysts.

phosphaadamantane) has been used successfully for the reduction of alkenoic and oxo acids under atmospheric hydrogen pressure in aqueous solution. Other water-soluble catalysts generated in situ by reaction of $[\mathrm{IrCl}(\mathrm{cod})(\mathrm{NHC})]$ complexes with mtppms-Na (sodium 3diphenylphosphinobenzenesulfonate), mtppts- $\mathrm{Na}_{3}$ (trisodium 3,3', $3^{\prime \prime}$-phosphinetriylbenzenesulfonate), and PTA were also capable of promoting the hydrogenation of itaconic acid. Remarkably, these catalysts were also active for the redox isomerisation of allylic alcohols under relatively mild conditions. ${ }^{35}$

Hydrogenation reactions in aqueous solution are especially interesting in the case of $\mathrm{CO}_{2}$ reduction to formic acid, since this reaction is thermodynamically favoured in water $\left(\Delta \mathrm{G}=-4 \mathrm{kJmol}^{-}\right.$ $\left.{ }^{1}\right) .{ }^{36}$ In this regard, complexes $\mathbf{2 3}$ and 24, depicted in Figure 4, are efficient catalysts for the reduction of $\mathrm{CO}_{2}$ to potassium formate using $60 \mathrm{~atm}$ of a $\mathrm{CO}_{2} / \mathrm{H}_{2}$ mixture (1:1) at temperatures ranging from 80 to $200{ }^{\circ} \mathrm{C}$ in a $1 \mathrm{M}$ solution of $\mathrm{KOH}$ in water.

Remarkably, 24 shows higher activities (TOFs) than 23, which was attributed to the presence of two abnormally bound $\mathrm{NHCs},{ }^{8 h}$ thus resulting in a more electron-rich iridium centre in the case of $\mathbf{2 4 . 3 6 0}$

Recently, heterogeneous catalysts based on porous organic frameworks that feature $\mathrm{Cp}$ *IrNHC-py active sites have proved active for the hydrogenation of $\mathrm{CO}_{2}$ to formate in a $1 \mathrm{M}$ aqueous solution of $\mathrm{Et}_{3} \mathrm{~N}^{37}$

The straightforward functionalisation of imidazolium salts permits the synthesis of a great variety of molecular architectures, which opens a door to further development of NHC ligands by increasing their chemical complexity. For instance, CNP-complex $\mathbf{2 5}$ is an NHC-based pincer ligand, which acts as a catalyst for the hydrogenation of a variety of ketones in the presence of catalytic amounts of $\mathrm{KO}^{\mathrm{t}} \mathrm{Bu}$. The deprotonation of the $\mathrm{CH}_{2} \mathrm{P}$ moiety to give $\mathbf{2 6}$ triggers the activation of the $\mathrm{H}-\mathrm{H}$ bond by means of a ligand-assisted mechanism that affords the active species $\mathbf{2 7}$ upon rearomatisation of the pyridine moiety (Scheme 3 ). ${ }^{38}$

\section{Transfer hydrogenation reactions}

In contrast with the hydrogenation reactions described earlier, transfer hydrogenation reactions employ a sacrificial hydrogen donor instead of $\mathrm{H}_{2}$ for the reduction of multiple bonds, the most popular being isopropanol ('PrOH). According to the oxidation state of the metal centre, Ir-NHC catalysts for the transfer hydrogenation reaction may be classified into: (i) Iridium(I) complexes based on the scaffold $[\operatorname{IrX}(\mathrm{NHC})(\mathrm{cod})]$ or $[\mathrm{IrL}(\mathrm{NHC})(\mathrm{cod})]^{+}$; and iridium(III) complexes that respond to the general formula $\left[\operatorname{Ir}(\mathrm{AcO})(\mathrm{I})_{2}(\right.$ bis-NHC)$],\left[\operatorname{Ir}(\mathrm{I})_{2}(\mathrm{~L})_{2}(\text { bis-NHC) }]^{+}\right.$or $\left[\operatorname{Ir}\left(\mathrm{Cp}^{*}\right)(\mathrm{X})_{2}(\mathrm{NHC})\right]$, and their cationic derivatives $(\mathrm{X}=$ anionic ligand; $L=$ neutral ligand). $A$ compilation of the most significant Ir-NHC transfer hydrogenation catalysts hitherto reported is presented below, together with a brief description of their properties and activity. For more detailed information the reader may consult recent revisions on this topic. ${ }^{39,11 b}$ Iridium(I) catalysts have shown excellent activity in the transfer hydrogenation reaction (Figure 5, complexes 28-53 and Figure 6, complexes 54-63), performing, as a general rule, better than their Ir(III) counterparts.

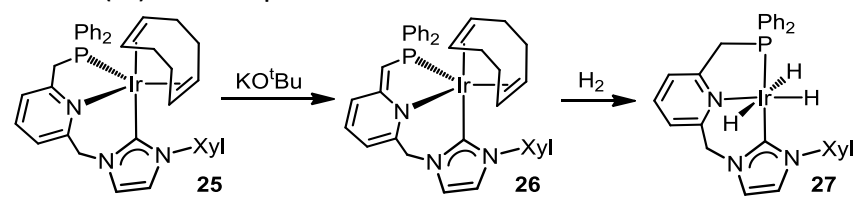

Scheme 3 Activation process for pre-catalyst 25. 

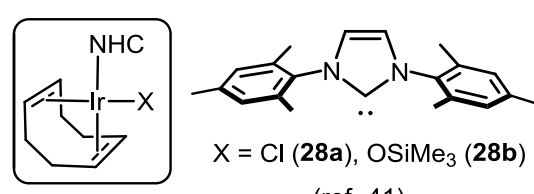

(ref. 41)

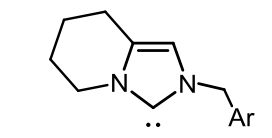

$\mathrm{X}=\mathrm{Br}$

$\mathrm{Ar}=\mathrm{Ph}(\mathbf{3 2 a})$

$\mathrm{Ar}=$ 2,3,5,6-tetramethylPh (32b)

$\mathrm{Ar}=$ pentamethylPh (32c)

(ref. 45)

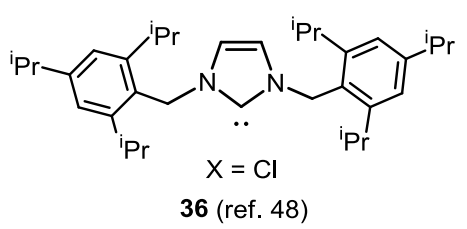

36 (ref. 48)

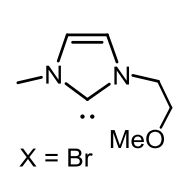

39 (ref. 40)

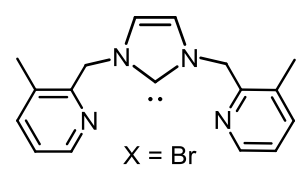

29 (ref. 42)

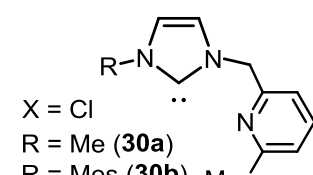

$\mathrm{R}=\operatorname{Mes}(\mathbf{3 0 b})$ (ref. 43)<smiles></smiles>

31 (ref. 44)

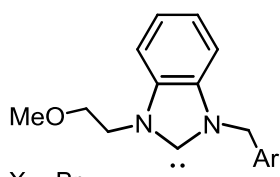

$\mathrm{X}=\mathrm{Br}$

$\mathrm{Ar}=2,3,5,6$-tetramethylPh (33a)

$\mathrm{Ar}=$ pentamethylPh $(\mathbf{3 3 b})$

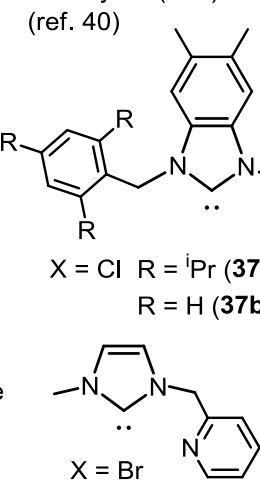

$\mathrm{X}=\mathrm{Br}$

42 (ref. 40 )

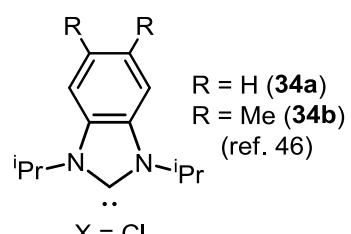

.

$\mathrm{X}=\mathrm{Br}$

35 (ref. 47)<smiles>[X]=CN(CCC)c1ccccc1OC</smiles>

$$
n=1, R=\operatorname{Mes}(44 a), \operatorname{DiPP}=(44 b)
$$

$n=2, R=\operatorname{Mes}(44 c), \operatorname{DiPP}=(44 d)$ (ref. 49)

$$
\begin{aligned}
& \mathrm{X}=\mathrm{Cl}, \mathrm{R}=\mathrm{Me}(50 \mathrm{a}) \\
& \mathrm{X}=\mathrm{I}, \mathrm{R}=\mathrm{Me}(50 \mathrm{~b}) \\
& \mathrm{X}=\mathrm{Cl}, \mathrm{R}=\mathrm{Cy}(51 \mathrm{a}) \\
& \mathrm{X}=\mathrm{I}, \mathrm{R}=\mathrm{Cy}(51 \mathrm{~b}) \\
& \mathrm{X}=\mathrm{Cl}, \mathrm{R}={ }^{\mathrm{t}} \mathrm{Bu}(52 \mathrm{a}) \\
& \mathrm{X}=\mathrm{Cl}, \mathrm{R}=4-\mathrm{F}-\mathrm{Ph}(52 \mathrm{~b}) \\
& \text { (ref. } 50)
\end{aligned}
$$<smiles>[X]=CN(C1CCCCC1)C1CCCCN1</smiles>

45 (ref. 49)<smiles></smiles>

(ref. 48)
(P)

$\mathrm{R}=\mathrm{H}(\mathbf{3 8 a})$

$\mathrm{R}=\mathrm{C}(\mathrm{O}) \mathrm{CH}_{3}(\mathbf{3 8 b})$

$\mathrm{R}=\mathrm{C}(\mathrm{O}) \mathrm{CH}\left(\mathrm{CH}_{3}\right)_{2}(38 \mathrm{c})$

$\mathrm{R}=\mathrm{C}(\mathrm{O}) \mathrm{C}\left(\mathrm{CH}_{3}\right)_{3}(\mathbf{3 8 d})$

$\mathrm{R}=\mathrm{C}(\mathrm{O}) \mathrm{C}_{6} \mathrm{H}_{5}(\mathbf{3 8 e})$

(ref. 14)

Figure 5 Summary of neutral $\operatorname{Ir}(\mathrm{I})$ transfer hydrogenation catalysts of general formula $[\operatorname{Ir}(\operatorname{cod})(\mathrm{NHC})(\mathrm{X})](\mathrm{X}=\mathrm{halide})$.

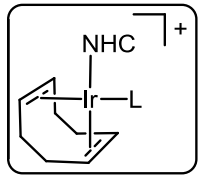

$\underset{\mathrm{L}=\text { py }}{\overbrace{\cdots}^{\mathrm{N}-\mathrm{N}}}$

$R=\operatorname{Mes}(54 a)$
$R=\operatorname{Dipp~(54b)}$
$R=$ Cy (54c)
(ref. 51)

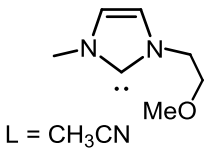

55 (ref. 40)<smiles>[X][V]1CN(C)C=NN1C</smiles>

46 (ref. 50)<smiles>[X]=[V]Cl</smiles>

43 (ref. 40)

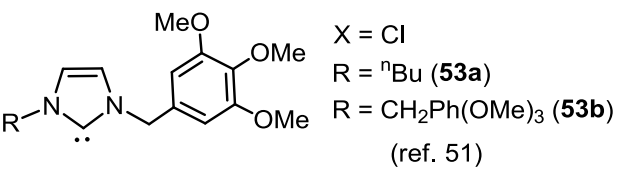

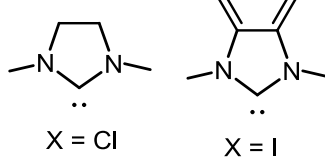

47 (ref. 50)

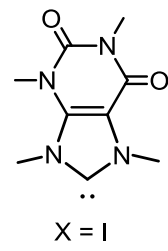

49 (ref. 50)

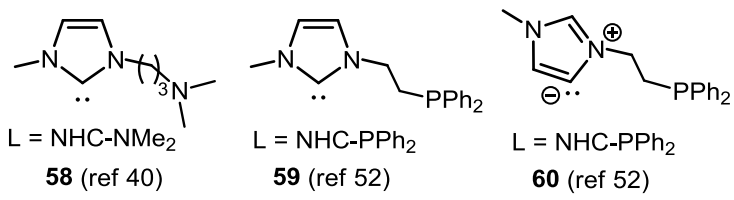

58 (ref 40)
59 (ref 52)

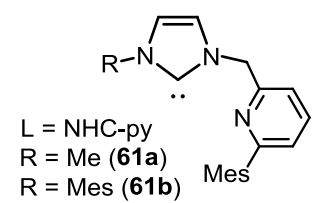

(ref 43)

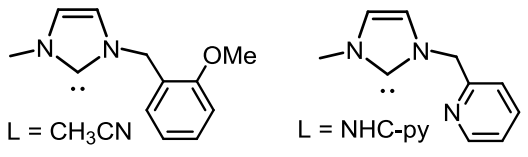

57 (ref. 40)<smiles></smiles>

$\mathrm{L}=$ py $(\mathbf{6 2 a}-\mathrm{c})$

$\mathrm{L}=\mathrm{PPh}_{3}(63 \mathrm{a}-\mathrm{c})$

$\mathrm{R}^{1}, \mathrm{R}^{2}={ }^{\mathrm{n}} \mathrm{Bu}, \mathrm{PhCH}_{2}$ (a)

$\mathrm{R}^{1}, \mathrm{R}^{2}=$ neopentyl, ${ }^{\mathrm{n}} \mathrm{Bu}(\mathrm{b})$

$\mathrm{R}^{1}, \mathrm{R}^{2}=$ neopentyl, $\mathrm{PhCH}_{2}$ (c)

Figure 6 Summary of cationic $\operatorname{Ir}(\mathrm{I})$ transfer hydrogenation catalysts of general formula $[\operatorname{Ir}(\operatorname{cod})(\mathrm{NHC})(\mathrm{L})](\mathrm{L}=$ neutral ligand). 


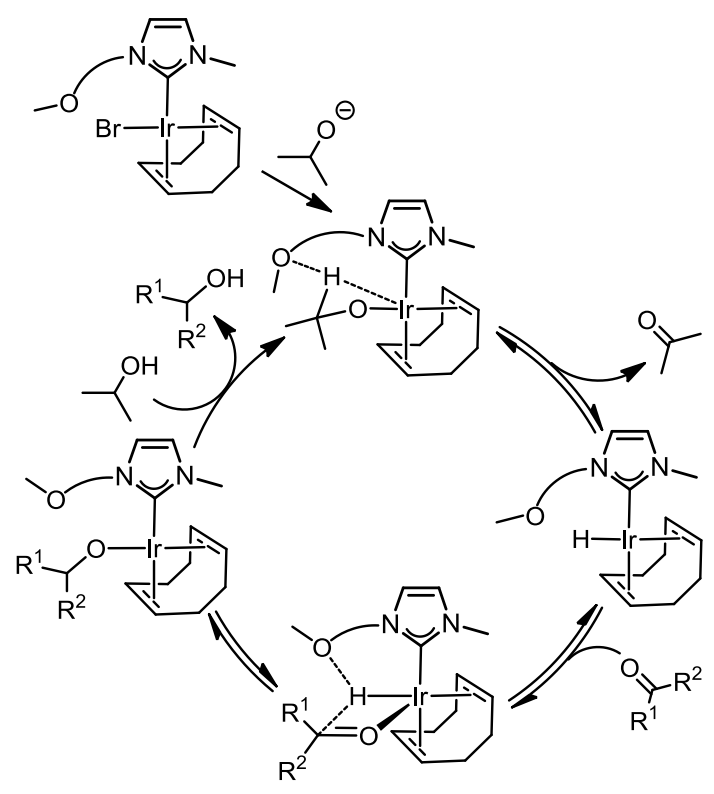

Scheme 4. Calculated catalytic cycle for the transfer hydrogenation of ketones employing $[\operatorname{Ir}(\operatorname{cod})(\mathrm{NHC}) \mathrm{X}]$ complexes having O-donors at the NHC as catalysts. ${ }^{40}$

Although the comparison with other catalysts is not straightforward due to the diverse reaction conditions and different indexes employed for measuring the catalytic activity that are present in the literature (TOFs at different stages of the reaction, TON, conversion/time, etc.), the highest TOF values so far reported for Ir-NHC catalysts usually feature $\operatorname{Ir}(\mathrm{I})$ metal centres. Remarkable examples are complexes $\mathbf{3 6}$ and $\mathbf{3 7}$ that yield TOF values up to $24000 \mathrm{~h}^{-1}$, or $\mathbf{3 4}$, with a TOF value of 7560 $\mathrm{h}^{-1}$ for the hydrogenation of acetophenone. However, the highest TOF so far reported is that obtained with $\operatorname{Ir}(\mathrm{III})$ bisNHC complex 72b (TOF $\left.=50000 \mathrm{~h}^{-1}\right)$.

The nature of the donor function at Ir-NHC catalysts featuring heteroditopyc ligands seems to play an important role in the activity of the catalyst. The presence of a hemilabile function often gives rise to higher activities than a strongly coordinating wingtip group, since the related chelate complexes are less prone to render the square-planar Ir-alkoxo intermediate. Metal-ligand cooperation in monohydride mechanisms has also been postulated for $[\operatorname{Ir}(\operatorname{cod})(\mathrm{NHC}) \mathrm{X}]$ complexes that feature an ether function at the wingtip group of the NHC (Scheme 4). 40 Noteworthy cases of highly active iridium complexes containing NHCs with hemilable side arms are $\mathbf{2 9}$ (TOF values up to $7500 \mathrm{~h}^{-}$ 1 for acetophenone), 31 (TOF $=11400 \mathrm{~h}^{-1}$ for $\mathrm{p}$ chloroacetophenone, $5400 \mathrm{~h}^{-1}$ for acetophenone) or $\mathbf{5 6}$ (TOF = $4622 \mathrm{~h}^{-1}$ for cyclohexanone) (Figure 6, complexes 54-63).

$\operatorname{Ir}(\mathrm{I})$ biscarbene complexes have also proved to be active catalysts for the transfer hydrogenation reaction, although usually lower activities were observed in comparison with their monocarbene counterparts. This agrees with the fact that hemilabile ligands usually lead to better activities than those featuring a strongly coordinating moiety (Figure 7, complexes 64-65).

The reaction mechanism for complexes 64a-c was studied in detail by theoretical calculations to conclude that the monohydride and MPV-like mechanisms were both possible
$(\mathrm{MPV}=$ Meerwein-Ponndorf-Verley $)$ under the reaction conditions. $^{55}$

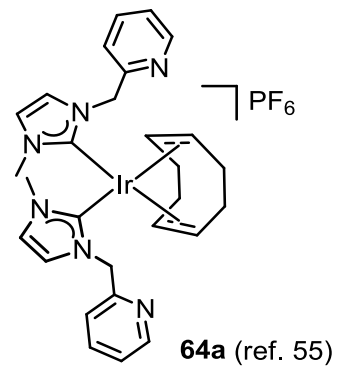

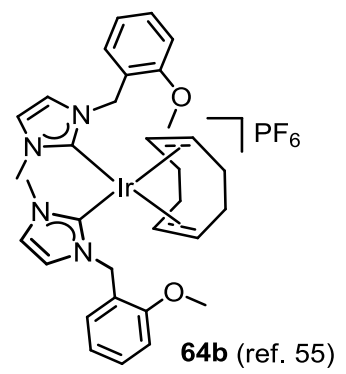<smiles>CCCCCC(C)(C)C(C)(C)C</smiles>

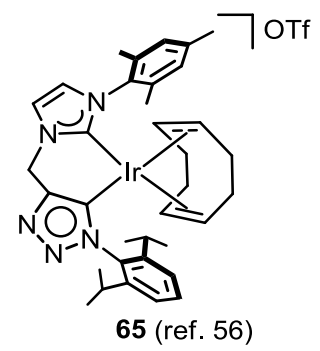

Figure 7 Summary of bis-NHC iridium(l) catalysts for transfer hydrogenation.

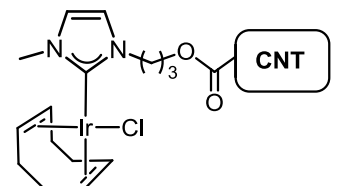

66 (ref. 57)<smiles></smiles>

68 (ref. 57)

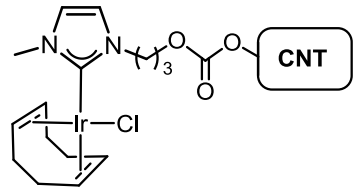

67 (ref. 57)

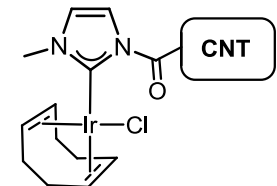

69 (ref. 57)

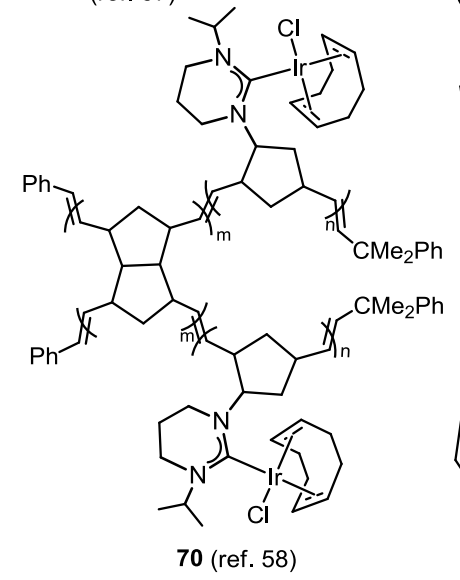

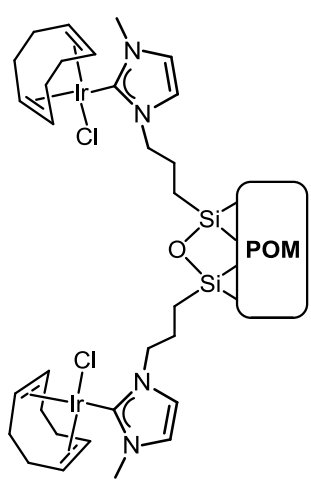

71 (ref. 58)

Figure 8 Summary of supported iridium(I) catalysts for transfer hydrogenation (POM = Polyoxometalate; CNT = Carbon nanotube). 


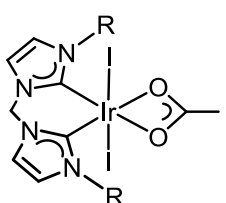

$\mathrm{R}={ }^{\mathrm{i}} \operatorname{Pr}(\mathbf{7 2 a})$ (ref. 59)

$R=$ neo-pentyl (72b) (ref. 59 )

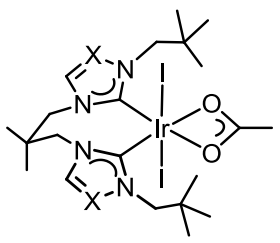

$\mathrm{X}=\mathrm{CH}(73 \mathrm{a})$

$X=N(73 b)$

(ref. 60)

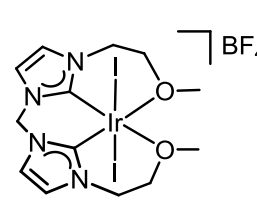

74 (ref. 62)

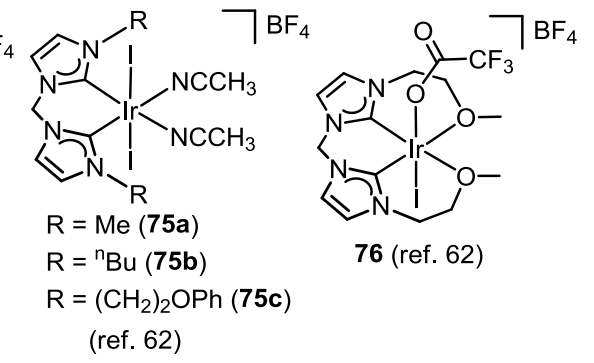

Figure 9 Summary of bis-NHC iridium(III) catalysts for transfer hydrogenation.

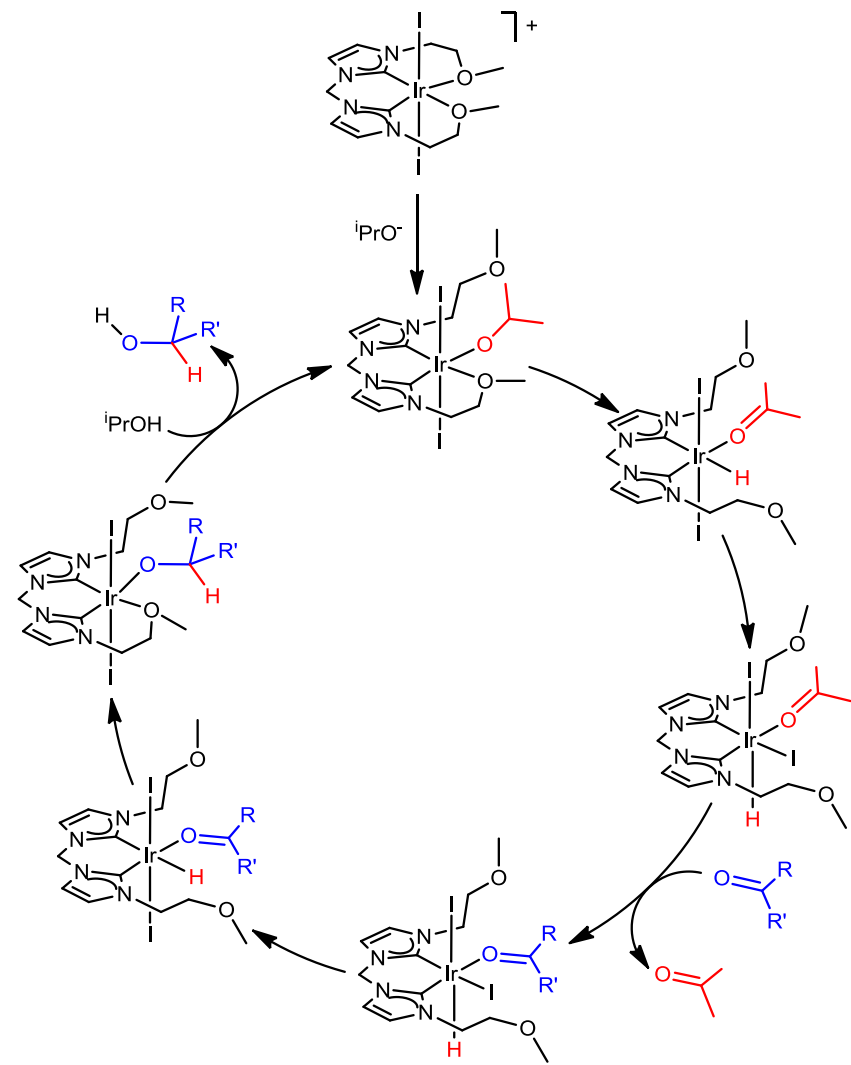

Scheme 5 Proposed catalytic cycle for the transfer hydrogenation of ketones using catalyst $74 .^{62}$

The hydride mechanism was proposed to be more likely for $\mathbf{6 4 b}$, although due the similar energy spans observed for both mechanisms, direct hydrogenation should not be discarded. ${ }^{55}$ A number of iridium(I) catalysts supported on a variety of materials have also been reported (Figure 8, complexes 66-71). In addition to the advantages resulting from the recyclability of the heterogenised catalyst, in some cases they even surpass the activity of their parent homogeneous catalyst. For example, carbon nanotube (CNT) supported Ir-NHC complex 66 renders a
TOF value of $5550 \mathrm{~h}^{-1}$, which is significantly higher than that obtained with its homogeneous analogue (TOF $=4680 \mathrm{~h}^{-1}$ ). BisNHC-Ir(III) complexes have shown good activities in the transfer hydrogenation of ketones, aldehydes, imines and $\alpha, \beta-$ unsaturated ketones (Figure 9, complexes 72-76). Moreover, Peris and co-workers have described the use of this type of complexes, namely $\mathbf{2 3}$ and $\mathbf{2 4}$, as catalysts for transfer hydrogenation reactions using glycerol as the solvent and hydrogen donor. ${ }^{54}$

The most commonly proposed mechanism for iridium(III) catalysed transfer hydrogenation reactions takes place via the hydridic route. ${ }^{61}$ In this regard, a detailed reaction mechanism has been proposed for catalysts $\mathbf{7 4}$ and $\mathbf{7 5} .{ }^{62}$ Scheme 5 shows the postulated catalytic cycle for complex 74. The initial step requires the dissociation of one of the ether moieties to allow the coordination of the isopropoxide, which undergoes $\beta$ elimination of the $\mathrm{C}-\mathrm{H}$ bond upon decoordination of the second wingtip group. The subsequent hydride species undergoes an isomerisation process due to the high trans effect of the NHC ligand, which forces the hydrido ligand to situate trans to the iodide in the apical position while the second iodide is now trans to the NHC. At this stage, the acetone is substituted by the substrate (ketone) and a new isomerisation process that releases the steric congestion in the equatorial plane takes place. This isomerisation process permits the migratory insertion of the ketone into the $\mathrm{Ir}-\mathrm{H}$ bond to afford an alkoxo complex, which coordinates an isopropanol molecule that transfers the $\mathrm{OH}$ proton to render the hydrogenated product and the regeneration of the active species.

$\mathrm{Cp}^{*}(\mathrm{NHC}) \operatorname{Ir}(\mathrm{III})$ complexes have been extensively studied in transfer hydrogenation reactions. They have proved active in the reduction of ketones, imines, nitrobenzene (to aniline, azobenzene or azoxybenzene), $\alpha, \beta$-unsaturated ketones and alkenes (Figure 10, complexes 77-101). In this context, it is worth mentioning that the transfer hydrogenation of alkenes is generally more complicated than that of polarized bonds. Remarkably, a variety of $\mathrm{Cp} *(\mathrm{NHC}) \mathrm{Ir}(\mathrm{III})$ complexes featuring 1,2,3-triazol-5-ylidene ligands have recently shown excellent activities for this type of substrates. 63

In contrast with the majority of mechanisms proposed for metal-complex-catalysed transfer hydrogenation, an outersphere mechanism centred at the amido ligand was postulated for pre-catalysts $\mathbf{9 0 . 6 4}$

A strategy for the heterogenisation of this type of complexes on magnetic $\mathrm{Fe}_{3} \mathrm{O}_{4}$ nanoparticles (102) has been developed by Mata and co-workers (Figure 11). ${ }^{70}$ The poor recyclability of the supported catalyst was attributed to the formation non-active Ir species throughout the reaction.

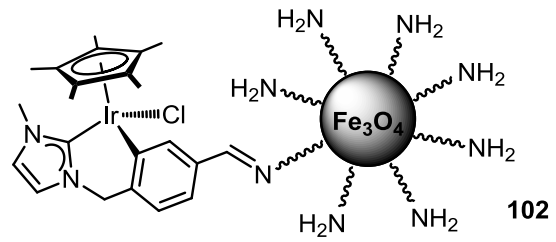

Figure $11 \mathrm{Cp} * \operatorname{Ir}(\mathrm{III})-\mathrm{NHC}$ anchored to $\mathrm{Fe}_{3} \mathrm{O}_{4}$ nanoparticles. 


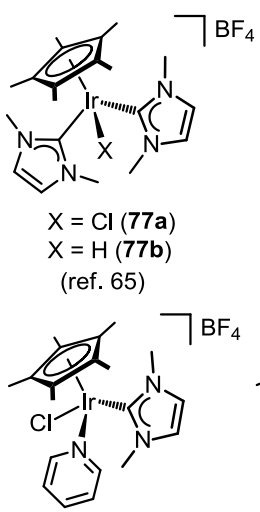

82 (ref. 65b)

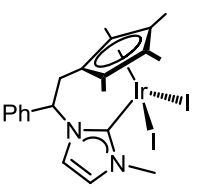

86 (ref. 68)

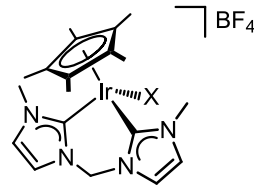

$X=I(78 a)$

$\mathrm{X}=\mathrm{H}(\mathbf{7 8 b})$

(ref. 65b)

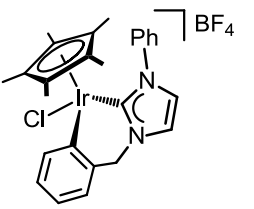

83 (ref. 66)

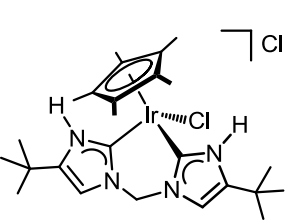

87 (ref. 69)

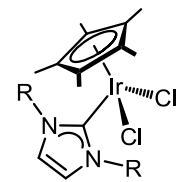

$\mathrm{R}={ }^{\mathrm{n}} \mathrm{Bu}(79 \mathrm{a})$

$\mathrm{R}=\mathrm{Me}(\mathbf{7 9 b})$

(ref. 65b)

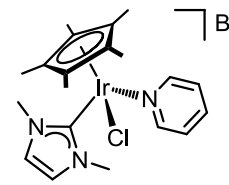

80 (ref. 64b)

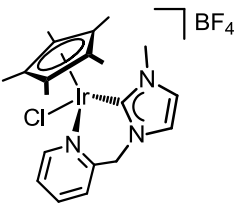

81 (ref. 65b)

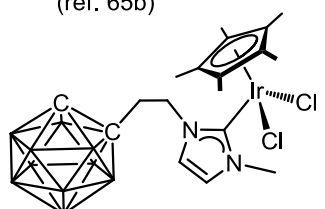

84 (ref. 66)

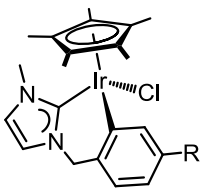

$\mathrm{R}=\mathrm{C}(\mathrm{O}) \mathrm{H}(\mathbf{8 8 a})$

$\mathrm{R}=\mathrm{C}(\mathrm{O}) \mathrm{Me}(\mathbf{8 8 b})$ (ref. 70)
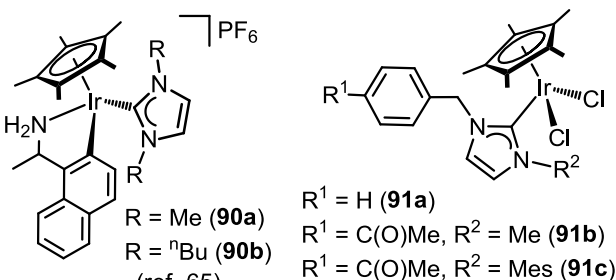

$\mathrm{R}^{1}=\mathrm{H}(\mathbf{9 1} \mathrm{a})$

$R^{1}=C(O) M e, R^{2}=$ Me (91b) (ref. 65)

$R^{1}=C(O) M e, R^{2}=$ Mes (91c)

$R^{1}=\mathrm{C}(\mathrm{O}) \mathrm{Me}, \mathrm{R}^{2}=4$-acetylbenzyl (91c)

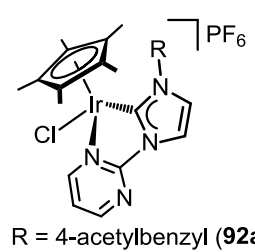

$\mathrm{R}=4$-acetylbenzyl (92a)

$\mathrm{R}=\operatorname{Mes}(\mathbf{9 2 b})$
$\mathrm{R}=\mathrm{n}-\mathrm{Bu}(\mathbf{9 2 c} \mathrm{c})$
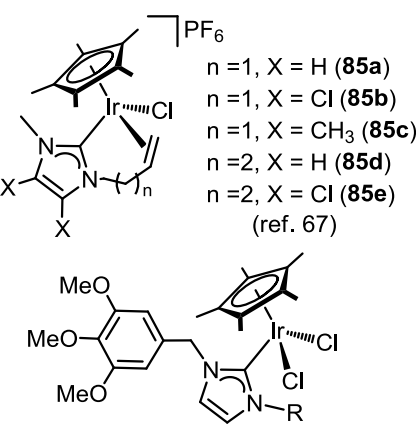

$\mathrm{R}={ }^{\mathrm{n}} \mathrm{Bu}(\mathbf{8 9 a})$

$\mathrm{R}=\mathrm{CH}_{2} \mathrm{Ph}(\mathrm{OMe})_{3}(\mathbf{8 9 b})$

(ref. 31b)
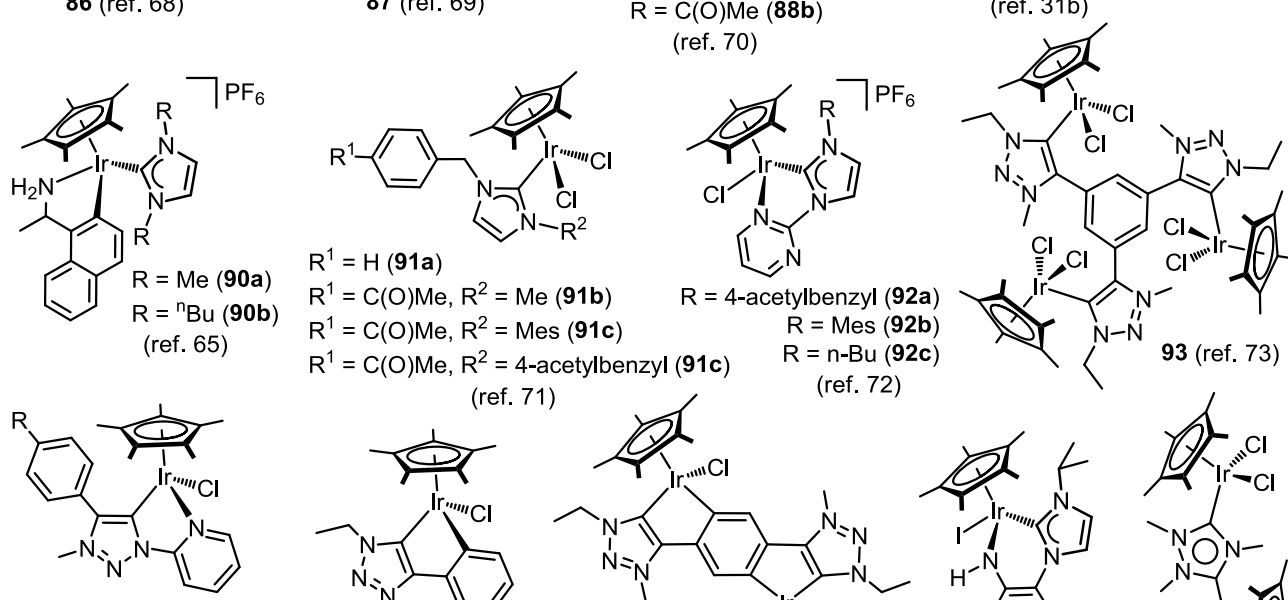

$$
\mathrm{R}=\mathrm{H}(\mathbf{9 4} \mathrm{a})
$$

$\mathrm{R}=\mathrm{Me}(94 \mathrm{~b}) \quad \mathrm{R}=\mathrm{CF}_{3}(94 \mathrm{e})$

$\mathrm{R}=\mathrm{OMe}(\mathbf{9 4 c}) \mathrm{R}=\mathrm{Br}(\mathbf{9 4 f})$

$\mathrm{R}=\mathrm{CN}(\mathbf{9 4} \mathrm{d}) \quad \mathrm{R}=\mathrm{NO}_{2}(\mathbf{9 4} \mathrm{g})$
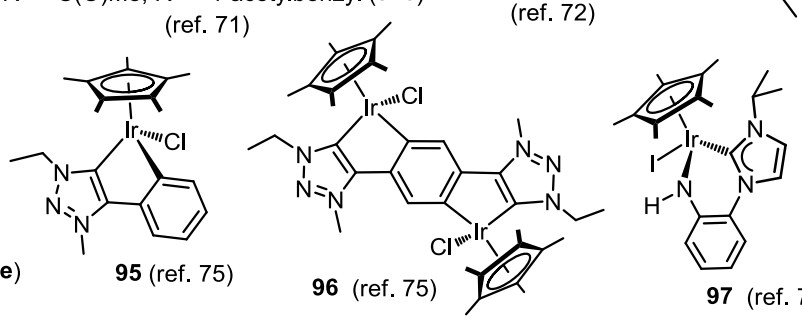

97 (ref. 76)

(ref. 74)
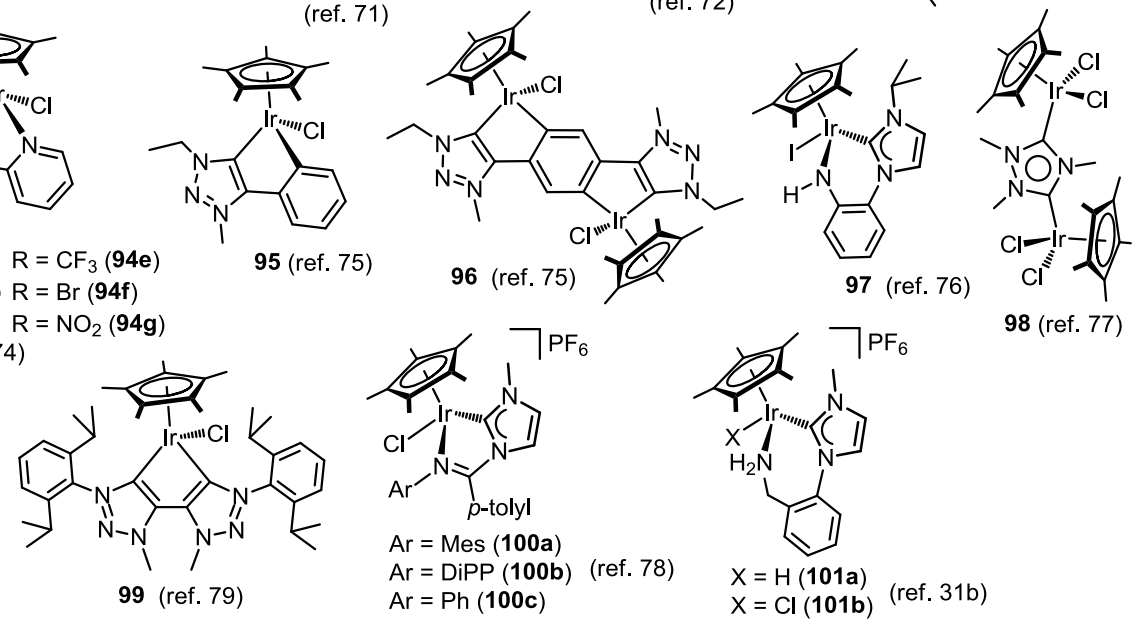

98 (ref. 77)

Figure 10 Summary of $\mathrm{Cp}^{*} \operatorname{Ir}(\mathrm{III})-\mathrm{NHC}$ catalysts for transfer hydrogenation.

The development of chiral iridium catalysts containing NHC ligands is a promising methodology owing to the good activities shown by Ir-NHC complexes (Figure 12, complexes 103-114); however, mostly moderate ee values were usually obtained when iridium complexes based on chiral NHC ligands were employed as catalysts. Complex $\mathbf{1 1 3} \mathbf{d z}$ represents a remarkable exception, since excellent ee's that range from 81 to $97 \%$ were obtained for the reduction of a variety of ketones.

\section{Hydrogen borrowing reactions}

The hydrogen borrowing approach represents an atom efficient alternative to the use of stoichiometric processes for the functionalisation of substrates susceptible of undergoing dehydrogenation reactions to afford reactive unsaturated intermediates (Scheme 6a). 


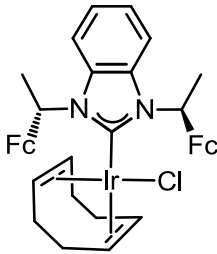

103 (ref. 80)

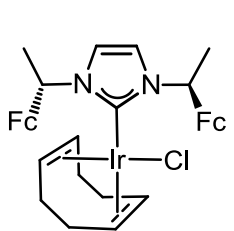

104 (ref. 80)

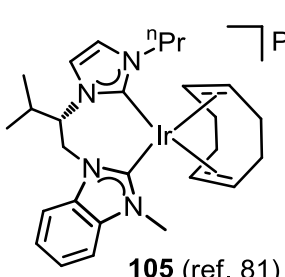

105 (ref. 81)<smiles></smiles>

(ref. 81)
$\mathrm{PF}_{6}$

$\mathrm{R}^{1}={ }^{\mathrm{i}} \operatorname{Pr}, \mathrm{R}^{2}=\mathrm{Me}(\mathbf{1 0 6 a})$

$R^{1}={ }^{n} \operatorname{Pr}, R^{2}=\operatorname{Me}(106 b)$

$R^{1}=R^{2}=\operatorname{Me~(106c)~}$

$\mathrm{R}^{1}=\mathrm{CH}_{2} \mathrm{Ph}, \mathrm{R}^{2}=\mathrm{Me}(106 \mathrm{~d})$

$\mathrm{R}^{1}={ }^{\mathrm{n}} \mathrm{Pr}, \mathrm{R}^{2}={ }^{\mathrm{i}} \operatorname{Pr}(\mathbf{1 0 6 e})$ $\mathrm{R}^{1}={ }^{\mathrm{n}} \mathrm{Pr}, \mathrm{R}^{2}=\mathrm{Ph}(\mathbf{1 0 6 f})$

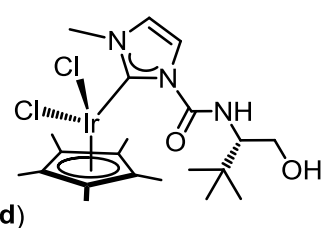

107 (ref. 82)

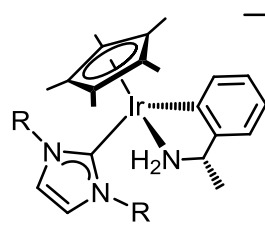

$R=M e(108 a)$

$\mathrm{R}={ }^{\mathrm{n}} \mathrm{Bu}(108 \mathrm{~b})$ (ref. 64)

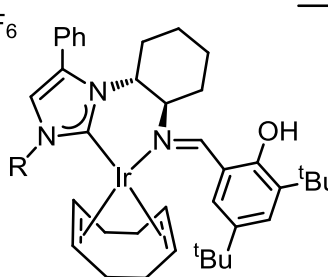

${ }_{\mathrm{Bu}}$

$7 \mathrm{PF}_{6}$

$R=E t(\mathbf{1 0 9 a})$

$R={ }^{i} \operatorname{Pr}(109 b)$

$\mathrm{R}=\mathrm{Bn}(109 \mathrm{c})$

$\mathrm{R}=\mathrm{Ph}_{2} \mathrm{CH}(109 \mathrm{~d})$

(ref. 83)

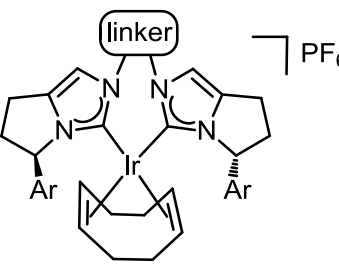

110 (ref. 84)

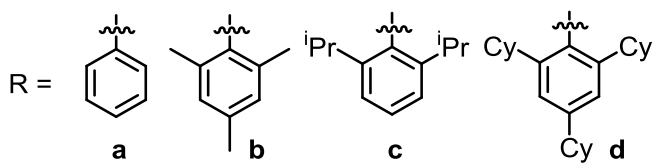

c

Cy d<smiles>[Y]c1ccc(C(c2ccc(C)cc2)C(C)(C)c2ccc(OC)cc2)cc1</smiles>

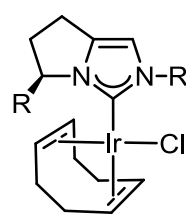

112 (ref. 84)

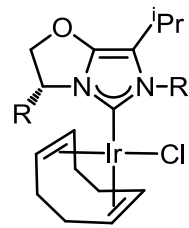

113 (ref. 84)

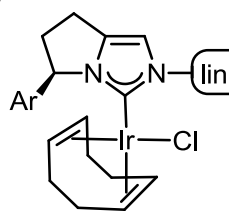

110-111a linker = $A r=P h$

110-111b linker $=\int_{5}^{\frac{y}{3}} \mathrm{Ar}=$ Mes

Figure 12 Summary of chiral Ir-NHC catalysts for asymmetric transfer hydrogenation (Fc = Ferrocene).

a)

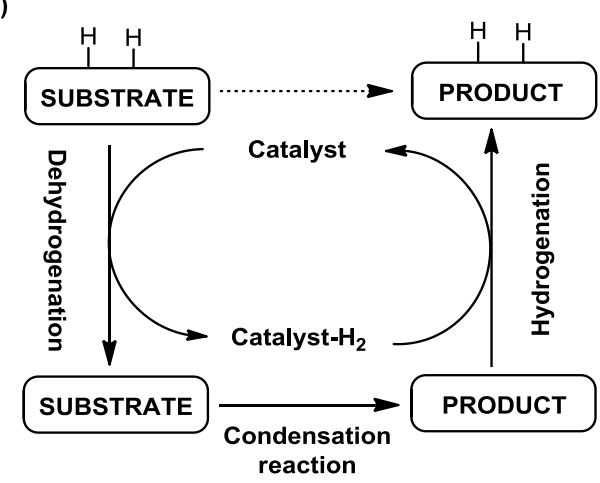

b)

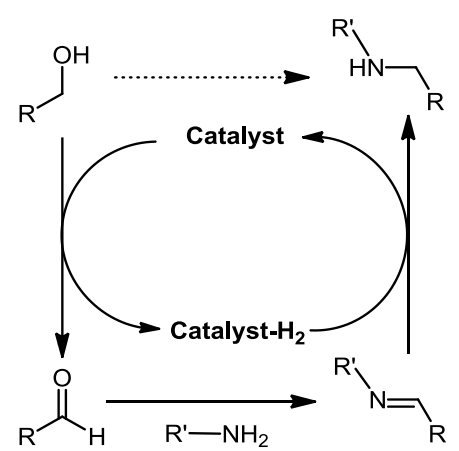

Scheme 6 General mechanism for hydrogen borrowing reactions (a) and mechanism for the $N$-alkylation of amines with alcohols (b).

The most widely employed substrates for this type of reaction are alcohols and amines, which can be straightforwardly oxidised to aldehydes (or ketones) and imines, respectively. In the case of the $\mathrm{N}$-alkylation of amines with alcohols (Scheme $6 b)$, the dehydrogenation of a primary alcohol affords an aldehyde and the hydrogenated catalyst. The latter formally adds a hydrogen molecule across the $\mathrm{C}=\mathrm{N}$ bond of the newly formed imine molecule, which was previously generated by condensation of the aldehyde with a primary amine. Hence, at variance with classic methods, this process circumvents the use of stoichiometric reagents for alcohol oxidation or for the generation of a good leaving group (from the hydroxyl moiety), and avoids the use of amine protecting groups.

The main hydrogen borrowing reactions catalysed by Ir-NHC complexes (Figure 13) are the $\mathrm{N}$-alkylation of amines or amides with alcohols, $\beta$-alkylation of alcohols and the $N$-alkylation of anilines with aliphatic amines. 


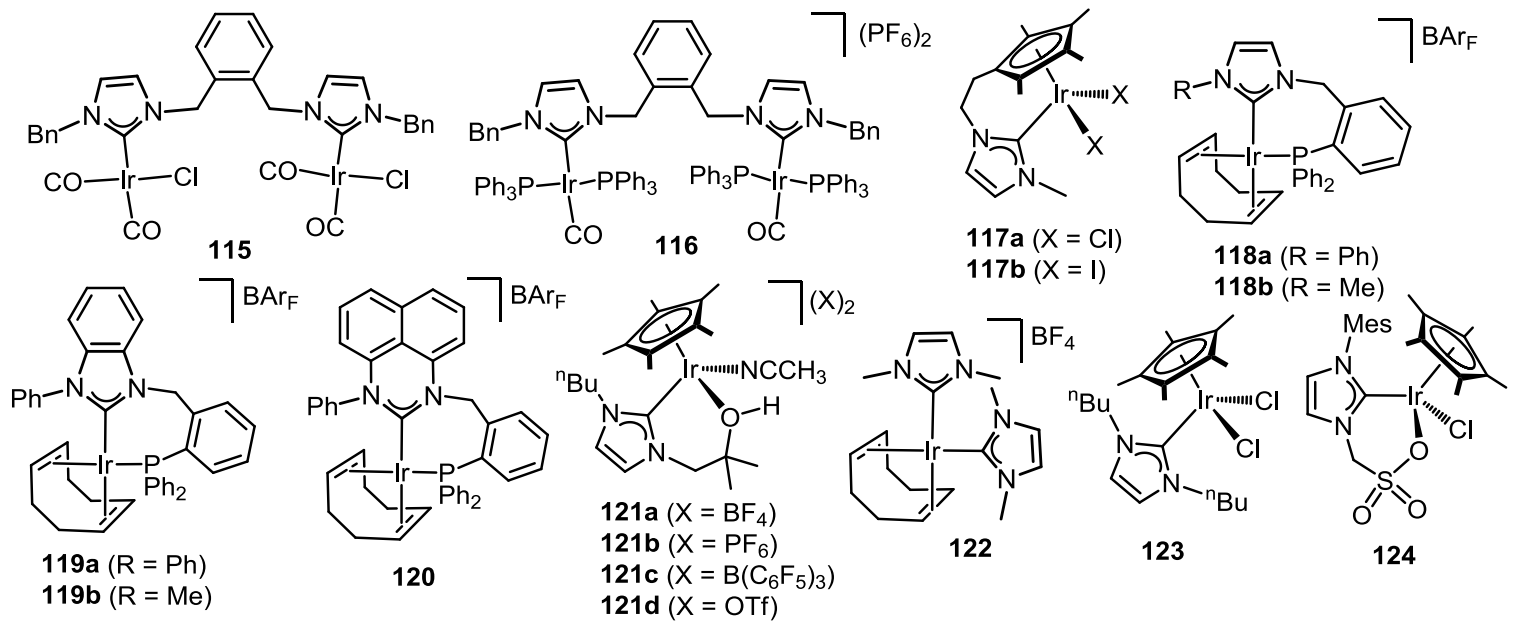

Figure 13 Ir-NHC catalysts for hydrogen borrowing reactions.

The $N$-alkylation of amines with alcohols has been hitherto accomplished with Ir-NHC catalysts $118 a, 85121,86122^{87}$ and 123. ${ }^{88}$ Remarkably, the $N$-alkylation of amides with primary alcohols to give $N$-alkylated amides, which are widely employed for the synthesis of fine chemicals, has also been described. The Ir-NHC complexes 118, 119 and 120 have shown excellent activities for this reaction, ${ }^{85}$ with the latter also performing well in the $\mathrm{N}$-alkylation of sulfonamides.

The excellent activities shown by complexes 121a-d for the $N$ alkylation of amines with alcohols without a base, even at low temperatures, have been attributed to the presence of an alcohol-alkoxide moiety at one of the wingtip groups of the NHC, which gives rise to a bifunctional catalyst. A cooperative mechanism where the alkoxide and the metal centre act as Lewis base and Lewis acid sites, respectively, has been proposed (Scheme 7). ${ }^{86}$

Complex 118a has been reported to catalyse the transformation of a variety of aromatic amines to the corresponding secondary amines under solvent-free conditions and, for the first time for this type of reaction, at room temperature. ${ }^{89}$ More recently, biscarbene complex $\mathbf{1 2 2}$ proved to be an effective catalyst for the methylation of anilines with methanol, exhibiting especially good performances under MW irradiation. ${ }^{88}$

In the presence of catalytic amounts of silver trifluoromethanesulfonate (AgOTf) complex $\mathbf{1 2 3}$ catalyses both the $N$-alkylation of primary amines with secondary alcohols and the $\mathrm{N}$-alkylation of secondary amines with benzyl alcohol.

The proposed activation process entails the abstraction of the chloride ligands by AgOTf. Complex 123 also catalyses the $N$ alkylation of anilines with aliphatic amines, showing excellent activities, similar to those obtained with Shvo's catalyst. ${ }^{87}$ Complex 124 effectively catalyses the $N$-alkylation of secondary aliphatic amines, namely piperidine, pyrrolidine, morpholine and piperazine, with primary and secondary alcohols. The use of aniline, however, resulted in noticeably lower yields. ${ }^{90}$

The $\beta$-alkylation of secondary alcohols with primary alcohols is a tandem reaction that requires the oxidation of both alcohols by an Oppenauer-type reaction to the corresponding ketone and aldehyde, which undergo a base-mediated aldol condensation. Finally, the $\alpha, \beta$-unsaturated compound thus formed is reduced to the $\beta$-alkylated alcohol, via an intermediate ketone, by means of the Ir-hydride species that result from the oxidation of the starting alcohols (Scheme 8). Jiménez et al. reported a series of iridium complexes of general formula $[\operatorname{Ir}(\operatorname{cod})(\mathrm{NHC}) \mathrm{X}](\mathrm{X}=\mathrm{Cl}$ or $\mathrm{Br})$ and their cationic derivatives $\left[\operatorname{Ir}\left(\mathrm{CH}_{3} \mathrm{CN}\right)(\mathrm{cod})(\mathrm{NHC})\right] \mathrm{BF}_{4}$ and $[\operatorname{Ir}(\mathrm{cod})(\mathrm{NHC})] \mathrm{BF}_{4}$, the latter featuring a coordinated wingtip group at the NHC. ${ }^{91}$ The most active catalysts tested in this study were neutral complex 125 and cationic complex 126. NHCs functionalised with $O$ donors show, in general, better activities than those featuring $\mathrm{N}$-donors; while non-funtionalised NHCs, i.e. those without potentially coordinating wingtip groups, such as IMe or IPr, give rise to remarkably lower activities.

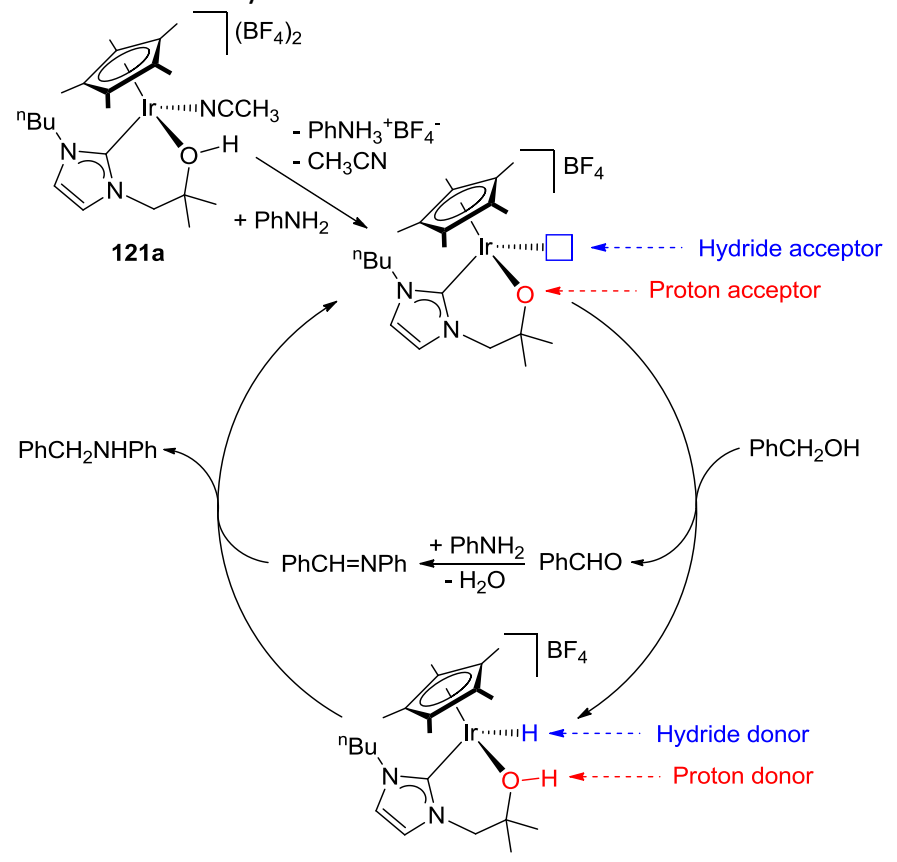

Scheme 7 Metal-ligand cooperative mechanism of hydrogen borrowing. ${ }^{86}$ 
Cat.:

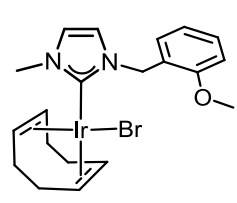

125
126
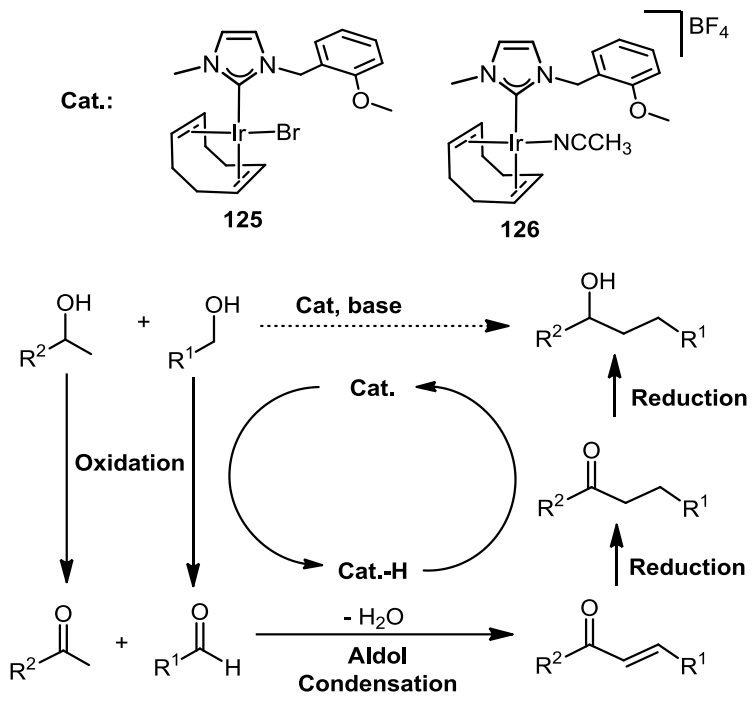

Scheme $8 \beta$-alkylation of alcohols.

In this work, a mechanism for the $\beta$-alkylation of benzyl alcohol with 1-phenylethanol was proposed based on DFT calculations. This mechanism can be divided into two processes: 1) the formation of $\alpha, \beta$-unsaturated ketones (Scheme 9) and 2) the reduction of $\alpha, \beta$-unsaturated ketones (Scheme 10). ${ }^{91}$

The role of the $\mathrm{N}$-substituent at the NHC ligand is probably related to the oxidation of the alcohol. The $\beta-\mathrm{H}$ of the alkoxo ligand interacts with the oxygen atom of the wingtip group, thus facilitating the $\beta-\mathrm{H}$ elimination reaction that affords the related hydrido species. ${ }^{40}$

Bimetallic complex $\mathbf{1 2 7}$ was compared against monometallic complexes 128 and $\mathbf{1 2 9}$ in the $\beta$-alkylation of 1-phenylethanol with primary alcohols (Figure 14). While complexes 128 and 129 showed similar activities, their related bimetallic complex 127 brought about remarkably higher yields for all the combinations of alcohols tested in this work. The higher activity of $\mathbf{1 2 7}$ was interpreted by the authors as a result of intermetallic cooperativity, since $\mathbf{1 2 8}$ is virtually identical from an electronic and structural viewpoint. ${ }^{92}$

Several examples of supported Ir-NHC catalysts for the $\mathrm{N}$ alkylation of imines with alcohols and the $\beta$-alkylation of secondary alcohols with primary alcohols have been reported. Complex 130 presents an $\operatorname{Ir}(\mathrm{III}) \mathrm{Cp}$ *(NHC) complex linked to the mesoporous silica support SBA-15 by a siloxane moiety at the wingtip group of the NHC ligand.

This catalyst has been successfully employed for the $\mathrm{N}$ alkylation of imines with alcohols, and the $\beta$-alkylation of secondary alcohols with primary alcohols. In both cases the supported catalyst showed better activities than its homogeneous analogue, which contains a butyl group instead of the SBA-15 linkage. This increased activity may be attributed to the dehydrating capability of the mesoporous silica, which would promote the condensation reaction and, consequently, the formation of the imine or $\alpha, \beta$-unsaturated ketone.
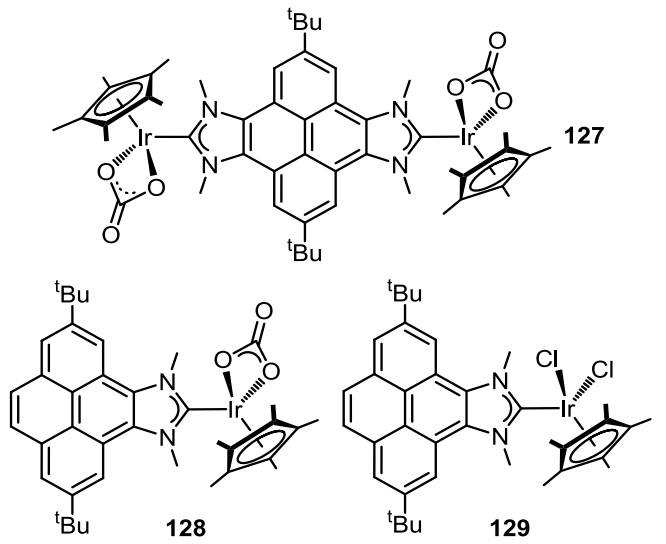

Figure 14 Bimetallic catalyst for hydrogen borrowing reactions and its related mononuclear complexes.

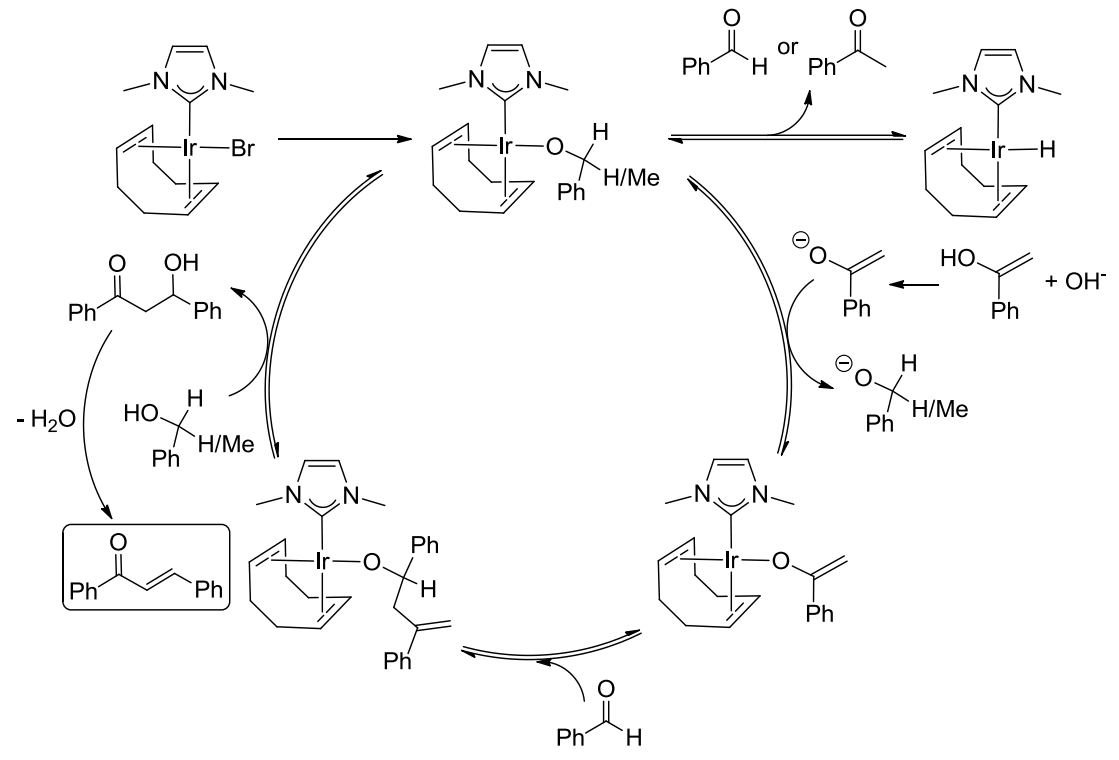

Scheme 9 Formation of $\alpha, \beta$-unsaturated ketones by complex $126 .{ }^{91}$ 


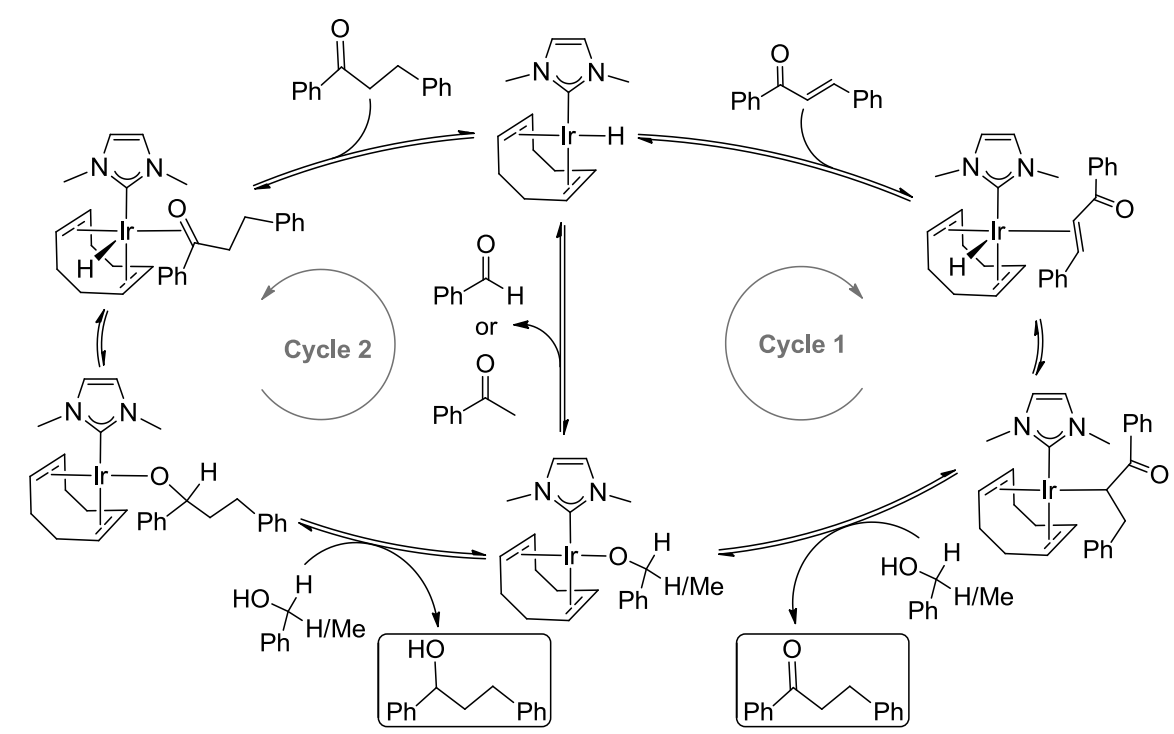

Scheme 10 Reduction of $\alpha, \beta$-unsaturated ketones. ${ }^{91}$

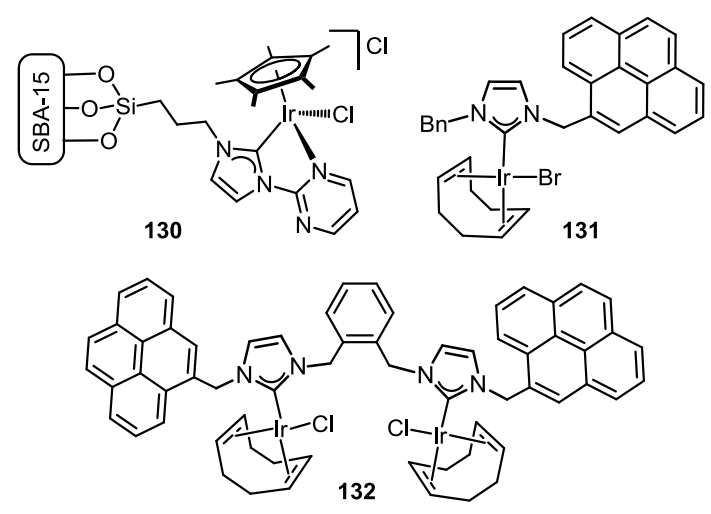

Figure 15 Supported catalyst for hydrogen borrowing.

Complexes 131 and $\mathbf{1 3 2}$ were heterogenised onto a surface of reduced graphene oxide ( $\mathrm{rGO}$ ) by means of non-covalent interactions ( $\pi$-stacking) between the pyrene tags at the $N$ substituents of the NHC ligands and the rGO (Figure 15). The catalytic activity of both complexes and their heterogenised counterparts were tested in the $\beta$-alkylation of 1-phenylethanol with primary alcohols. The material 132-rGo was recycled 12 times without any apparent loss of activity, while 131-rGO was recycled effectively only 3 times. This, together with the measurements of metal content before and after the catalytic reaction, suggests that the number of pyrene moieties is crucial to achieve a stable complex-support interaction. Remarkably, the addition of pyrene to reactions catalysed by nonheterogenised complexes $\mathbf{1 3 1}$ and $\mathbf{1 3 2}$ with aromatic substrates shows an inhibiting effect. Conversely, this effect is not observed when related catalysts without pyrene tags or aliphatic substrates were employed. This observation can be rationalised in terms of $\pi$-stacking interactions between the pyrene tags, aromatic substrates, and the external pyrene added to the reaction. Moreover, the kinetic studies presented in this work offer further insights, suggesting substrate-tag interactions and even self-association of pyrene-tagged catalysts. ${ }^{93}$
Another hydrogen borrowing reaction worth mentioning is the $\alpha$-methylation of ketones with methanol catalysed by complex 118a. The reaction mechanism entails as initial step the dehydrogenation of methanol to formaldehyde, which reacts with the ketone to give the $\alpha, \beta$-unsaturated compound via aldol condensation. Finally, hydrogenation of the olefin affords the methylated ketone (Scheme 11). 85

\section{Hydrosilylation}

To the best of our knowledge no Ir-NHC catalysts have been described for the hydrosilylation of alkenes. Conversely, in the case of alkynes, which are more reactive substrates, a variety of Ir-NHC catalysts proved to be active catalysts for the synthesis of vinylsilanes (Figure 16).

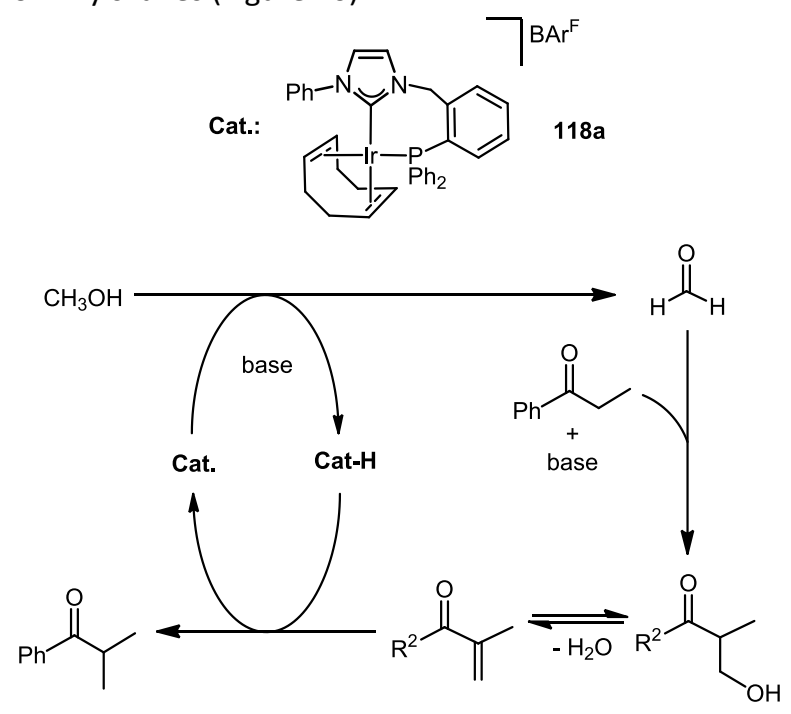

Scheme 11 Mechanism for the $\alpha$-methylation of ketones. ${ }^{85}$

$$
\mathrm{R}^{\prime}=+\mathrm{R}_{3} \mathrm{SiH} \stackrel{\text { Cat. }}{\longrightarrow} \mathrm{R}_{\beta(\mathrm{E})}^{\prime} \overbrace{}^{\mathrm{SiR}_{3}}+\mathrm{R}^{\prime} \underset{\beta(\mathrm{Z})}{=}{ }^{\mathrm{SiR}_{3}}+\underset{\alpha}{=} \overbrace{\mathrm{R}^{\prime}}^{\mathrm{SiR}_{3}}
$$

Scheme 12 Possible products produced in the hydrosilylation of terminal alkynes. 


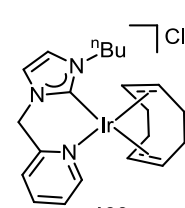

133

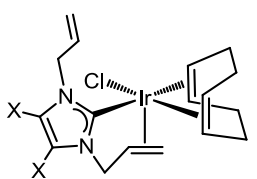

$136 \mathbf{a}(X=\mathrm{H})$

$136 \mathbf{b}(X=\mathrm{Cl})$

136c $\left(X=\mathrm{CH}_{3}\right)$

Figure 16 Ir-NHC catalysts for the hydrosilylation of alkynes.

The hydrosilylation of alkynes may result in the formation of three isomers, $\beta(E)-, \beta(Z)-$ and $\alpha$-vinylsilanes (Scheme 12). Besides, dehydrogenative silylation products, namely alkenes and silylalkynes, may also be formed during the reaction. Therefore, the selectivity of this reaction is one of the main issues that need to be solved in order to achieve practical applicability.

Complexes 133-135 showed good activities the hydrosilylation of a variety of terminal alkynes, but low selectivities were generally reported. ${ }^{94}$ Catalysts $\mathbf{1 3 6 - 1 3 8}$ allowed for the hydrosilylation of phenylacetylene with selectivities between $65-90 \%$ for the formation of the $\beta(Z)$-vinylsilane, with the $\beta(E)$ vinylsilane being the only reaction by-product. ${ }^{95}$

The selectivity and activity of complex $\mathbf{7 4}$ was tested in the hydrosilylation of a wide range of aliphatic and aromatic alkynes and hydrosilanes. The $\beta(\mathrm{Z})$-vinylsilanes were formed as major reaction product in selectivities that ranged from 82 to $99 \%$, the best selectivities being obtained for aromatic alkynes. ${ }^{96}$

A combined theoretical and experimental study discards the commonly proposed modified Chalk-Harrod mechanism. The oxidative addition of the $\mathrm{Si}-\mathrm{H}$ bond was proved implausible, mainly because of the high trans effect of the NHC ligands and the excessive steric hindrance at the metal centre, which prevents the formation of the corresponding $\operatorname{Ir}(\mathrm{V})$ species. ${ }^{97}$ Instead, the authors postulated an outer-sphere mechanism that resembles that described by Brookhart and Oestreich for the hydrosilylation of ketones. ${ }^{98}$ The catalytic cycle entails: i) the end-on coordination of the hydrosilane; ii) heterolytic cleavage of the $\mathrm{Si}-\mathrm{H}$ bond assisted by an acetone molecule according to an $\mathrm{S}_{\mathrm{N}} 2$ mechanism to give an $\mathrm{Ir}-\mathrm{H}$ species and an oxocarbenium ion $\left(\left[\mathrm{R}_{3} \mathrm{Si}-\mathrm{O}\left(\mathrm{CH}_{3}\right)_{2}\right]^{+}\right)$; iii) the oxocarbenium ion transfers the silyl moiety to the alkyne to give the carbocation $\left[\mathrm{R}_{3} \mathrm{Si}-\mathrm{CH}=\mathrm{C}-\mathrm{R}\right]^{+}$; and, finally, iv) the Ir-hydride species transfers the hydrido ligand to the carbocation via the least hindered approach to give the $\beta-Z$ vinylsilane. The more hindered attack, with the silane moiety of the carbocation facing the metal complex leads to the $\beta(E)$-vinylsilane (Scheme 13). ${ }^{96 b}$

A great variety of Rh-NHC catalysts have been reported for the hydrosilylation of carbonyl compounds; ${ }^{39}$ however, examples of their iridium counterparts are scarce.

In fact, the only Ir-NHC hydrosilylation catalyst so far reported is complex 139, which features a carbene ligand with a chiral $\alpha$ amino acid $\mathrm{N}$-substituent. Efficient asymmetric hydrosilylation (ee's up to 96\%) was achieved with 139c under ambient conditions using (EtO) ${ }_{2} \mathrm{MeSiH}$ for a broad variety of aromatic and aliphatic ketones (Figure 17). ${ }^{99}$

\section{Water oxidation}

Water splitting to produce $\mathrm{H}_{2}$ and $\mathrm{O}_{2}$ is a carbon-neutral process that permits the conversion of solar energy into chemical energy ("green" fuel). The oxidation of $\mathrm{H}_{2} \mathrm{O}$ to give $\mathrm{O}_{2}$, protons and electrons (water oxidation) is the most challenging part of this process due to the high energy barrier of the reaction and its multiproton and multielectron mechanism. Therefore, a catalyst able to adopt a wide range of oxidation states that makes this energy-demanding reaction possible is required. ${ }^{100}$

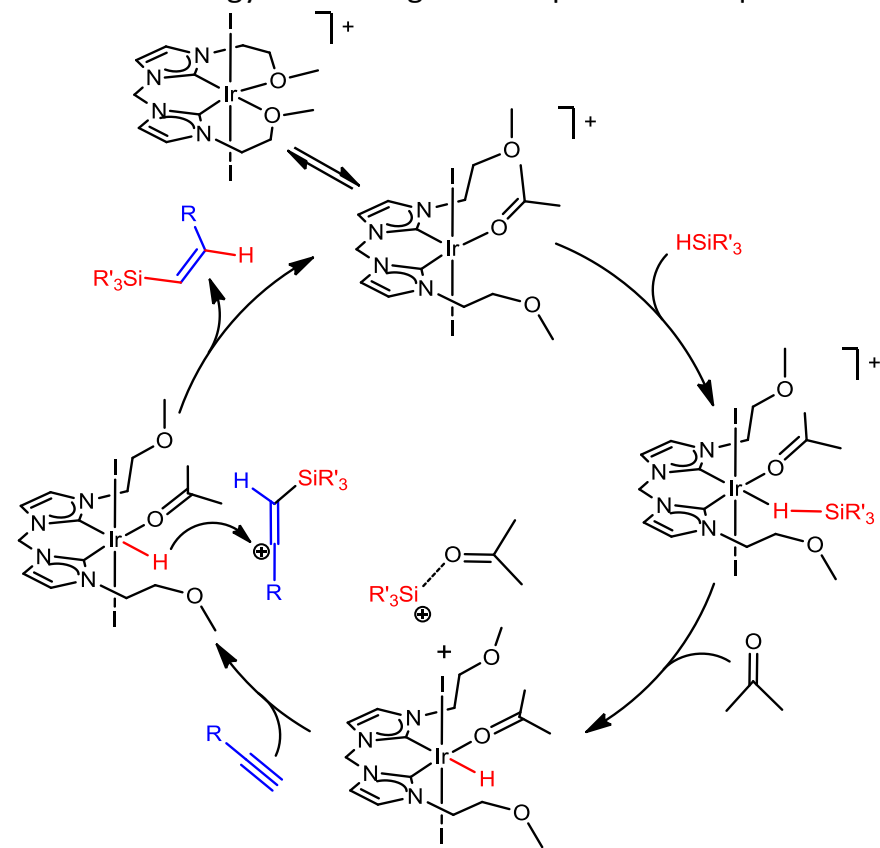

Scheme 13 Proposed outer-sphere catalytic cycle for the hydrosilylation of terminal alkynes. ${ }^{96 b}$

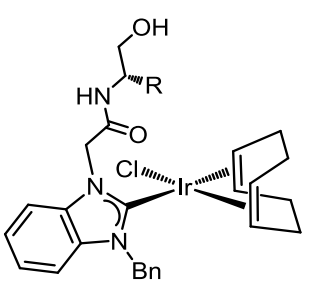

$139 a(R=M e)$

$139 b(R=E t)$

139c $\left(R={ }^{i} B u\right)$

$139 d\left(R={ }^{t} B u\right)$

139e $\left(R={ }^{\mathrm{s}} \mathrm{Bu}\right)$

$139 f(R=B n)$

Figure $\mathbf{1 7}$ Ir-NHC catalysts (139a-f) for the hydrosilylation of ketones.

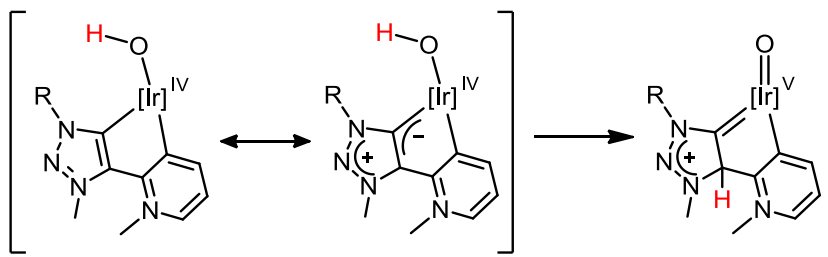

Scheme 14 Non-innocent behaviour of triazolylidene ligands in Ir-NHC WOC ([Ir] = (rCp*). ${ }^{103 d}$ 
The use of $\mathrm{N}$-heterocyclic carbenes as ancillary ligands for water oxidation catalysts (WOCs) has received much attention in the last decade, primarily sparked by the disclosure of Ir-based molecular-WOCs (Figure 18). ${ }^{101}$ Although Ru-based catalysts have been at the forefront of research in molecular water oxidation catalysis, the $\mathrm{Cp}{ }^{*} \operatorname{Ir}(\mathrm{NHC})$ catalysts recently developed have shown outstanding performances, even surpassing some of the most active Ru-based catalysts.
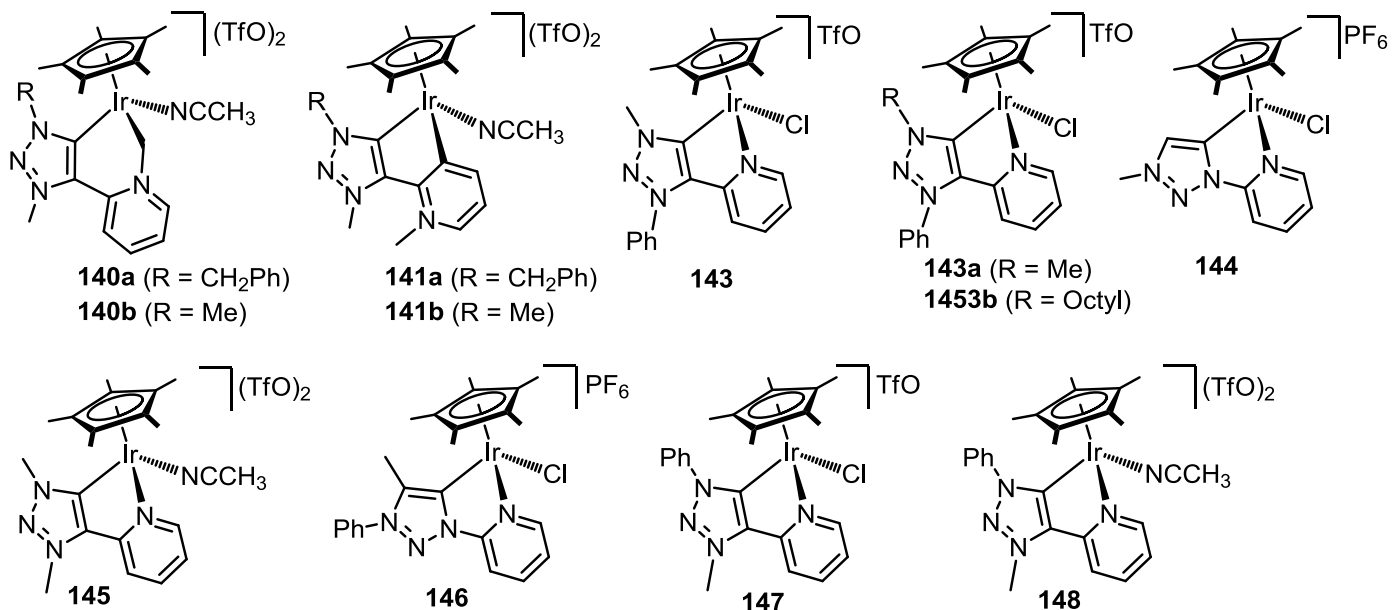

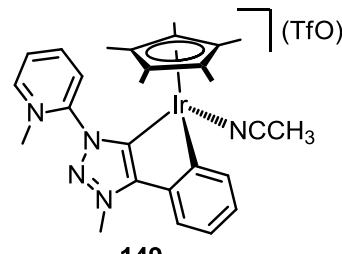

149

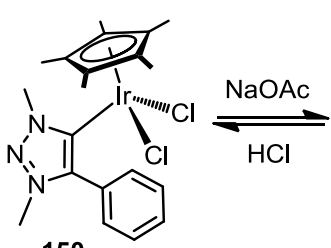

150

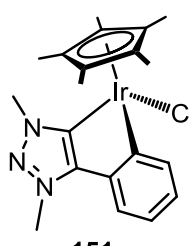

151
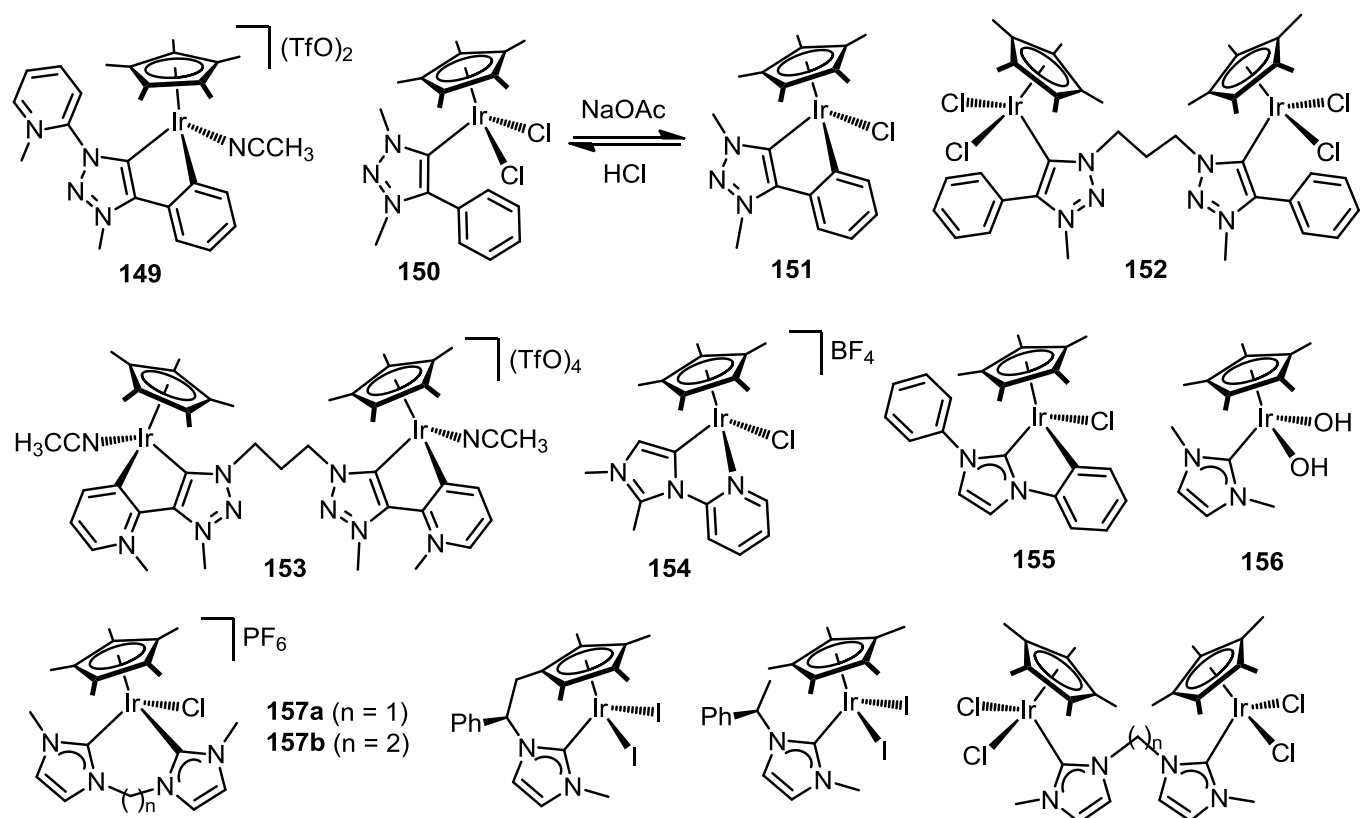

159

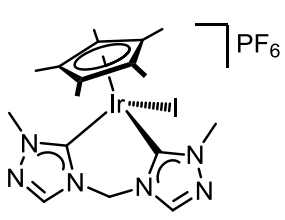

161
158

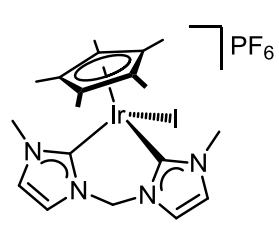

162

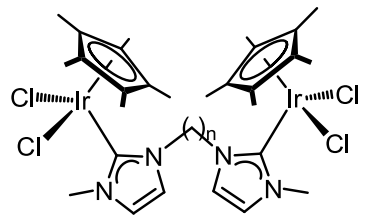

$160 \mathrm{a}(\mathrm{n}=1)$

$160 \mathrm{~b}(\mathrm{n}=2)$

$160 \mathrm{c}(\mathrm{n}=3)$

$\operatorname{160d}(\mathrm{n}=4)$

Figure 18 Summary of Ir-NHC catalysts WOCs.

Complexes 140 and 141, developed by Albrecht and co-workers, are among the most active catalysts hitherto reported for the oxidation of water using cerium ammonium nitrate (CAN) as sacrificial oxidant. ${ }^{102}$ Further studies on mesoionic triazolylidene $\mathrm{C}, \mathrm{C}$ - and $\mathrm{C}, \mathrm{N}$-chelating ligands has shed light on the impact of this type of ancillary ligands in the performance of Cp*Ir-based WOCs (complexes 140-153), which have been proposed to stabilise a variety of oxidation states at the Ir centre and to behave as non-innocent ligands capable of promoting proton-coupled electron transfer (PCET) reactions (Scheme 14). ${ }^{103}$ 
In operando mechanistic investigations together with dynamic light scattering (DLS) experiments strongly support the homogeneous nature of these catalysts, and seem to exclude the formation of metal nanoparticles or nanoclusters throughout the reaction. ${ }^{103 \mathrm{~d}}$ An important consequence of the molecular integrity of these catalysts, together with the presence of easily tuneable NHC ligands, is that it permits the optimisation of the catalytic activity by means of subtle structural modifications of the ligand system.

For example, the substitution of a peripheral methyl group in 143a by an octyl group in 143b brings about more than a 10 fold increase in the catalytic activity of water oxidation when CAN is used as sacrificial oxidant. A plausible explanation for this result may be the formation of micelles that would place the Ir centres in close proximity, thus favouring the formation of $\mathrm{O}-\mathrm{O}$ bonds, which is the rate limiting step in binuclear mechanisms. Two main mechanisms have been postulated for WO reactions, the water nucleophilic attack on a singlet oxo species (S) and the radical oxocoupling of two triplet oxo moieties (T), WNA and I2M pathways, respectively (Scheme 15). ${ }^{104}$ Both pathways have been proposed for Co and Ru catalysts. ${ }^{105}$ In the case of Ir (including Ir-NHC) WOCs, although no conclusive proof of the mechanism has been presented to date, WNA and I2M mechanisms seem to coexist. ${ }^{106,103 d, 104}$

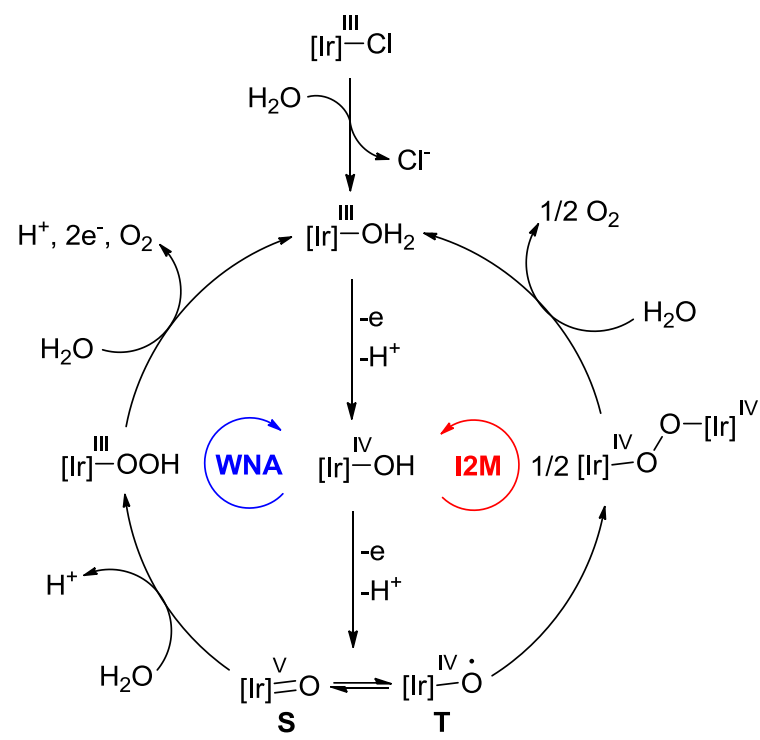

Scheme 15 WNA and ROC mechanisms for WOC. ${ }^{104}$

The decomposition of molecular Ir complexes under wO conditions to afford catalytically active $\mathrm{IrO}_{\mathrm{x}}$ nanoparticles has also been described in some cases. ${ }^{107,104,103 e}$

In a comparative study, imidazole-4-ylidene complex 154 showed remarkably higher catalytic rates than its related $1,2,3-$ triazolylidene 144, especially at initial stages of the reaction. This behaviour was attributed to the higher donor ability of the former, which may trigger a different reaction mechanism or facilitate the access to $\operatorname{Ir}(\mathrm{V})$ oxo species, probably the rate limiting step. Imidazol-2-ylidenes have been successfully employed as ancillary ligands for WOC, namely complexes 155-
163, although somewhat lower activities were observed compared to mesoionic ligands.

\section{Dehydrogenation reactions}

\subsection{Dehydrogenation of alcohols}

The transition metal catalysed Oppenauer-type oxidation of alcohols permits the preparation of value-added organic compounds by means of an environmentally benign process ${ }^{108}$ or may even play an important role in the production of hydrogen from methanol in the frame of the "Methanol Economy". ${ }^{109}$

The use of NHC ligands remarkably increases the activity of $\mathrm{Cp}^{*}$ Ir in the transfer dehydrogenation of alcohols, namely complexes 164-166 are significantly more active than $\left[\mathrm{Cp}^{*} \mid \mathrm{ICl}_{2}\right]_{2}$ in the oxidation of 1-phenylethanol to acetophenone. ${ }^{110}$ Moreover, complex 166a efficiently catalyses the oxidation of a variety of primary and secondary alcohols featuring aliphatic and aromatic substituents (Figure 19).The proposed mechanism entails as initial step the formation of the Ir-alkoxide complex by reaction of 165a with the alcohol and the corresponding base. Subsequently, $\beta$-hydride elimination affords the Irhydride intermediate and the oxidised product. Finally, the IrOiPr intermediate formed by the migratory insertion of acetone into the $\mathrm{Ir}-\mathrm{H}$ bond reacts with a new molecule of the alcohol (substrate) to close the catalytic cycle (Scheme 16).

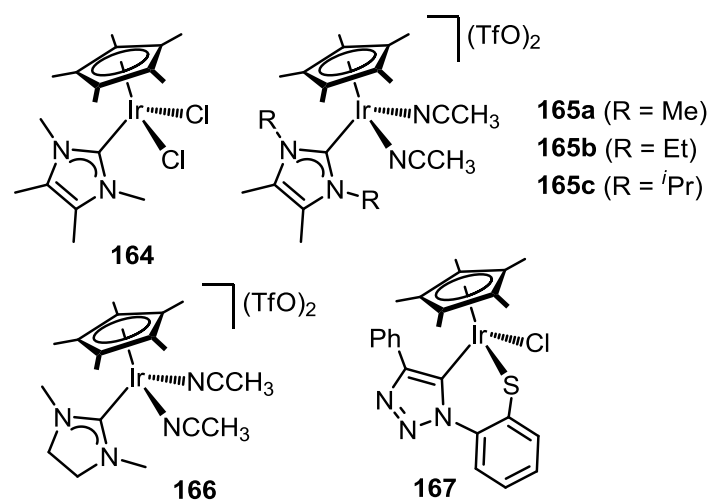

Figure $19 \mathrm{Ir}-\mathrm{NHC}$ catalysts for the oxidation of alcohols. 


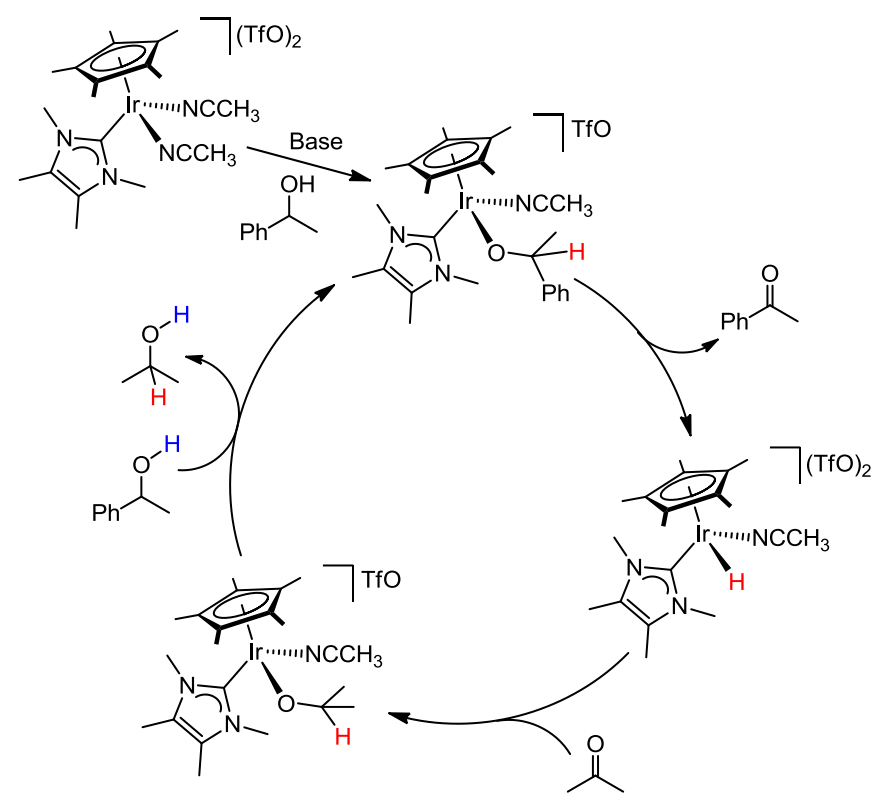

Scheme 16 Proposed mechanisms for the dehydrogenation of alcohols. ${ }^{110}$<smiles>CC(O)C(=O)O[C@@H](C)C(=O)O[Mg]</smiles>

Scheme 17 Ir-NHC catalysed oxidation of glycerol into lactic acid.

The higher activity of $\mathrm{Cp}^{*} \mathrm{Ir}$ complexes that present NHCs as ancillary ligands has been explained on the grounds that an increased electron density at the Ir centre, owing to the presence of an NHC ligand, would favour the $\beta$-hydride elimination step.

Complex 167 catalyses the oxidative dehydrogenation of benzyl alcohol to benzaldehyde and benzoic acid in a 78/22 ratio using $\mathrm{N}$-methylmorpholine- $\mathrm{N}$-oxide (NMO) as sacrificial oxidant. The oxidation of diphenylmethanol to benzophenone can also be achieved under analogous conditions, although low yields were obtained. ${ }^{111}$

Glycerol is a waste stream in the production of biodiesel and soap and is, therefore, a readily available an inexpensive bulk chemical that may become a key renewable carbon source, especially owing to the upsurge of biofuel demand. The development of sustainable processes for the preparation of commodity chemicals from glycerol, such as, glyceric acid, dihydroxyacetone, hydroxypyruvic acid, dihydroxyacetone, cyclic acetals, propanediols, acrolein or lactic acid, is an important academic and industrial goal. Complexes 79a, 126 and 168 (Figure 20) are efficient catalysts for the selective transformation of glycerol into lactic acid. The latter has allowed for conversions as high as $90 \%$ and selectivities over 95\%, obtaining only 1,2-propanediol and ethylene glycol as byproducts. This reaction operates under mild conditions, with low catalysts loadings and no solvent is required (Scheme 17). ${ }^{112}$ The first step of the proposed mechanism is the Ir-catalysed acceptorless dehydrogenation of glycerol to dihydroxyacetone (DHA) and glyceraldehyde (GAL), which interconvert in the presence of a base $\left(\mathrm{OH}^{-}\right)$. The dehydration of $\mathrm{GAL}$ affords pyruvaldehyde (PAL) via keto-enol tautomerisation and, subsequent irreversible hydration of PAL yields a molecule of lactic acid (Scheme 18). These catalysts were found to decompose throughout the reaction to give an inactive binuclear species and various polyhydride clusters featuring a high $\mathrm{NHC} / \mathrm{Ir}$ ratio. ${ }^{113}$ In order to prevent the formation of binuclear species, a series of self-supported catalyst based on an Ir-bisNHC coordination polymer were prepared by Tu and coworkers (complexes 169a-e, Figure 20). ${ }^{114}$ Complex 169b was found to be the most active and selective catalyst of the series and, remarkably, direct comparison with its homogeneous analogue shows that the self-supported catalyst displays higher activities and selectivities. Moreover, these self-supported catalysts can be reused up to 31 times without a significant loss of activity. A major current challenge in this field of research lies in the utilisation of polyols such as erythritol, xylitol and sorbitol as renewable carbon sources. ${ }^{115}$ In this context, complex 123 has been employed as catalyst in the transformation of a series of polyols into lactic acid, showing better activities and selectivities than analogous catalysts featuring ethyl or $n$-butyl $N$-substituents at the NHCs. ${ }^{116}$

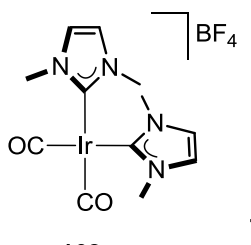

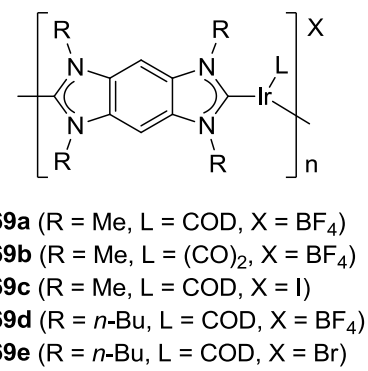

Figure $\mathbf{2 0} \mathrm{Ir}-\mathrm{NHC}$ catalysts for the oxidation of glycerol into lactic acid.

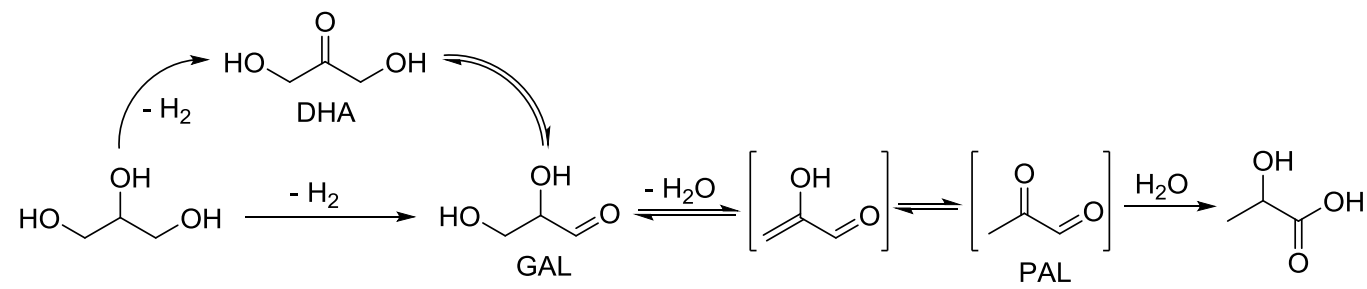




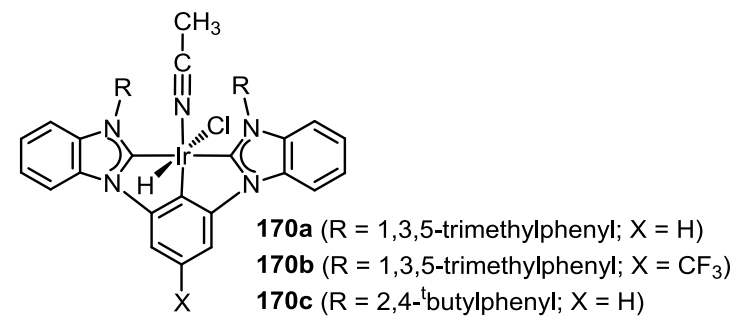

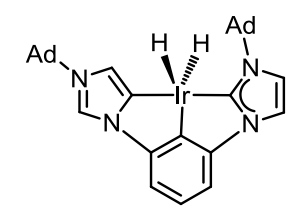

171

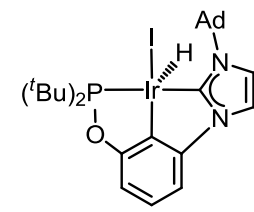

$172 \mathrm{a}(\mathrm{R}=\mathrm{Me})$

$172 b\left(\mathrm{R}={ }^{n} \mathrm{Bu}\right)$
Figure 21 NHC-based pincer Ir(III) catalysts for the dehydrogenation of alkanes.

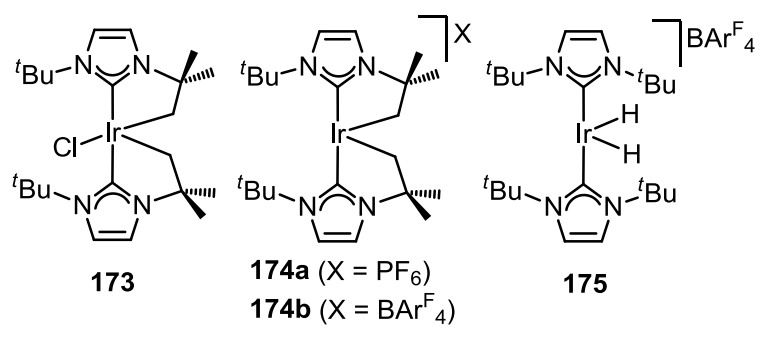

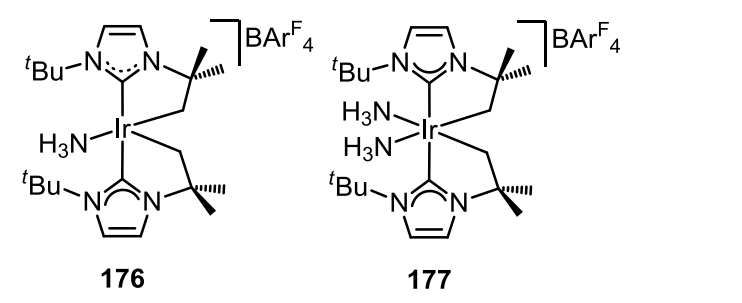

Figure $22 \mathrm{Ir}-\mathrm{NHC}$ catalysts for dehydrogenation of $\mathrm{BH}_{3} \cdot \mathrm{NH}_{3}$.

A similar mechanism to the one proposed above for the conversion of glycerol to lactic acid (Scheme 18) has been postulated in this case; however, retro-aldol condensation reactions are invoked in order to explain the fragmentation of long-chain polyols to lactic acid and other short-chain byproducts. ${ }^{116}$

The generation of molecular hydrogen from methanol has been mainly catalysed by ruthenium complexes. ${ }^{117}$ Ir-NHC catalysts for these reaction have been reported by Crabtree and coworkers, the most active being 123 followed by 168 . Cp*Ir complexes displayed somewhat lower activities. In contrasts with previous catalysts, selective formation of formate instead of carbon dioxide was observed. ${ }^{88}$

\subsection{Dehydrogenation of alkanes}

PCP-Ir systems are the most prolific catalysts for the dehydrogenation of alkanes and are often employed as benchmark for this type of reaction. ${ }^{118}$ Based on these results, several groups have reported iridium complexes featuring pincer ligands with NHC donor groups, which show moderate to low catalytic activity for the transfer and acceptorless dehydrogenation of alkanes compared to their PCP counterparts (Figure 21).
The catalytic activity of complexes $\mathbf{1 7 0}$ is closely related to the steric hindrance at the $\mathrm{N}$-substituents of the NHC; in fact, the use more bulky groups such as 2,6-diisopropylphenyl inhibits the catalyst. ${ }^{119}$ On the other hand, the utilisation of an abnormal NHC as donor group (complex 171) increases the activity of the corresponding Ir complex. ${ }^{120}$ A plausible explanation for this behaviour is the reduced steric hindrance stemming from the orientation of the $\mathrm{N}$-substituent, which is further from the metal centre in this type of ligand. The presence of a more electron-rich metal centre may also be invoked; however, PCP and especially POCOP systems are expected to render less electron-rich metal centres than CCC pincers, which seems to make this explanation more improbable. The substitution of an NHC by a $t$-butylphosphinite moiety (complexes 172a-c) gives rises to active catalysts for the transfer dehydrogenation of cyclooctane, although still low activities are observed compared to PCP-Ir systems.

\subsection{Dehydrogenation of $\mathrm{BH}_{3} \cdot \mathrm{NH}_{3}$}

The use of $\mathrm{BH}_{3} \cdot \mathrm{NH}_{3}$ as a means to safely transport and store hydrogen in a "hydrogen economy" has been explored mainly due to its high weight per cent of hydrogen. ${ }^{121}$ In spite of the success of NHC-complexes of various transition metals in the dehydrogenation of ammonia-borane, Ir-NHC complexes have been somewhat less explored. ${ }^{122}$

Complexes 173 and 174a are highly active catalysts for the dehydrogenation of $\mathrm{BH}_{3} \cdot \mathrm{NH}_{3}$ in $\mathrm{H}_{2} \mathrm{O} / \mathrm{THF}$ mixtures. Catalyst 174a led to the formation of 3 equivalents of $\mathrm{H}_{2}$ in 10 min under mild conditions $\left(40^{\circ} \mathrm{C}\right)$ and low catalyst loading $(0.005 \mathrm{~mol} \%) .123$ The use of $\mathrm{BAr}_{4}$ (tetrakis((3,5-trifluoromethyl)phenyl)borate) as counteranion (complex 174b) improved slightly the catalytic activity. ${ }^{124} \mathrm{~A}$ further improvement of the catalytic activity was achieved reacting $174 b$ with $\mathrm{H}_{2}$ to give $\mathbf{1 7 5}$ or with ammonia to afford complexes 176 and 177 (Figure 22), 176 being the most active catalyst.

The greater activity of complexes 175-177, mainly due to remarkably shorter induction periods than 175 , has been attributed to the fact that these species have been identified as possible reaction intermediates and, therefore, their use may ease the access to the active species.

\subsection{Dehydrogenation of aqueous sodium formate or formic acid}

Formic acid is a promising $\mathrm{H}_{2}$ carrier as it has the ability to release hydrogen under relatively mild conditions, and the only reaction by-product, carbon dioxide, can be hydrogenated back to formic acid, which makes the process suitable for fuel-cell technology. ${ }^{125}$

Water soluble complexes $\mathbf{1 7 8}$ and $\mathbf{1 7 9}$ show remarkably high activities for the dehydrogenation of aqueous sodium formate and, in addition, both catalysts are able to hydrogenate bicarbonate to formate. This formate-bicarbonate hydrogen storage system operates in a reversible manner with a noticeable loss of activity after 4 cycles. ${ }^{126}$ The hydrogenation of $\mathrm{NaHCO}_{3}$ was achieved at a $\mathrm{H}_{2}$ pressure of 10 bar and a temperature of $80^{\circ} \mathrm{C}$, leading to conversions up to $74.9 \%$. 


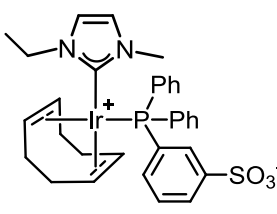

178

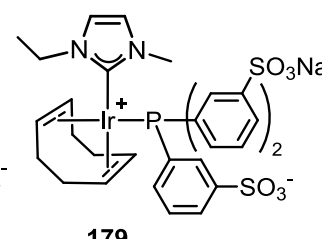

179

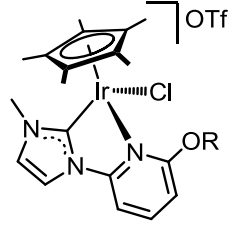

180a $\left(\mathrm{R}={ }^{t} \mathrm{Bu}\right)$

$180 b(R=H)$

180c $(R=M e)$
Figure 23 Ir-NHC catalysts for dehydrogenation of formic acid.

(A)

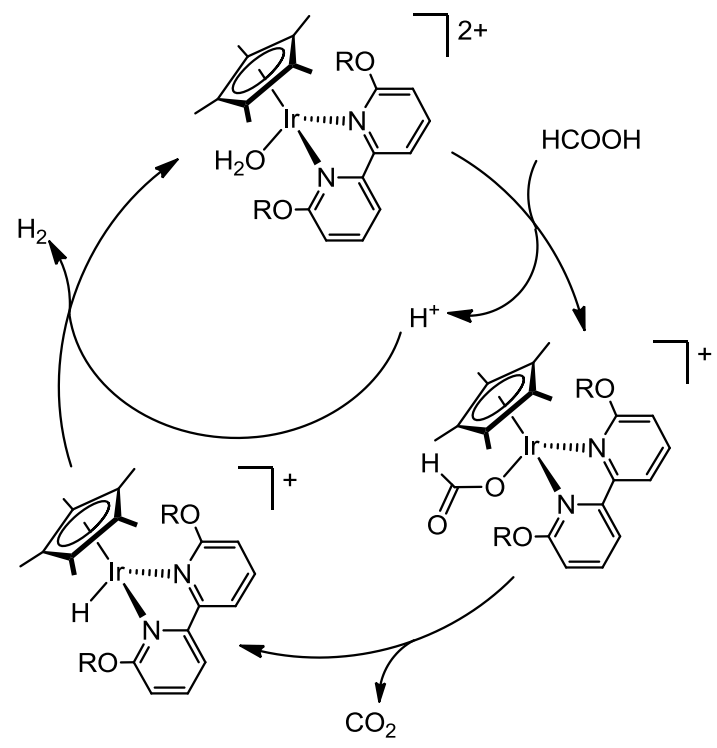

(B)

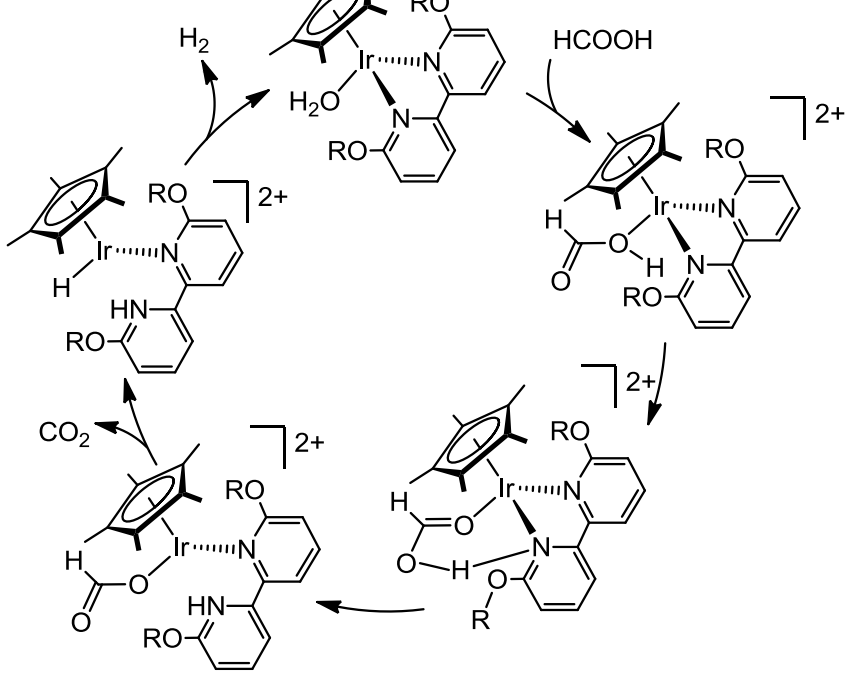

Scheme 19 Reaction mechanisms proposed for the dehydrogenation of formic acid with $\mathrm{Cp} *$ Ir complexes that present a 6,6'-dmbp or 6,6'-dhbp ligand $(\mathrm{R}=\mathrm{H}$ or $\mathrm{Me}) .{ }^{127}$

The dehydrogenation process led to impressive TOFs up to $15110 \mathrm{~h}^{-1}$ at $80{ }^{\circ} \mathrm{C}$, with catalysts 178 being the most active despite its lower solubility when compared to $\mathbf{1 7 9}$ (Figure 23).

Cp*Ir complexes 180a-c, which present an NHC ligand with a pyridinol as $\mathrm{N}$-substituent ( $\mathrm{NHC}-\mathrm{py}{ }^{\mathrm{OR}}$ ), perform well as precatalysts for the hydrogenation of $\mathrm{CO}_{2}$ and formic acid dehydrogenation. The activity of 180a-c, however, is lower than the related $\mathrm{Cp} * \mathrm{Ir}$ complexes featuring 6,6'-dmbp (dimethoxybipyridine) or 6,6'-dhbp (dihydroxybipyridine) ligands. This may be due to the lower stability of the NHC-pyOR ligand, which has been proved to cyclometalate under basic conditions via activation of the ortho $\mathrm{C}-\mathrm{H}$ bond of the py moiety. ${ }^{127}$ The reaction mechanisms proposed in this work, based on DFT calculations, were only studied for the Cp*Ir complexes that present a 6,6'-dmbp or 6,6'-dhbp ligand. However, analogous catalytic cycles may be expected for the related NHC complexes (Scheme 19). Two mechanisms, one featuring an inter- (Scheme 19A) and the other an intramolecular (Scheme 19B) proton transfer, were predicted to be possible for the dehydrogenation of formic acid. Remarkably, under acidic conditions, the presence of a methoxy or hydroxy moiety produces only marginal differences in the activity of the catalyst.

This is likely due to the impossibility to form anionic species under acidic conditions, together with the similar electronic characteristics of $\mathrm{HO}$ - and $\mathrm{MeO}-$ groups, both having a similar ability to stablish hydrogen bonds.

\section{Hydrogen isotope exchange}

The hydrogen isotope exchange (HIE) reaction is a key strategy in the first stage of drug discovery since it allows to monitor the metabolic stability and/or toxicity of the compound under study by introducing a tracer that does not affect the biochemical properties of the original molecule. ${ }^{128}$ The importance of iridium catalysts in HIE is well illustrated by the widespread use in these reactions of Crabtree's catalyst, which has been considered as the model complex to promote isotopic exchange. Related complexes featuring NHC ligands, 181 and 182 , have been developed in the search for new catalysts that overcome the drawbacks associated with the use of Crabtree's catalyst, namely, stoichiometric or overstoichiometric quantities of Ir-complex, production of substantial amounts of radioactive waste and long reaction times. ${ }^{129}$ Complexes 181ae bring about high deuterium and tritium incorporation in aromatic compounds using $D_{2}$ or $T_{2}$ as sources. These reactions are compatible with a great variety of directing groups, including relevant bioactive molecules. In most cases, isotopic exchange takes place at both $\mathrm{C}-\mathrm{H}$ bonds adjacent to the directing group. ${ }^{129 a}$ Mechanistic investigations suggest that the rate limiting step of the reaction is the $\mathrm{C}-\mathrm{H}$ activation process, which is favoured by the presence of the strongly $\sigma$-donating NHC ligands. This would explain the high reactivity of these complexes, which work at room temperature and maintain their activity under aerobic conditions. Moreover, these catalysts show excellent activities in solvents different from dichloromethane, which is one of the main challenges in HIE reactions. ${ }^{129 c}$ The use of a less coordinating counterion, namely $\mathrm{BAr}^{\mathrm{F}}$ instead of $\mathrm{PF}_{6}$, brings about an increase of the reactivity, although the counterion/solvent couple plays an important role in the selectivity of the reaction. ${ }^{130} \mathrm{~A}$ catalytic cycle was proposed for this reaction based on stoichiometric experiments and theoretical calculations (Scheme 20). 


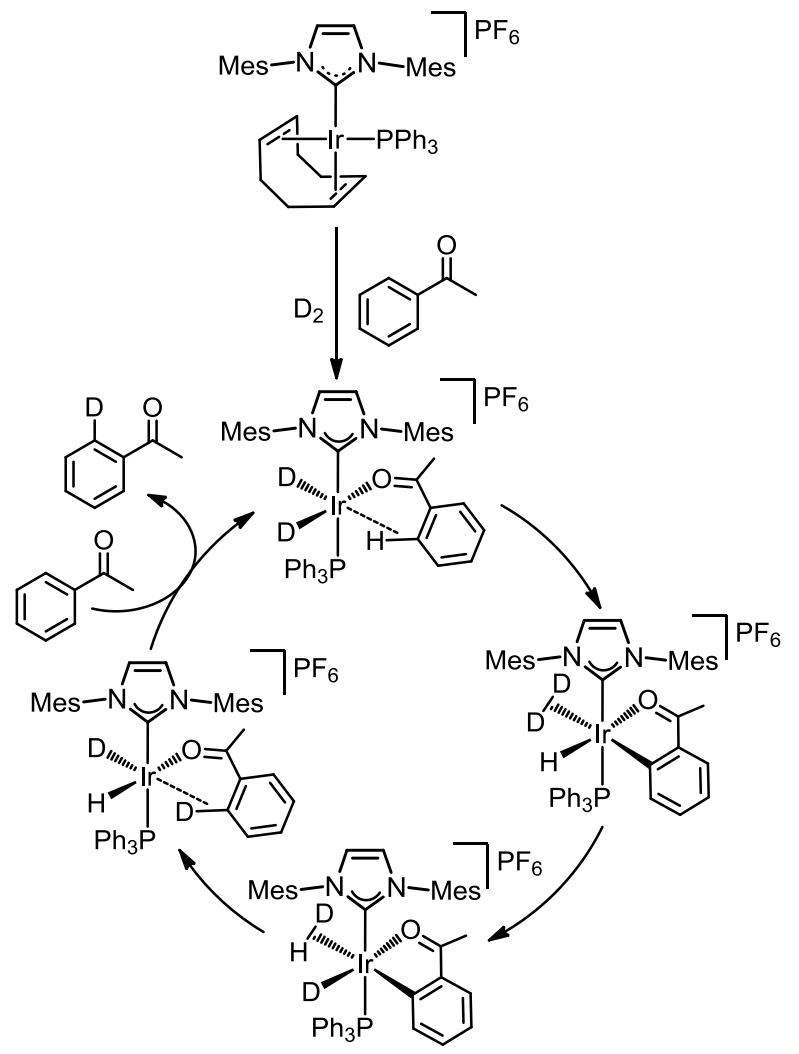

Scheme 20 Proposed catalytic cycle for the directed deuteration of acetophenone. ${ }^{130}$

These data suggest that the first step would entail the hydrogenation of the 1,5-cyclooctadiene ligand and the formation of an unsaturated $\operatorname{Ir}($ III) dideuteride intermediate with concomitant coordination of the substrate, analogously to the hydrogenation catalysts described in section 2 . Subsequently, cyclometallation of the substrate affords a hydride-dideuterium intermediate, which by a fluxional process allows a deuteride to situate cis to the $\mathrm{Ir}-\mathrm{C}$ bond. Finally, reductive elimination leads to deuteration of the ortho $\mathrm{C}-\mathrm{H}$ bond. The main difference with the mechanism proposed by Heys' group is the stabilisation of the substrate by means of an agostic interaction with the ortho- $\mathrm{C}-\mathrm{H}$ bond. ${ }^{131}$

Complexes 182a-c have proved highly efficient and selective catalysts for the isotopic labelling of various aromatic targets. Remarkably, complex 182c leads to the selective monodeuteration of pharmaceutical agent SR 121463 (Figure 24). ${ }^{129 b}$

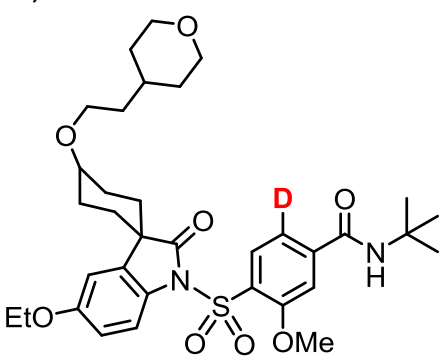

Figure 24 Molecular structure of pharmaceutical agent SR 121463
Coordinatively unsaturated complexes 173, 174a (Figure 22) and 185 (Figure 25) have shown good activity for the deuteration of a wide range of secondary and tertiary hydrosilanes with $D_{2}$. Mechanistic studies suggest that the tertbutyl groups at the nitrogen atoms reversibly cyclometallate under a hydrogen atmosphere, thus generating or blocking coordination sites throughout the catalytic reaction. ${ }^{132}$

Complexes of the type $\left[C p^{*} \mid r^{\prime \prime \prime}\left(\mathrm{PR}_{3}\right)\right]$ have proved to be efficient catalysts for $H / D$ exchange only when strongly $\sigma$-donating trialkylphosphines were employed. ${ }^{133}$ The use of NHC's instead of phosphines has led to the development of very efficient HIE catalysts for a variety of organic molecules that use deuterated solvents as deuterium source. Complexes 186 and 187 show remarkably better activities, conversions and catalyst stability than their phosphine analogues for a wider range of substrates using $\mathrm{CD}_{3} \mathrm{OD}$ as deuterium source. ${ }^{134}$ Complexes 185, 186 and 188-189 (Figure 25) are able to deuterate benzene using methanol- $d_{4}$, acetic acid- $d_{4}$ and trifluoroacetic acid- $d_{1}$ as deuterium source. ${ }^{135}$ This study suggests that strong donor ligands promote the formation of Ir-hydrides that facilitate the activation of $\mathrm{C}-\mathrm{H}$ bonds in weakly acidic solvents. Besides, the reaction mechanism seems to change depending on the acidity of the solvent. Classic organometallic mechanisms have been proposed to take place in methanol and acetic acid, while an Ar$\mathrm{S}_{\mathrm{E}}$ mechanism would operate in trifluoroacetic acid.

Interestingly, Burgess catalyst, complex $\mathbf{7}$, is an efficient catalyst for the deuteration of $\mathrm{C}-\mathrm{H}$ bonds ortho to a directing group in a variety of solvents. ${ }^{136}$

Complex 190 catalyses the selective formyl $\mathrm{C}-\mathrm{H}$ deuteration deuteration of aldehydes without the formation of decarbonylation by-products; however, small amounts of aryl deuteration were observed. The formation of these two products was explained by means the two competing catalytic cycles depicted in Scheme $21 .{ }^{137}$ The formyl labelling (Scheme $21 \mathrm{~A})$ requires the pre-activation of 190 with $D_{2}$ to give an $\operatorname{Ir}(\mathrm{III})$ active species as initial step. The resulting dideuteride complex undergoes oxidative addition of the formyl $\mathrm{C}-\mathrm{H}$ bond to give an $\operatorname{Ir}(\mathrm{V})$ intermediate. Remarkably, DFT calculations predict a higher activation energy for the alternative $\sigma$-CAM mechanism. Reductive elimination of an H-D molecule affords an $\operatorname{Ir}(\mathrm{III})$ intermediate that may go back to $\operatorname{Ir}(\mathrm{V})$ by oxidative addition of the H-D ligand. The new $\operatorname{Ir}(\mathrm{V})$ intermediate now presents two deuterides cis to the acyl ligand. Finally, reductive elimination affords the formyl-labelled molecule. In contrast to the $\operatorname{Ir}(I I I)-$ $\operatorname{Ir}(\mathrm{V})$ catalytic cycle proposed for the formyl deuteration (Scheme 21A), aryl labelling would proceed by an $\operatorname{Ir}(\mathrm{III})$ mechanism. In the case of the latter, the $\mathrm{C}-\mathrm{H}$ bond activation takes place by a $\sigma$-bond metathesis pathway that results in the cyclometallation of the benzaldehyde molecule and the formation of a hydride and a $D_{2}$ ligand. DFT calculations predict a high energy barrier for this process that accounts for the low percentage of aryl labelled product (Scheme 21B). Finally, H-D rearrangement followed by $\sigma$-bond metathesis affords the aryldeuterated compound. Notably, the steric congestion about the iridium centre originated by the steric impact of the NHC ligand disfavours the decarbonylation process. In this regard, DFT 


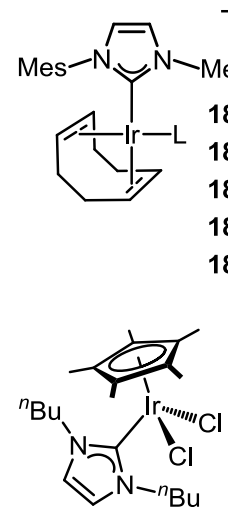

186
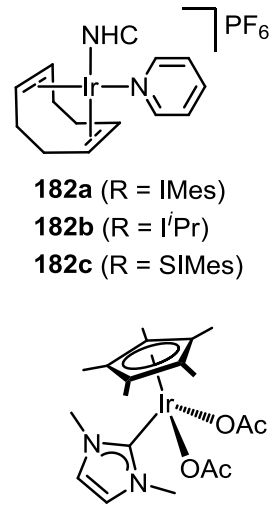

188

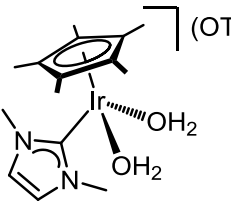

183

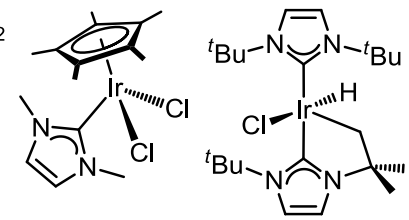

184

185

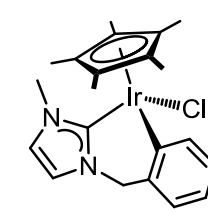

187

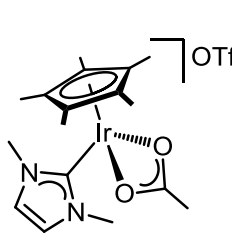

189

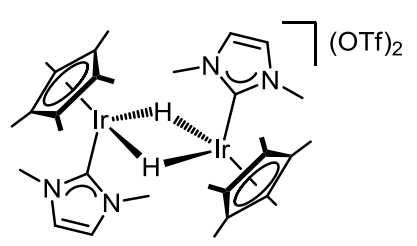

190

Figure 25 Ir-NHC catalysts for H/D exchange.

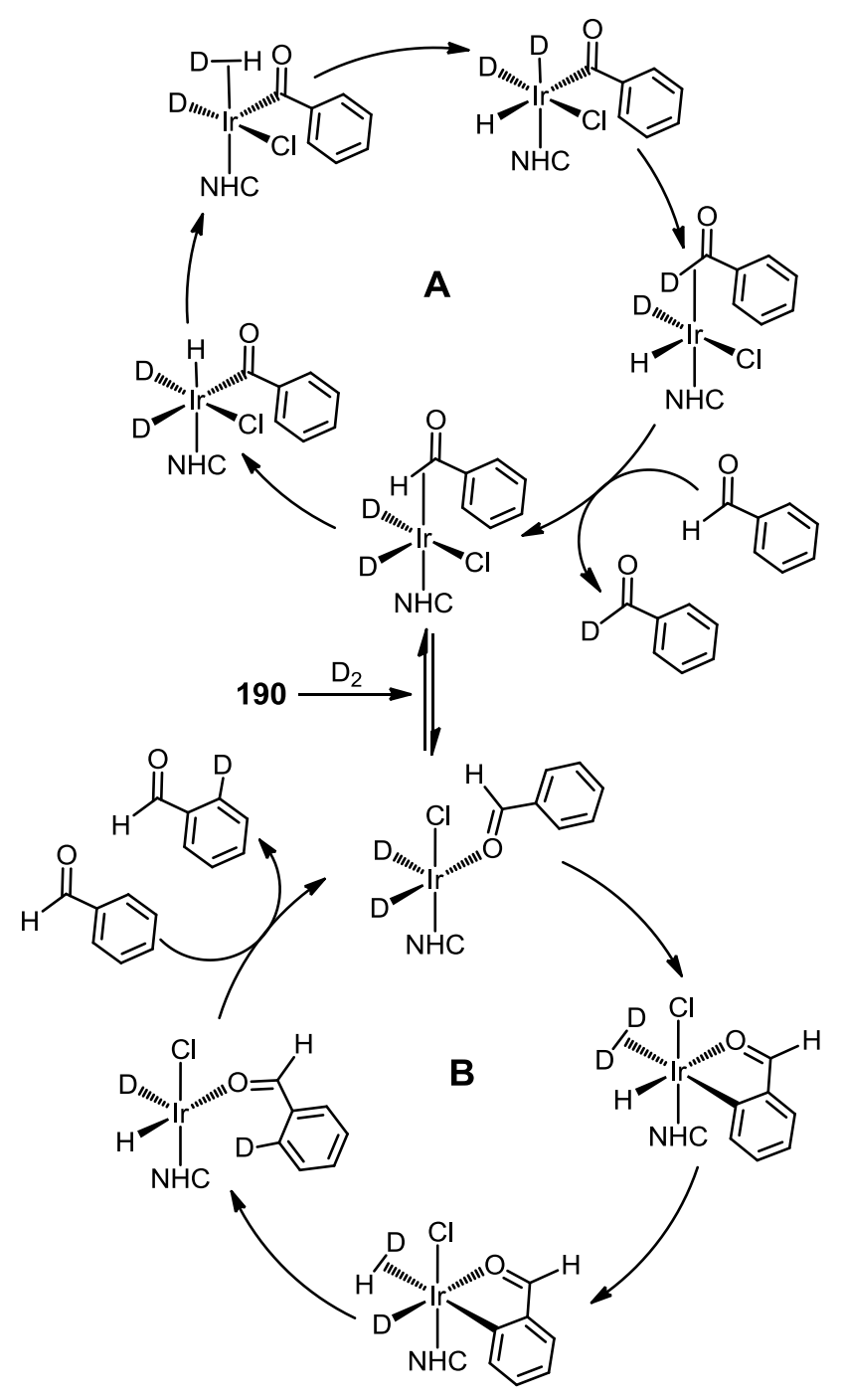

Scheme 21 Competing mechanisms for formyl (A) and aryl (B) labelling. ${ }^{137}$

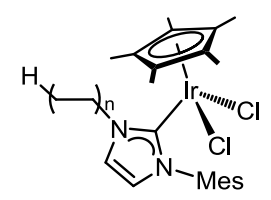

$191(n=$ ca. 30$)$

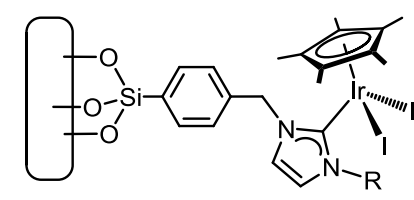

$192 \mathrm{a}(\mathrm{R}=\mathrm{Me})$

$192 b(R=$ Mes $)$
Figure 26 Supported Ir-NHC catalysts for H/D exchange.

calculations show a lower activation energy for the decarbonylation reaction when the wingtip group is a mesityl moiety.

The need for a thorough separation of the catalyst from the target molecule in the pharmaceutical industry has led to the development of supported Ir-NHC complexes $\mathbf{1 9 1}{ }^{138}$ and $\mathbf{1 9 2 . 1 3 9}$ Both hybrid materials were active catalysts for the deuteration of acetophenone with methanol- $d_{4}$. The thermomorphic properties of polyethylene-based material 191 lead to better activities than silica supported 192 (Figure 26).

\section{Signal amplification by reversible exchange (SABRE)}

The prominent applications of NMR spectroscopy in chemical and biomedical research have as major obstacle the intrinsically low sensitivity of the technique. ${ }^{140}$ Hyperpolarisation methods have been developed to circumvent this problem inducing signal enhancement by increasing the population difference between spin states promoting non-Boltzmann nuclear spin populations in organic substrates. Dynamic nuclear polarisation (DNP) makes use of the polarisation transfer from an unpaired electron to the nuclei in the substrate at temperatures close to $1 \mathrm{~K}$, which requires a period of several hours. ${ }^{141}$ Para-hydrogen induced polarisation (PHIP) entails the hydrogenation of the target molecule with $p-\mathrm{H}_{2}$, which results in the chemical modification of the hyperpolarised molecule. ${ }^{142}$ Signal amplification by reversible exchange (SABRE), on the other hand, leads to hyperpolarisation by temporary simultaneous coordination of $p-\mathrm{H}_{2}$ and the substrate to the polarisation 
transfer catalyst. ${ }^{143}$ This technique was first developed using Crabtree's catalyst, $\left[\operatorname{Ir}(\mathrm{cod})\left(\mathrm{PC}_{3}\right)(\mathrm{py})\right] \mathrm{BF}_{4}$, for the transfer polarisation from $p-\mathrm{H}_{2}$ to pyridine. The reaction of $\left[\operatorname{Ir}(\operatorname{cod})\left(\mathrm{PCy}_{3}\right)(\mathrm{py})\right] \mathrm{BF}_{4}$ with $p-\mathrm{H}_{2}$ and py affords the active species, $\left[\operatorname{Ir}(\mathrm{H})_{2}\left(\mathrm{PCy}_{3}\right)(\mathrm{py})_{3}\right] \mathrm{BF}_{4}$, which is able to produce significant signal enhancement in the ${ }^{1} \mathrm{H},{ }^{13} \mathrm{C}$ and ${ }^{15} \mathrm{~N}$ NMR spectra of pyridine by polarisation transfer from the $p-\mathrm{H}_{2-}$ derived hydrides to the coordinated substrate via scalar coupling. ${ }^{144}$

Theoretical calculations suggested that the use of strongly donating and encumbered phosphines favour the SABRE process. ${ }^{145}$ This prompted the use $\mathrm{N}$-heterocyclic carbenes to substitute the phosphine ligand $\left(\mathrm{PC}_{3}\right)$ in Crabtree's catalyst. [ $\mathrm{IrCl}(\mathrm{cod}) \mathrm{IMes}]$ (28a), which is transformed into $\left[\operatorname{Ir}(\mathrm{H})_{2}(\mathrm{IMes})(\mathrm{py})_{3}\right] \mathrm{BF}_{4}(\mathbf{1 9 4})$ in the presence of $p-\mathrm{H}_{2}$ and $\mathrm{py}$, is remarkably more active than $\left[\operatorname{Ir}(\mathrm{H})_{2}\left(\mathrm{PCy}_{3}\right)(\mathrm{py})_{3}\right] \mathrm{BF}_{4}$ as a SABRE catalyst. ${ }^{146}$ This result has led to the publication of a myriad of studies on SABRE catalysts based on this scaffold (Figure 27). ${ }^{147}$ Various NHC ligands have been tested as ancillary ligands for this process, namely, SIMes (1,3-Bis(2,4,6-trimethylphenyl)-4,5dihydroimidazol-2-ylidene), $\quad \operatorname{Pr} \quad$ (1,3-bis(2,6diisopropylphenyl)imidazol-2-ylidene), $\quad \operatorname{SIPr} \quad$ (1,3-Bis(2,6diisopropylphenyl)-4,5-dihydroimidazol-2-ylidene), ICy (1,3bis(cyclohexyl)imidazol-2-ylidene), $\mathrm{IMe}$

$(1,3-$ bis(dimethyl)imidazol-2-ylidene), $\mathrm{ImMe}_{2} \mathrm{~N}^{\mathrm{P} \mathrm{Pr}_{2}}$ $(1,3-$ bis(diisopropyl)-4,5-dimethylimidazol-2-ylidene), $\operatorname{ImNiPr}_{2} \quad(1,3-$ bis(diisopropyl)-imidazol-2-ylidene) and $\operatorname{SImN}^{i} \mathrm{Pr}_{2}$ (1,3bis(diisopropyl)-4,5-dihydroimidazol-2-ylidene) (complexes 193a-h).

The influence of the electron-donating ability of the ligands is almost negligible; therefore, the different signal enhancements observed upon NHC substitution should be mainly attributed to steric effects. ${ }^{147 c}$ An increase of the NHC's steric bulk, measured in terms of $\% \mathrm{~V}_{\text {bur, }}$ leads to higher pyridine exchange rates, which suggests a dissociative mechanism. However, the signal enhancement is not directly related with the $\% \mathrm{~V}_{\text {bur. }}$. This may be due to the fact that the polarisation transfer process needs to be sufficiently rapid to allow signal enhancement at high exchange rates, otherwise the relaxation processes that take place in solution would lead to signal decay. The NHC ligands that render the most effective catalyst for SABRE are in decreasing order: IMes, SIMes, IPr, ImMe ${ }_{2} \mathrm{NPP}_{2}$, IMe, ICy and SIPr. ${ }^{147 d}$

Other substrates, different from pyridine, have been hyperpolarised using SABRE, for example, nicotinamide underwent hyperpolarisation mainly to the ${ }^{1} \mathrm{H}$ nuclei of the pyridyl ring, and in a lesser extent to the ${ }^{13} \mathrm{C}$ nuclei. ${ }^{147 f}$ Signal enhancement of nicotinic acid at different $\mathrm{pH}$ values has also been studied in view of employing this hyperpolarised molecule as a probe to assist in medical diagnosis. Complex 195 was obtained upon reaction of 28a with nicotinic acid. Under $p-\mathrm{H}_{2}$ atmosphere (3 bar) 195 is converted into 196, which reacts with 2 equivalents of nicotinic acid to afford 197, presumably the active species. ${ }^{147 i}$ Complex 197 was found to be soluble in water, a very desirable characteristic for the potential biomedical application of SABRE hyperpolarisation, since most systems require methanol as solvent, which is not compatible with in vivo injection. ${ }^{1471}$ The efficiency of water soluble SABRE catalysts $198^{147 f}$ and $199^{147 g}$ drops drastically upon using pure water or biocompatible mixtures as solvents. A noteworthy catalyst is $\mathbf{2 0 0}$, which is capable of achieving hyperpolarisation in pure water, showing enhancement levels for nicotinamide similar to those obtained with $\mathbf{2 8 a}$ derivatives in ethanol/water mixtures. Besides, $\mathbf{2 0 0}$ shows a wide substrate scope; namely, pyridine, methyl nicotine, $N$-methylnicotinamide and nicotinamide. ${ }^{147 \mathrm{~h}, \mathrm{~m}}$ Complex 201 shows activities in methanol similar to those described for $\mathbf{2 0 0}$ in water.

More recently, the advancement of this technique has allowed the efficient enhancement of nucleus such as ${ }^{15} \mathrm{~N},{ }^{147 n}{ }^{13} \mathrm{C},{ }^{1470, \mathrm{r}}$ and ${ }^{19} \mathrm{~F}^{147 \mathrm{q}}$.

The heterogenisation of homogeneous SABRE catalysts on solid supports is an interesting strategy for the separation of the catalyst from the hyperpolarised substrate in solution (Figure 28). This characteristic is of crucial importance for SABRE catalysts owing to the stringent requirements for in vivo experiments. Hybrid material 202 presents the Ir(cod)IMes fragment bound to a micropolymer bead by means of a 4dimethylaminopyridine linkage.

202 is able to produce a fivefold enhancement of the RNM signals of pyridine, which is relatively low in comparison with homogeneous SABRE. However, the heterogeneous catalysis was performed under disadvantageous conditions compared to homogeneous catalysis, such as lower catalyst-substrate ratio or reduced $p \mathrm{H}_{2}$ fraction. ${ }^{147 \mathrm{j}}$ Heterogeneous SABRE catalysts 203 and 204 contain the $\operatorname{Ir}(\mathrm{COD})$ IMes fragment linked to $\mathrm{TiO}_{2} / \mathrm{PMAA}$ core-shell nanoparticles or a PVP polymer comb via a pyridine moiety. Both can be separated and recycled achieving enhancements up to 11 -fold. ${ }^{147 \mathrm{k}}$

\section{Functionalisation of $\mathrm{C}-\mathrm{H}$ bonds}

The functionalisation of $\mathrm{C}-\mathrm{H}$ bonds enables the direct derivatisation of organic molecules without the need for prefunctionalisation, thus eluding the use of additional steps and reducing the amount of by-products generated during the course of the synthetic route. ${ }^{148} \mathrm{NHCs}$ promote $\mathrm{C}-\mathrm{H}$ bond activation by: i) enhancing $\pi$-backbonding from the $\mathrm{d}$ orbitals at the metal centre to the $\sigma^{*}$ orbital of the $\mathrm{C}-\mathrm{H}$ bond, and ii) stabilising high oxidation states of the catalyst, thus facilitating the oxidative addition reaction. ${ }^{149}$

The intramolecular $\mathrm{C}-\mathrm{H}$ bond activation of the aromatic $\mathrm{N}$ substituents has been proposed to occur reversively throughout the catalytic cycle, playing a key role in the improvement of the catalytic activity.

The cyclometallation-decyclometallation of the wingtip groups was proposed to bring about steric and electronic adjustments in the catalyst that affect its reactivity. The postulated catalytic cycle entails the cyclometallation of 2-phenylpyridine and the $\mathrm{N}$-substituent to give $\mathbf{B}$, followed by reaction with triethylsilane to afford $\mathbf{C}$ and the corresponding silylacetate. 

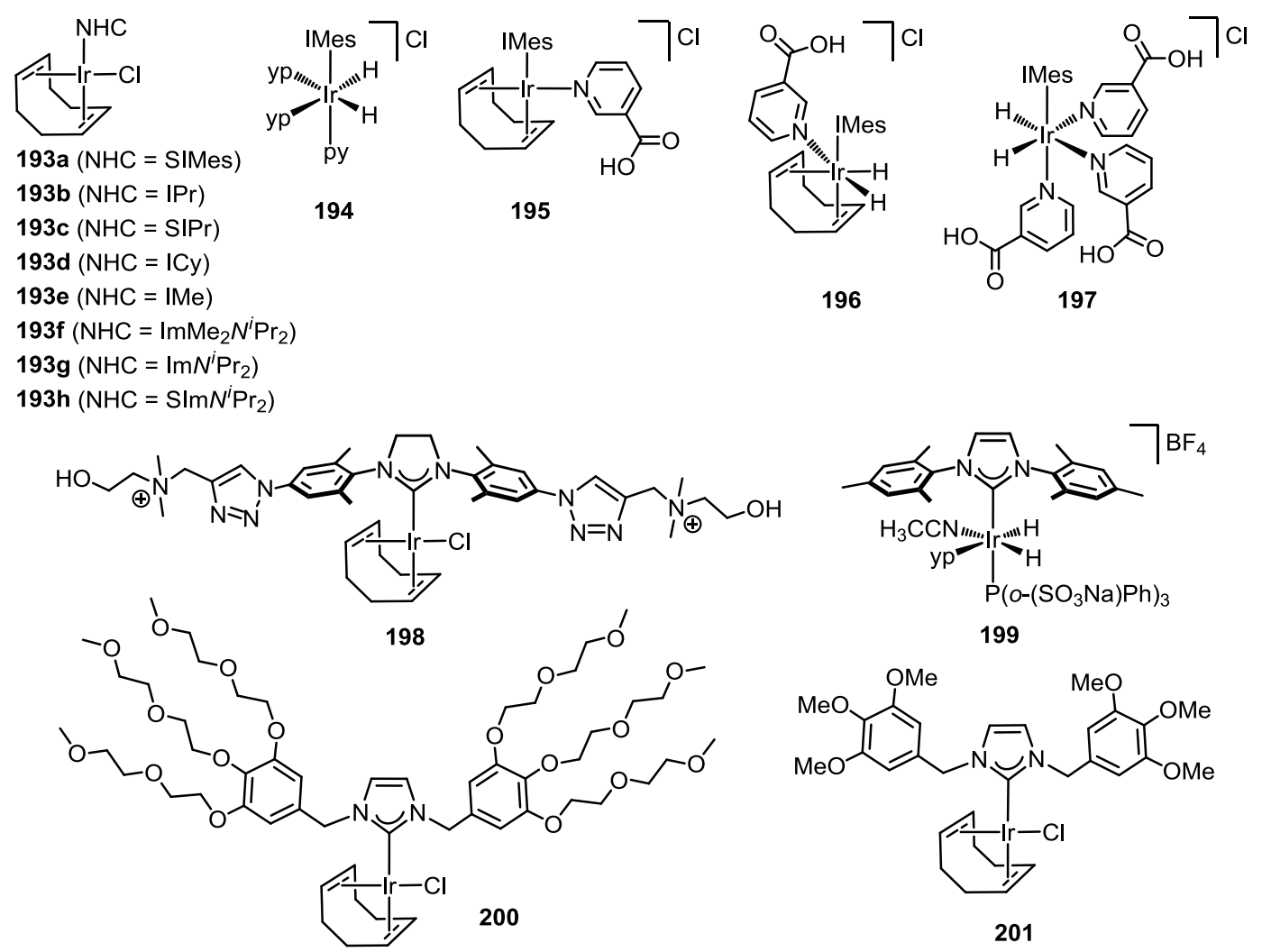

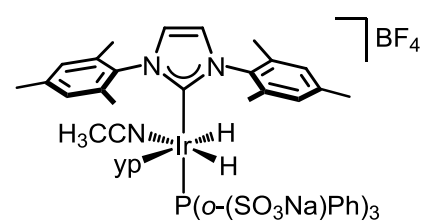

199<smiles></smiles>

201

Figure 27 Ir-NHC catalysts for SABRE.

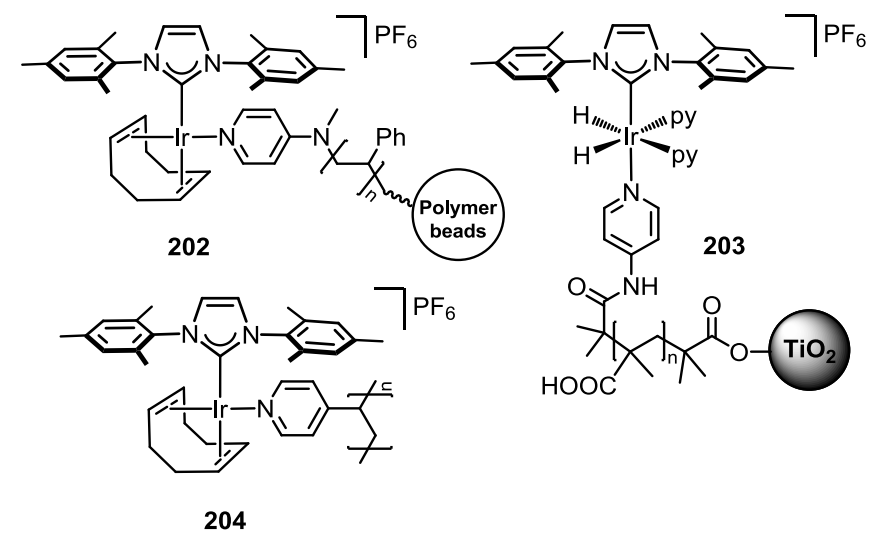

Figure 28 Supported Ir-NHC catalysts for SABRE.

\subsection{C-H Silylation}

Complexes $\mathbf{2 0 5}$ and $\mathbf{2 0 6}$ are capable of selective mono-silylation of a variety of arenes in ortho to pyridyl or iminyl directing groups (Figure 29)..$^{150}$

The oxidative addition of a molecule of silane triggers the decyclometallation of the NHC, thus yielding D. Coordination and migratory insertion of the hydrogen acceptor (norbornene) gives $\mathbf{E}$, which after cyclometallation of the NHC and reductive elimination of norbonane renders $\mathbf{F}$. Coordination of the silane gives $\mathbf{G}$, which promotes the formation of the $\sigma$-CAM intermediate $\mathbf{H}$ and, consequently, the silylation of the substrate. Finally, substitution of the silylated product in I restarts the catalytic cycle (Scheme 22). ${ }^{150}$

Complex 207 catalyses the directed and non-directed dehydrogenative silylation of a wide range of (hetero)arenes with various hydrosilanes, including for the first time (EtO) ${ }_{3} \mathrm{SiH}$. The catalyst works efficiently with and without a hydrogen acceptor, although better yields and reaction rates were observed in the presence of a sacrificial hydrogen acceptor. The mechanism of the reaction was proposed based on theoretical calculations and supported by experimental evidences.
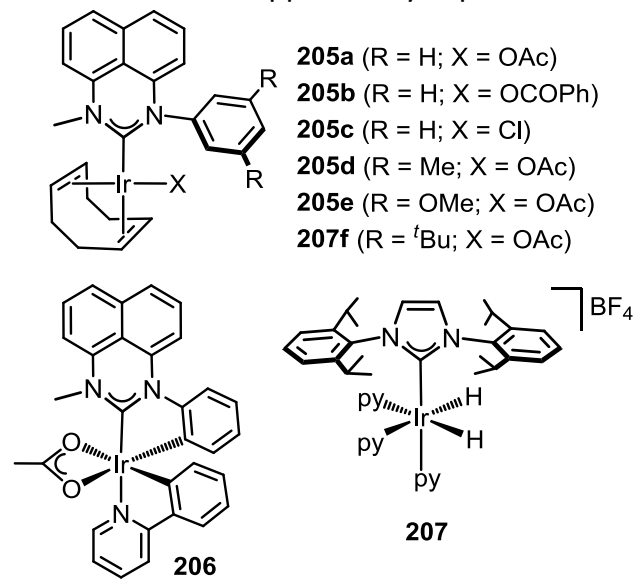

207

Figure $\mathbf{2 9} \mathrm{Ir}-\mathrm{NHC}$ catalysts for $\mathrm{C}-\mathrm{H}$ silylation. 


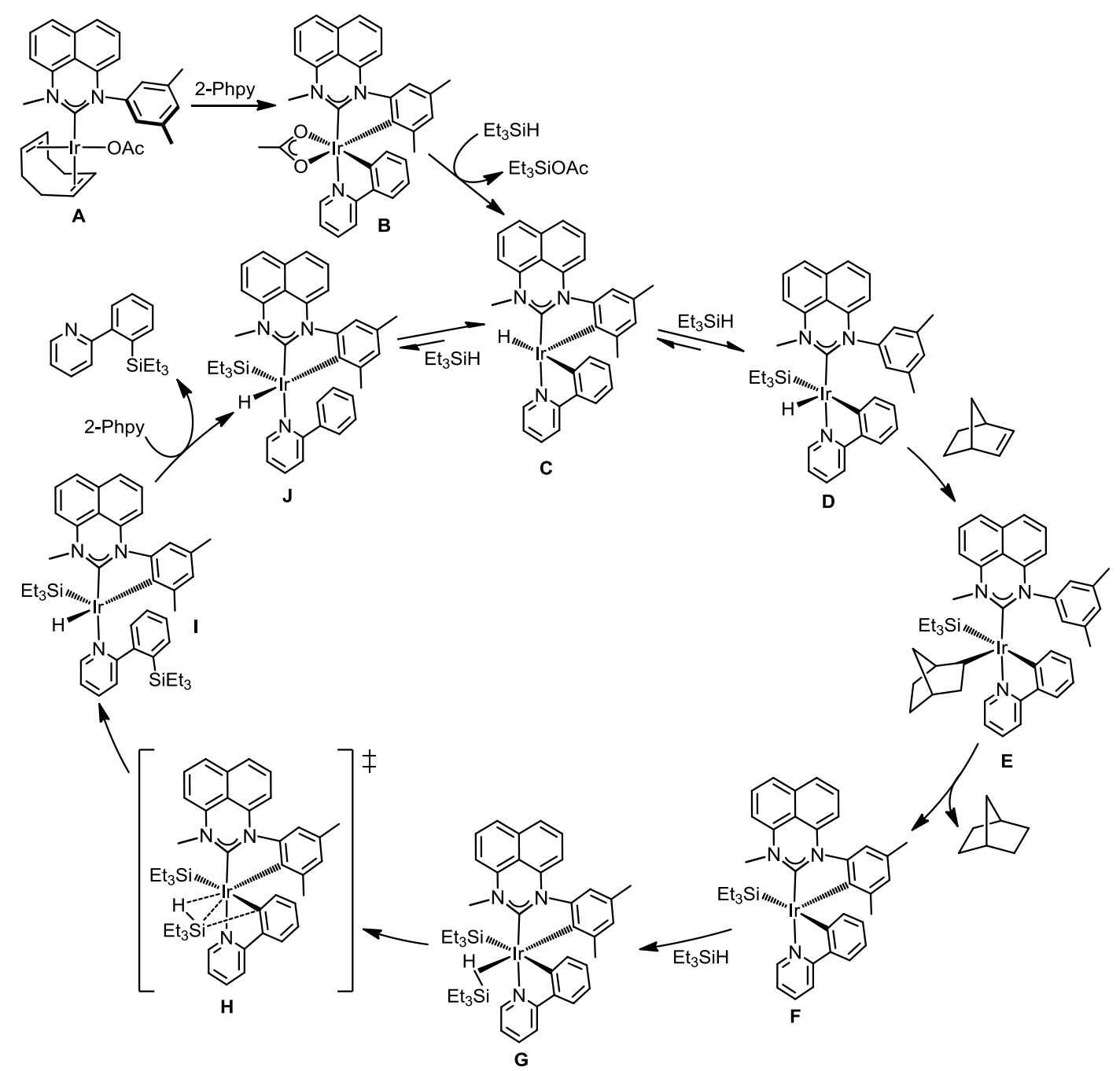

Scheme 22 Proposed catalytic cycle for the directed silylation of 2-phenylpyridine with $205 .{ }^{150}$

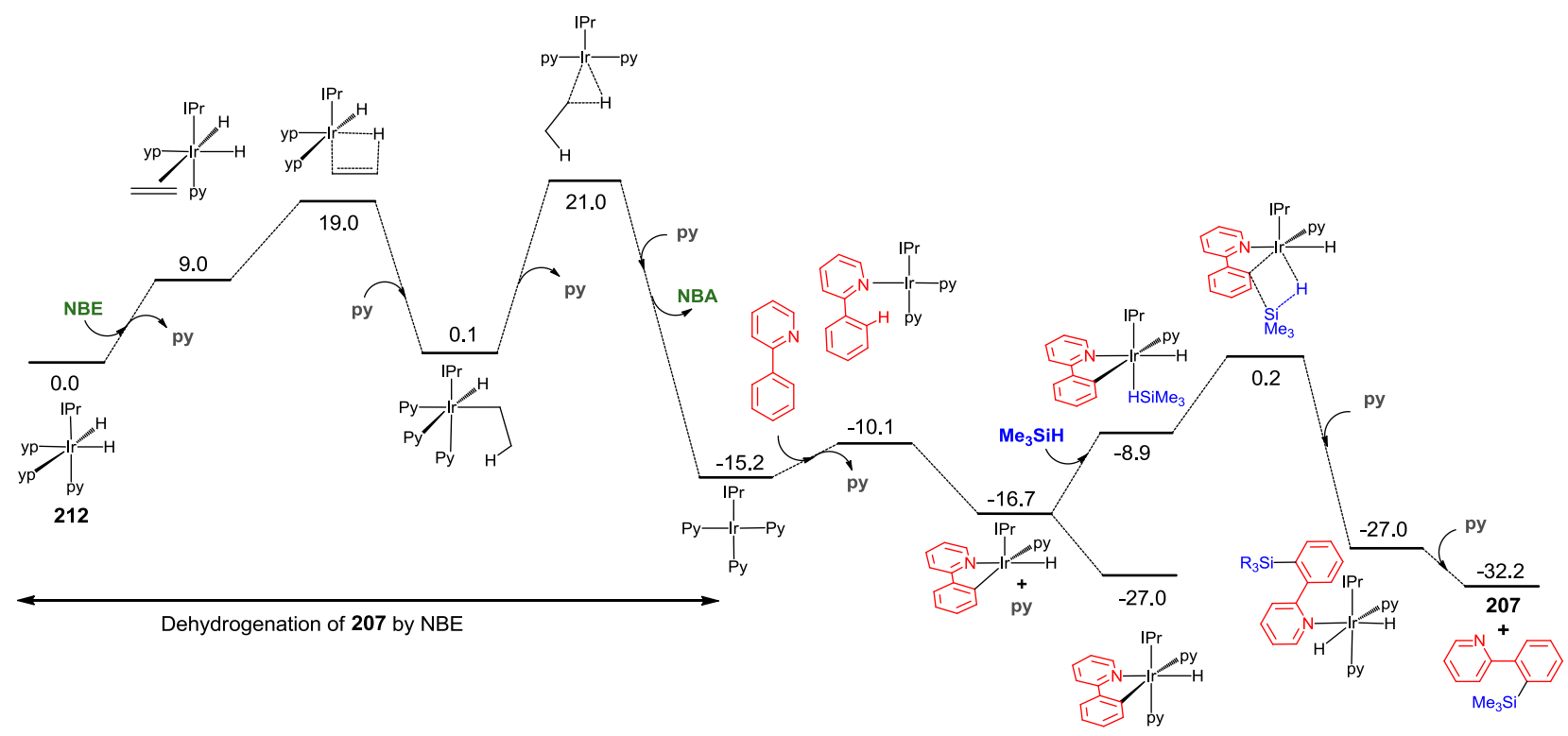

Figure $\mathbf{3 0}$ Calculated energetic profile for the directed silylation of 2-phenylpyridine with 207. ${ }^{151}$ 


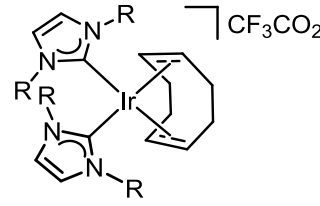

208a $(R=M e)$ 208b $(R=C y)$

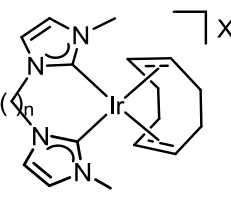

212a $\left(n=2 ; X=P F_{6}\right)$

212b $\left(\mathrm{n}=3 ; \mathrm{X}=\mathrm{CF}_{3} \mathrm{CO}_{2}\right)$

212c $\left(n=3 ; X=B F_{4}\right)$

212d $\left(n=3 ; X=P F_{6}\right)$

212e $(n=3 ; X=1)$

$212 f\left(n=3 ; X=\mathrm{CF}_{3} \mathrm{SO}_{3}\right)$

212b ( $\left.\mathrm{n}=4 ; \mathrm{X}=\mathrm{CF}_{3} \mathrm{CO}_{2}\right)$

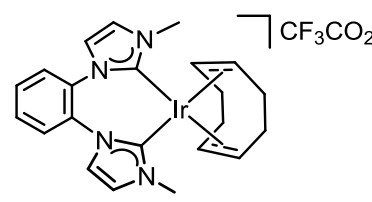

213

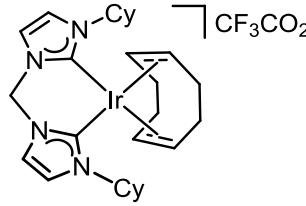

209

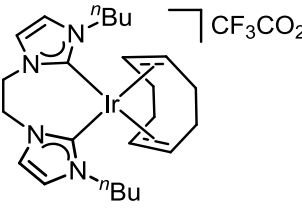

210

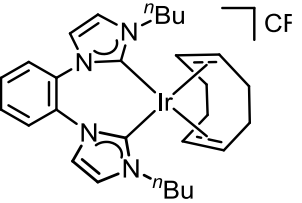

211

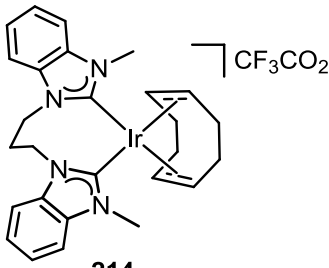

214

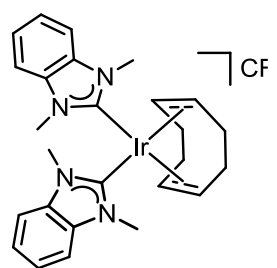

215
Figure $\mathbf{3 1} \mathrm{Ir}-\mathrm{NHC}$ catalysts for $\mathrm{C}-\mathrm{H}$ borylation.

The $\operatorname{Ir}(\mathrm{I}) / \operatorname{Ir}(\mathrm{III})$ mechanism requires as first step the dehydrogenation of $\mathbf{2 0 7}$ to generate an electron-rich $\mathrm{NHC}-\operatorname{Ir}(\mathrm{I})$ intermediate $\left(\left[\operatorname{Ir}(\operatorname{IPr})(\mathrm{Py})_{3}\right]\right)$. The formation of this very reactive species permits the $\mathrm{C}-\mathrm{H}$ bond activation to occur under mild conditions. Coordination of the substrate (2-phenylpyridine) to $\left[\operatorname{Ir}(\mathrm{IPr})(\mathrm{Py})_{3}\right]$ leads to the barrierless oxidative addition of the $\mathrm{C}$ $\mathrm{H}$ bond with concomitant loss of a pyridine ligand followed by silane coordination. Finally, the silylated substrate is formed via a $\sigma$-CAM mechanism, which, after substitution of the reaction product by a pyridine ligand, regenerates 209 (Figure 30). ${ }^{151}$

\subsection{C-H Borylation}

The first example of $\mathrm{C}-\mathrm{H}$ borylation and, notably, of arene $\mathrm{C}-\mathrm{H}$ functionalisation, by NHC complexes makes use of the $\operatorname{Ir}(\mathrm{I})$ catalysts of general formula $\left[\operatorname{Ir}(\mathrm{COD})(\mathrm{NHC})_{2}\right]^{+}$. Complexes 208 211 catalyse the borylation of a series of substituted arenes with $\mathrm{B}_{2} \mathrm{Pin}_{2}{ }^{152}$ Further studies on this type of bis-NHC complexes (212-217) led to excellent results in the borylation of arenes under microwave irradiation using HBPin, especially in the case of $\mathbf{2 1 2} \mathbf{b}$. The reaction times are shorter than those observed for thermic processes and these systems permit the use of efficient solventless systems. Related mono-NHC catalysts were proved less effective, probably due to the low stability of the catalysts. ${ }^{153}$

Iridium CCC-pincer complexes 170a, 170c, and 218 catalyse the borylation of aryl $\mathrm{C}-\mathrm{H}$ bonds in the presence of $\mathrm{NaO}^{t} \mathrm{Bu} .^{119}$ Attempts to use stoichiometric amounts of the arene with these catalysts were unsuccessful, in fact, no stoichiometric process has been described so far for catalysts based on Ir-NHC scaffolds (Figure 31).

\section{Miscellaneous}

\subsection{Hydroalkynylation of imines}

Ir(II) dinuclear complex $\mathbf{2 1 9}$ catalyses the hydroalkynylation of a variety of imines with aliphatic and aromatic alkynes. ${ }^{154}$ Dinuclear $\operatorname{Ir}(\mathrm{II})$ complexes have been often described as inactive species in catalysis, 19219 being one of the few exceptions hitherto reported (Figure 32). ${ }^{155}$

The proposed catalytic cycle involves a dinuclear cooperative mechanism (Scheme 23) where the oxidation state of the Ir centres and the hapticity of the aryl ligand change throughout the catalytic cycle. The key steps of are: (i) one of the Ir centres undergoes oxidative addition of the $\mathrm{C}-\mathrm{H}$ bond; (ii) deprotonation of the complex by the imine; (iii) the protonated imine coordinates by the $\pi$-system; (iv) migratory insertion of the imine into the Ir-alkynyl bond to form the propargyl amine and regeneration of the catalyst.

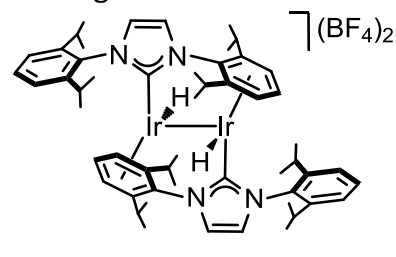

219

Figure 32 Binuclear $\operatorname{Ir}(I I)$ catalysts for the hydroalkynylation of imines. 


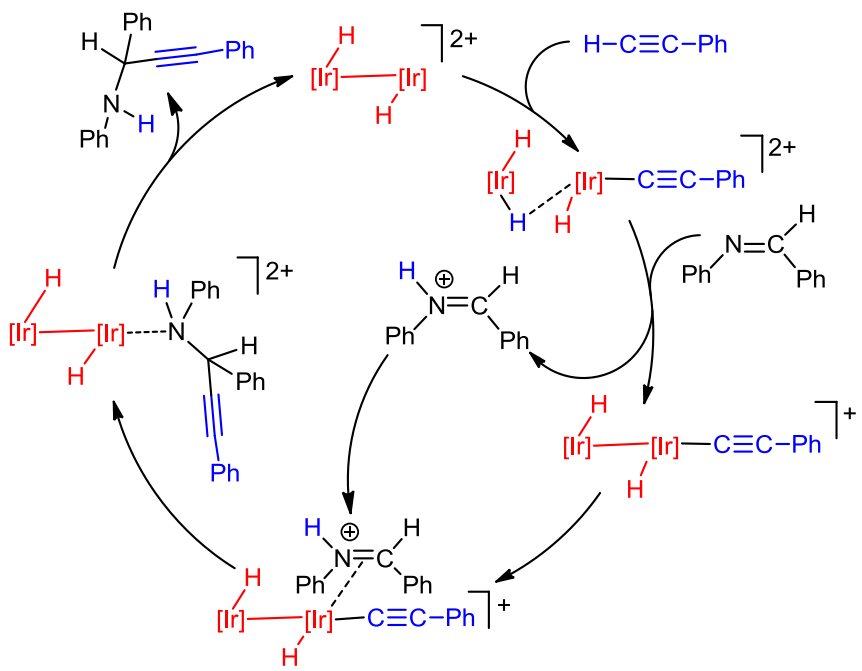

Scheme 23 Calculated mechanism for the hydroalkynylation of imines by complex 219. ${ }^{154}$<smiles>[R]CNCC(CCC=CC)(c1ccccc1)c1ccccc1</smiles>

Scheme 24 Hydroamination/cyclisation.

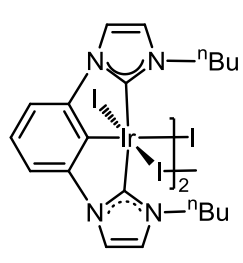

220

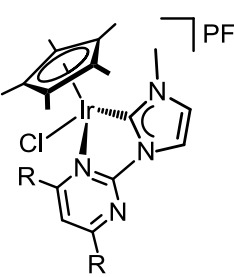

221a $(R=P h)$

221b $\left(\mathrm{R}={ }^{t} \mathrm{Bu}\right)$

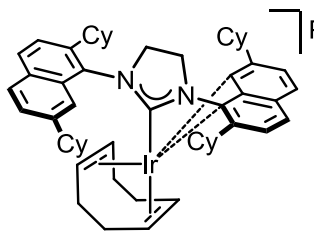

223

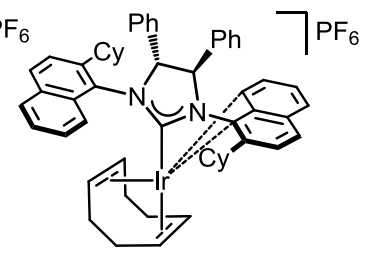

224
Figure 33 Ir-NHC catalysts for intramolecular hydroamination.

\subsection{Hydroamination}

The hydroamination reaction, formally the addition on an $\mathrm{N}-\mathrm{H}$ bond across a double or triple $\mathrm{C}-\mathrm{C}$ bond, is one of the most atom-economic and versatile routes to the formation of new $\mathrm{C}-$ $\mathrm{N}$ bonds. ${ }^{156} \mathrm{Ir}$ (III) complex 220, which features a CCC-NHC pincer ligand (Figure 33), is capable of catalysing the hydroamination/cyclisation of unactivated alkynes in water to give 5- and 6-membered nitrogen-containing rings (Scheme 24). 157

Complexes 91c, 221 and 222, which present hemilabile N-donor functions at one of NHC's sidearms, are also active catalysts for the intramolecular hydroamination reaction. However, reaction rates are lower than those obtained with $\mathbf{2 2 0}$ under comparable conditions. The increase of steric hindrance about the hemilabile group improves the catalytic performance, probably due to a weaker $\mathrm{Ir}-\mathrm{N}$ bond, as suggested by the longer bond distances observed for $\mathbf{2 2 1 b}$ and 222 compared to 91c and 221a. ${ }^{158}$

Complex 223 showed excellent activities for the intramolecular hydroamination of aliphatic and aromatic amines. The cyclisation takes places under very mild conditions $(0.5 \mathrm{~mol} \%$ catalyst loading, room temperature) and short reaction times (full conversion in ca. $3 \mathrm{~min}$ ). The enantiopure complex 224 gives rise to excellent enantioselectivities in the asymmetric version of this reaction. Somewhat lower activities were observed for $\mathbf{2 2 4}$ when compared to $\mathbf{2 2 3}$, although full conversion can still be achieved under mild conditions with the former. ${ }^{159}$

The intramolecular hydroamination of aminoalkynes, namely 4pentyn-1-amine to 2-methyl-1-pyrroline, to give the corresponding 5-membered derivative is efficiently catalysed by complexes $\mathbf{2 2 5}$ and $\mathbf{2 2 6}$. The success of these catalysts has been attributed to the NHC-P ligand, which allows the catalytic reaction while avoiding the decomposition of the complexes (Figure 34). ${ }^{160}$ The higher activity of $\mathbf{2 2 5}$ and $\mathbf{2 2 6}$ compared to related complexes featuring a bis-NHC ligand, namely $\left[\mathrm{Rh}(\mathrm{mdd})(\mathrm{CO})_{2}\right] \quad \mathrm{BPh}_{4} \quad\left(\right.$ mdd $=1,1^{\prime}$-methylene-3, $3^{\prime}-$ dimethylimidazoline-2,2'-diylidene), has been ascribed to the increased lability of the CO ligand in the NHC-P complexes, since they feature less electron-rich metal centres. However, the fact that a phosphine moiety is more labile than a NHC should not be totally discarded as an explanation for the increased activity of the NHC-P complexes.

\subsection{Diboration of olefins}

The first example of diboration reactions with iridium catalysts is the diboration of olefins with bis(catecholato)diboron $\left(\mathrm{B}_{2} \mathrm{Cat}_{2}\right)$ employing 227 as catalyst and sodium acetate as additive (Figure 35). ${ }^{161}$ This catalytic system has proved to trigger asymmetric induction in the presence of $\mathrm{AgBF}_{4}$, rendering modest enantiomeric excesses for the diboration/oxidation process (ca. $10 \%$ ee) . The proposed mechanism entails that the heterolytic splitting of the $\mathrm{B}_{2} \mathrm{Cat}_{2}$ molecule is aided by the acetate anion, without the need for the oxidative addition reaction to take place.

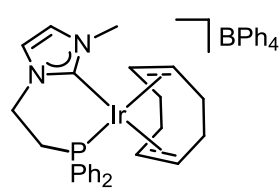

225

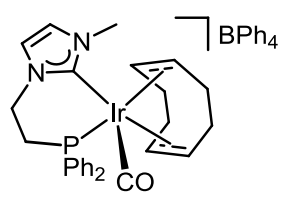

226
Figure 34 Ir-NHC-P catalysts for intramolecular hydroamination.

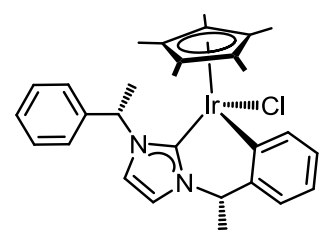

Figure 35 Ir-NHC catalysts for the diboration of olefins. 


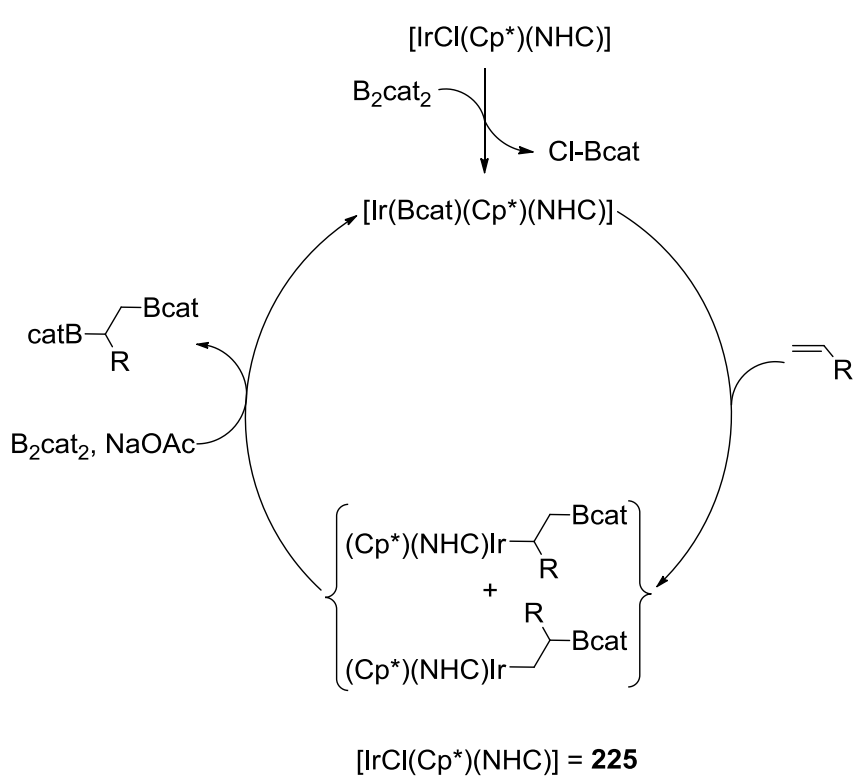

Scheme 25 Proposed catalytic cycle for the diboration of olefins with $225 .{ }^{161}$

Therefore, the oxidation state of the $\operatorname{Ir}($ III) centre remains unaffected throughout the catalytic cycle.

Thus, the first step would be the formation of the $\operatorname{Ir}(\mathrm{III})$-Bcat complex. Subsequently, alkene coordination and migratory insertion into the Ir-B bond would take place. Finally, the Iralkylboronate thus formed would transmetalate with $\mathrm{B}_{2} \mathrm{Cat}_{2}$ to afford the diboronated product while regenerating the active species (Scheme 25). ${ }^{161}$

\subsection{Hydrolysis and methanolysis of silanes}

The hydrolysis and methanolysis of hydrosilanes to give molecular hydrogen and silanols or silyl ethers, respectively, is effectively catalysed by complexes $\mathbf{7 4}, \mathbf{7 5 b}$ and $\mathbf{7 5 c}$ at room temperature. Complex $\mathbf{7 5 c}$ is the most active of these catalysts and can be reused 5 times without an apparent loss of activity. The higher activity of $\mathbf{7 5 c}$ may be rationalised in terms of the coordination strength of the wingtip groups. The hemilabile ether functions at $\mathbf{7 5 c}$ permit the generation of vacant coordination sites while providing stability to the catalyst. On the other hand, the ether groups at $\mathbf{7 4}$ are too strongly coordinating and, consequently, hamper the catalytic reaction. The butyl substituents in $\mathbf{7 5 b}$ do not provide enough catalyst stabilisation, thus leading to catalyst decomposition, as suggested by the recycling experiments.

The reaction mechanism probably requires the end-on coordination of the hydrosilane, with the resulting complex undergoing the $\mathrm{Si}-\mathrm{H}$ bond cleavage aided by a water molecule. The hydride complex and protonated silanol thus formed react, likely through a proton transfer reaction, to give a dihydrogen complex that eliminates molecular hydrogen. Concomitantly, the active species is regenerated and a molecule of silanol is delivered (Scheme 26). ${ }^{162}$

\subsection{Arylation of aldehydes with boronic acid}

Complexes $\mathbf{2 2 8}$ and $\mathbf{2 2 9}$ catalyse the arylation of aldehydes with boronic acid to give the corresponding carbonyl compound or

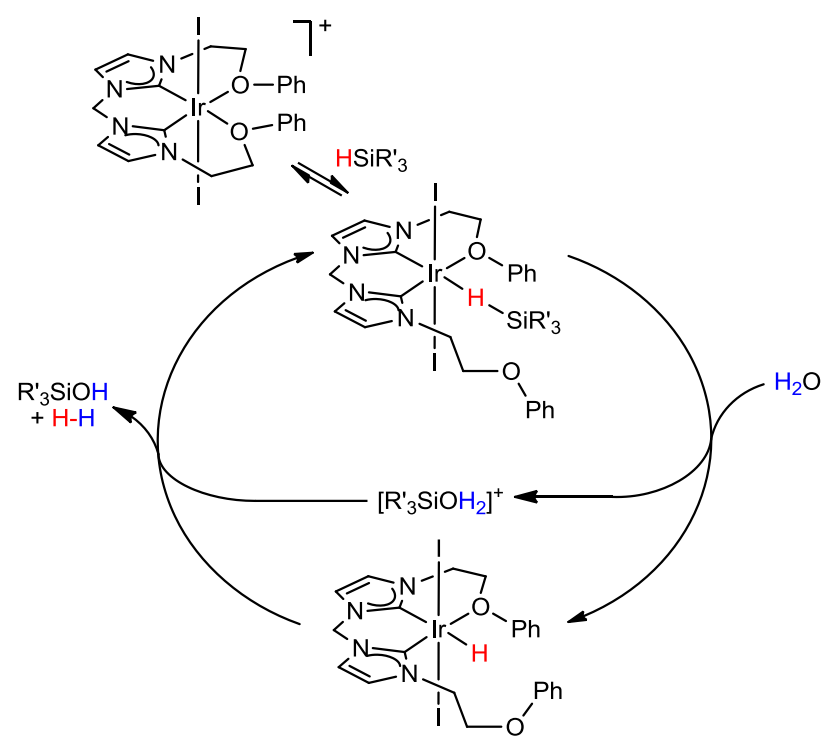

Scheme 26 Proposed mechanism for the hydrolysis of silanes with $\mathbf{7 5 c} .^{162}$

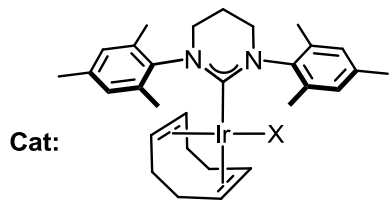

$228(\mathrm{X}=\mathrm{Cl} / \mathrm{Br}: 58 / 42)$

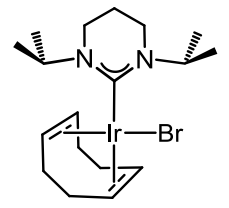

229

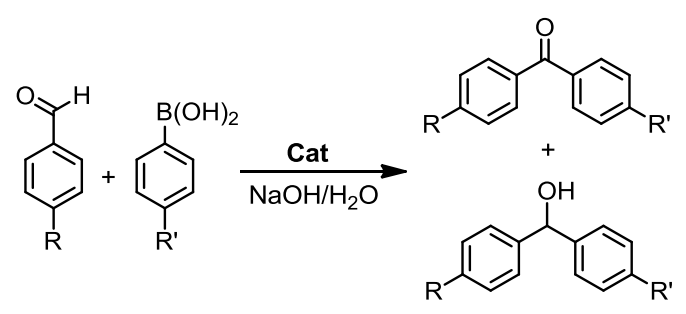

Scheme 27 Arylation of aldehydes with boronic acid using Ir-NHC catalysts 228 and 229.

the related secondary alcohol (Scheme 27). However, these catalysts show in general lower activities and yields than their rhodium counterparts. ${ }^{163}$

\subsection{Addition of aroylchlorides to alkynes}

The addition of the $\mathrm{C}-\mathrm{Cl}$ bond of aroylchlorides across a terminal alkyne is an atom efficient method for the preparation of $\alpha, \beta$-unsaturated ketones.

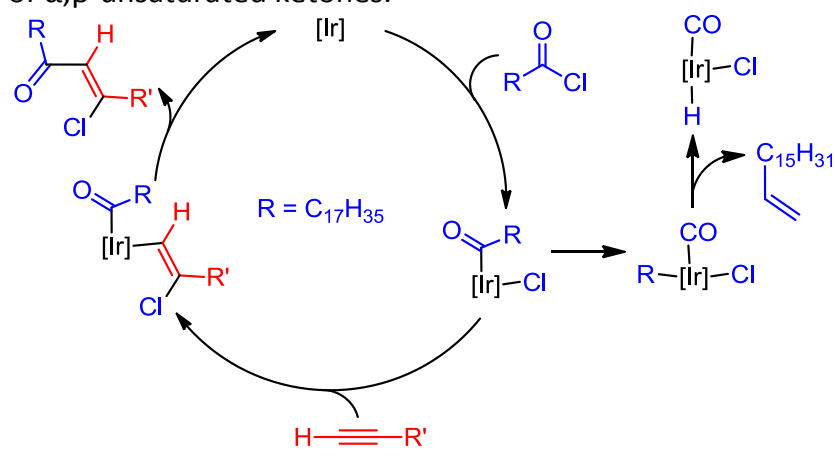

Scheme 28 Proposed mechanism for the addition of aroylchlorides to alkynes. ${ }^{164}$ 
This reaction proceeds in toluene at $90{ }^{\circ} \mathrm{C}$ in the presence of [ $\mathrm{IrCl}(\mathrm{cod}) \operatorname{IPr}]$ as catalysts. In situ generated catalysts with $[\mathrm{IrCl}(\operatorname{cod})]_{2}(2.5 \mathrm{~mol} \%)$ and monodentate phophines (5 mol\%) or IMes show significantly lower activities and selectivities when aromatic alkynes were used as substrate. The generation of [ $\mathrm{IrCl}(\mathrm{cod}) \mathrm{IPr}]$ in situ brings about higher yields and selectivities than those mentioned before, but lower than the isolated complex. The main reaction product is the $Z$-isomer, although the $E$ - and $\alpha$-isomers are also observed. Remarkably, products resulting from decarbonylation and subsequent $\beta$-hydride elimination were not observed when $[\mathrm{IrCl}(\operatorname{cod}) \mathrm{IPr}]$ was used as catalyst. Conversely, in the case of aliphatic alkynes the best performing catalyst was that generated in situ from $[\operatorname{IrCl}(\mathrm{COD})]_{2}$ (2.5 mol\%) and $\mathrm{PCy}_{2}(\mathrm{o}-\mathrm{Tol})(5 \mathrm{~mol} \%) .164$

The mechanism proposed for the addition of aroylchlorides to alkynes entails the oxidative addition of the aroyl chloride's C$\mathrm{Cl}$ bond followed by alkyne insertion into the $\mathrm{Ir}-\mathrm{Cl}$ bond. Finally, reductive elimination affords the reaction product and regenerates the active species (Scheme 28). Alternatively, in the case of aliphatic aroyl chlorides, e.g. $\mathrm{C}_{17} \mathrm{H}_{35} \mathrm{C}(\mathrm{O}) \mathrm{Cl}$ in Scheme 29, decarbonylation followed by $\beta$-hydride elimination may take place. Although not specifically mentioned by the authors, a plausible explanation for the role of the ligand on the selectivity of the reaction may be that the steric bulk of IPr favours migratory insertion vs decarbonylation but, in the case of aliphatic aroyl chlorides, the high electronic density at the Ir centre owing to the NHC and alkyl ligands resulting from the decarbonylation reaction overstabilises the carbonyl species. This would finally promote the formation of the decarbonylation/ $\beta$-hydride elimination product.

\subsection{Visible-light-driven reactions}

11.7.1. Radical cyclisation. The reductive cyclisation of aryl iodides has been reported to proceed successfully using $\left[\operatorname{Ir}(\mathrm{ppy})_{2}(\mathrm{dtbbpy}) \mathrm{PF}_{6}\right.$ (where ppy $=2$-phenylpyridine and dtbbpy $=4,4^{\prime}$-Di-tert-butyl-2,2'-dipyridyl) as catalyst; however, aryl bromides proved to be more challenging substrates. ${ }^{165}$ Complexes 230-238 (Figure 36) catalyse the reductive cyclisation of aromatic and aliphatic bromides under blue LED light in the presence of formic acid and a reductant, e. g. diisopropylethylamine (DIPEA), ascorbic acid, tetramethylethylenediamine (TMEDA) or 1,8diazabicyclo[5.4.0]undec-7-ene (DBU) (Scheme 29). ${ }^{166}$ Remarkably, under the same conditions, common photocatalysts such as $\left[\mathrm{Ru}(\mathrm{bpy})_{3}\right] \mathrm{Cl}_{2}$ or $\left[\mathrm{fac}-\operatorname{Ir}(\mathrm{ppy})_{3}\right]$ displayed poor performances.

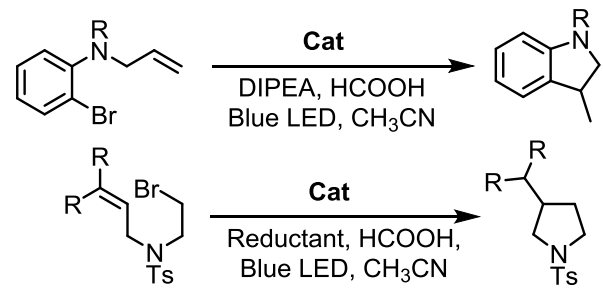

Scheme 29 Visible-light-induced radical cyclisation.
The improved activity that bis-NHC ligands bring about has been ascribed to various aspects that include: high photo-stability of the catalyst, strong absorptivity, and long lifetimes of excited species. This permits the photo-ionisation from $\operatorname{Ir}(\mathrm{III})^{*}$ to $\operatorname{Ir}(\mathrm{IV})$ that promotes the catalytic reaction. In summary, NHC ligands provide complex stability and tune the emission energy and lifetimes.

The reaction mechanism has been proposed to be initiated by the oxidative quenching of the catalyst in the excited state, due to its ability to promote the one-electron reduction of the alkyl or aryl bromide. This results in the splitting of the $\mathrm{C}-\mathrm{Br}$ bond, which is followed by the reaction of the alkyl or aryl radical with the $\mathrm{C}-\mathrm{C}$ double bond. Finally, the ammonium radical resulting from the oxidation of DIPEA by the catalyst completes the reduction by the transfer of one electron.

11.7.2. Thiol-ene additions. Luminescent iridium(III) complexes 239-248 present a chelating 2-pyridylidene ligand functionalised with an R group (Figure 37 ) that permits fine tuning of the electronic and photophysical properties of the complexes. These complexes catalyse the radical thiol-ene addition under blue LED irradiation in yields that span from 54 to $81 \%$ (Scheme 30 ). Moreover, this reaction is compatible with a variety of functional groups at the alkene.

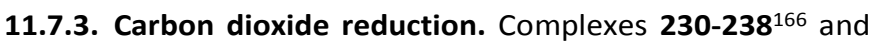
239-248 ${ }^{167}$ also catalyse the visible-light-driven reduction of $\mathrm{CO}_{2}$ to $\mathrm{CO}$ in the presence of blue LED irradiation and [CoCl(TPA)]Cl (TPA = Tris(2-pyridylmethyl)amine) by means of the highly reducing nature of the excited state (Scheme 31). A TON of 1900 for CO was observed after $75 \mathrm{~h}$. These catalytic process presents several advantages compared to the system based on $[\mathrm{CoCl}(\mathrm{TPA})] \mathrm{Cl}]$ that uses $\left[\mathrm{fac}-\operatorname{Ir}(\mathrm{ppy})_{3}\right]$ as photosensitiser (ppy = 2-phenylpyridine), ${ }^{168}$ which include (i) higher TON(CO) values, (ii) improved efficiency regarding solar-to-fuel conversion and (iii) elevated rates of $\mathrm{CO}$ generation over prolonged irradiation.

\subsection{Isomerisation of alkenes}

Various Ir-NHC complexes have been reported to catalyse the isomerisation of alkenes. Complex $\mathbf{7 2 a}$ is a catalyst for the isomerisation of allylbenzene to $\beta$-methylstyrene and $1,5-$ cyclooctadiene to the corresponding 1,3- or 1,4-diene. ${ }^{58}$

Complex 170a and 249a-b, in the presence of sodium tertbutoxide, efficiently catalyse the transformation of 1-hexene into internal alkenes, mainly trans and cis 2-hexene, although small amounts of 3-hexene were also observed. In the isomerisation of 1-octene, the use of complexes 249a-b (Figure 38) as catalysts lead to the formation of greater amounts of

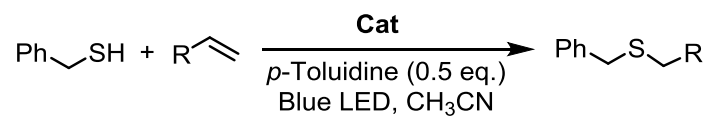

Scheme 30 Thiol-ene addition reaction.

$$
\mathrm{CO}_{2} \frac{\text { Cat }}{[\mathrm{CoCl}(\mathrm{TPA})]^{+}} \mathrm{CO}
$$

Scheme 31 Carbon dioxide reduction reaction. 

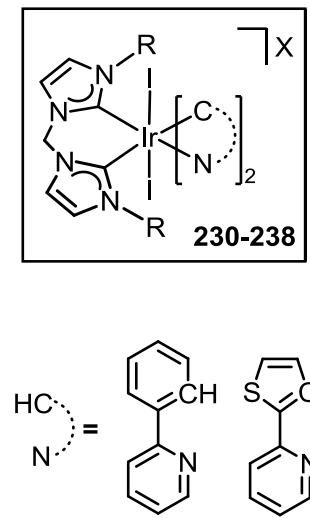<smiles>c1ccc(-c2cccs2)nc1</smiles>

230

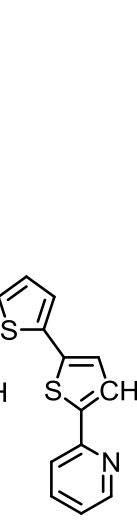

232

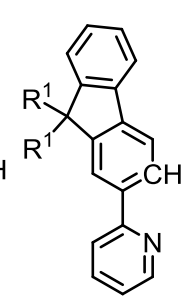

233

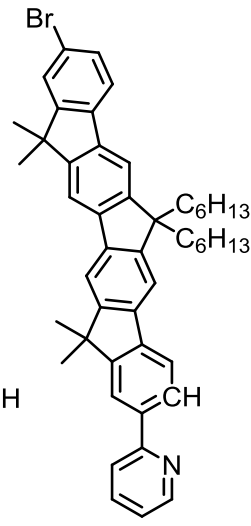

234<smiles>[R]c1ccc2nc(-c3ccccc3)sc2c1</smiles>

235<smiles>c1ccc2cc(-c3nccc4ccccc34)ccc2c1</smiles>

237<smiles>c1csc(-c2nccc3ccccc23)c1</smiles>

238

Figure $36 \mathrm{Ir}-\mathrm{NHC}$ catalysts for radical cyclisation.

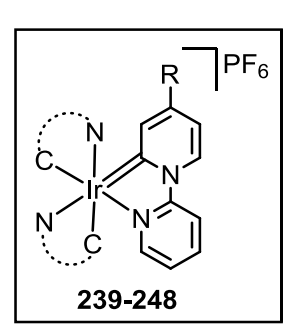<smiles>[CH]C(N)=C[C@H](N)C=Cc1ccccc1-c1ccccn1</smiles>

$239\left(\mathrm{R}={ }^{t} \mathrm{Bu}\right)$

$240\left(\mathrm{R}=\mathrm{NH}_{2}\right)$

$241\left(\mathrm{R}=\mathrm{NMe}_{2}\right)$

$241\left(\mathrm{R}=\mathrm{NMe}_{2}\right)$

$247\left(\mathrm{R}={ }^{t} \mathrm{Bu}\right)$

$248\left(\mathrm{R}=\mathrm{NMe}_{2}\right)$
$242(\mathrm{R}=\mathrm{N} \mathrm{O})$

$243(\mathrm{R}=\mathrm{N})$

$244(R=N)$

Figure 37 Ir-NHC catalysts for thiol-ene additions.

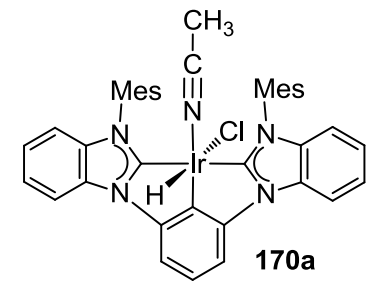

$170 a$

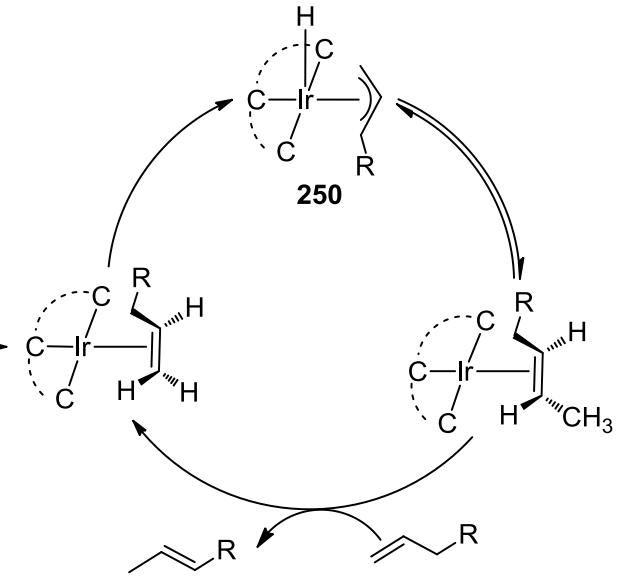

Scheme 32 Proposed mechanism for the isomerisation of alkenes catalysed by $172 a .^{170}$

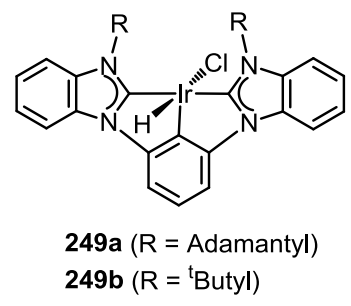

Figure 38 Ir-NHC catalysts for alkene isomerisation. 3-octene (even fractions of 4-octene) under the same conditions in comparison with 170a. This suggests that the sterically hindered complexes $\mathbf{2 4 9}$ are more active catalysts than 170a. ${ }^{169}$ The catalytic cycle was studied for 170a using H-D scrambling and crossover experiments. The proposed mechanism was supported by kinetic experiments and the isolation of complex 250, which acted as a kinetically competent catalyst.

According to these data, the isomerisation occurs via an intermolecular 1,3-hydrogen migration at the $\operatorname{Ir}(\pi$ allyl)(hydride) intermediate 250, which is described as the 
catalyst's resting state. The reversible reductive elimination of the allyl and hydride ligands at $\mathbf{2 5 0}$ affords the internal olefin coordinated to the metal centre in an end-on fashion. The substitution of the internal olefin by the starting material is the rate-liming step of the reaction (Scheme 32). Surprisingly, the more encumbered catalysts 249 a and 249 b operate by a completely different mechanism. The crossover and H-D scrambling experiments seem to suggest that a 1,3-deuterium shift and an intermolecular hydrogen transfer are taking place in this alternative catalytic cycle. However, the reaction mechanism in this case is still unclear. ${ }^{170}$

\subsection{Asymmetric intramolecular allylic amination}

The intramolecular allylic amination reaction is an interesting pathway for the preparation of a variety of $\mathrm{N}$-heteroclyclic compounds. The asymmetric version of this reaction is especially relevant for the synthesis of active pharmaceutical ingredients. ${ }^{171}$

The reaction requires the use of a chiral ligand and usually $[\operatorname{IrCl}(\operatorname{cod})]_{2}$ as metal precursor. The use of chiral triazolium salts as proligands (251-257; Figure 39), which generate in situ the related Ir-NHC complex in the presence of $[\mathrm{IrCl}(\operatorname{cod})]_{2}$ and $\mathrm{DBU}$, have proved an efficient class of catalyst for this type of reaction. ${ }^{172}$ These catalysts are compatible with a broad range of substituted indole- and pyrrolederived substrates, the latter being slightly less reactive than the former (Scheme 33). Metal catalyst loadings between 1.25 and $5 \mathrm{~mol}$ $\%$ lead to excellent yields and enantiomeric excess values that range from 74 to $99 \%$, thus providing a route to enantioenriched biological targets based on indolopiperazinone and piperazinone backbones. Moreover, plausible Friedle-Crafts alkylation products at the C3 of the indole are rarely observed.

A preliminary study of the reaction mechanism suggests that the active species is a cyclometallated $\mathrm{Ir}$ (III)-hydride complex where the ortho $\mathrm{C}-\mathrm{H}$ bond at the phenyl $\mathrm{N}$-substituent of the $\mathrm{NHC}$ ligand has been activated. In fact, addition of allyl methyl carbonate and $\mathrm{AgBF}_{4}$ to $[\operatorname{Ir}(\operatorname{cod}) \mathrm{Cl}(\mathrm{NHC})](\mathrm{NHC}=$ ligand derived from the deprotonation of 256) affords 258 (Figure 40), which proved to be a competent catalysts for the allylic amination reaction. In fact, a $93 \%$ yield and a $99 \%$ ee was obtained for the indole that features $H\left(R^{1}\right)$ and benzyl $\left(R^{2}\right)$ as substituents.

\subsection{Heterometallic catalysts containing iridium centres}

Heterometallic complexes that feature NHC-Ir moieties have shown interesting performances as catalysts for tandem reactions (Figure 41).

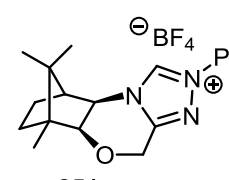

251<smiles></smiles>
255

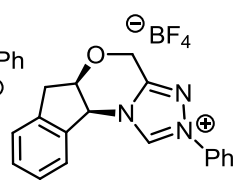

252
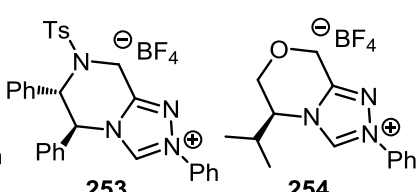

254

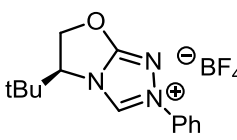

256<smiles>CC(C)[C@@H]1COc2n[n+]([18OH])cn21</smiles>

257

Figure 39 Imidazolium salt-derived proligands for intermolecular allylic amination.

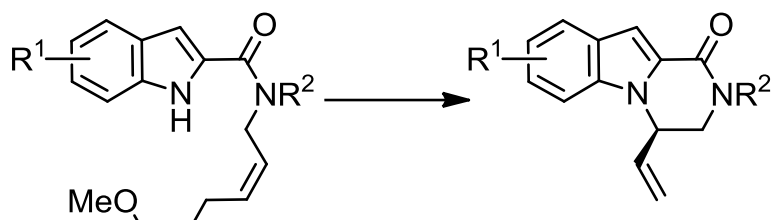<smiles>[Li]C(=O)[Hg]</smiles>

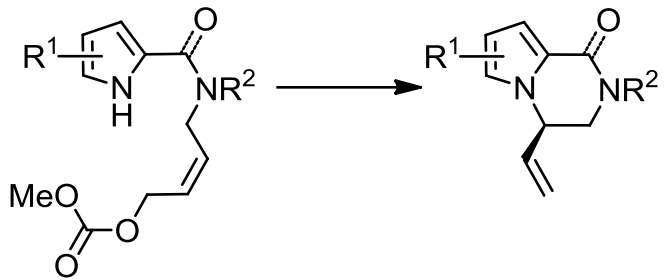

Scheme 33 Asymmetric intermolecular allylic amination of indoles and pyrroles.

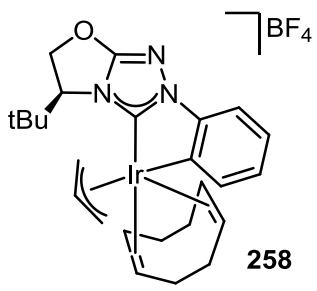

Figure $\mathbf{4 0}$ Depiction of reaction intermediate $\mathbf{2 5 8 .}$

Complex 259 catalyses the catalytic tandem cyclisation/alkylation of 2-aminophenyl ethyl alcohol and primary alcohols. ${ }^{173}$ The fact that this reaction is also catalysed by the related homonuclear Ir caralysts $\left[(\mathrm{Cl})_{2} \mathrm{Cp}^{*} \operatorname{Ir}(\operatorname{ditz}) \operatorname{IrCp} *(\mathrm{Cl})_{2}\right], \quad\left[(\mathrm{cod})(\mathrm{Cl}) \operatorname{Ir}(\operatorname{ditz}) \operatorname{IrCp} *(\mathrm{Cl})_{2}\right] \quad$ and $[(\operatorname{cod})(\mathrm{Cl}) \operatorname{Ir}(\operatorname{ditz}) \operatorname{Ir}(\operatorname{cod})(\mathrm{Cl})]$ (ditz = triazolyl-diylidene) suggests that the presence of the rhodium centre and, therefore, the heterometallic nature of the complex is not a requisite. In fact, the catalytic activity and the selectivity seem to be negatively affected by the presence of the rhodium centre.

Complex 260 catalyses the tandem oxidation of 1-(4halophenyl)ethanols and arylation of arylpyridines (Scheme 34). However, the role played by the Ir centre is unclear since complex $\left[(\mathrm{Cl})_{2} \mathrm{Cp} * \operatorname{Ir}(\operatorname{ditz}) \operatorname{IrCp} *(\mathrm{Cl})_{2}\right]$ shows no catalytic activity, while related ruthenium complexes, namely, $\left[(\mathrm{Cl})_{2}(p-\right.$ Cymene)Ru(ditz)Ru(p-Cymene $\left.)(\mathrm{Cl})_{2}\right]$ and $\left[\mathrm{RuRu}(\mathrm{Cl})_{2}(p\right.$ Cymene)(IBu)] (In Bu = 1,3-di-n-butyl-2,3-dihydro-1H-imidazol-2ylidene), show similar or better activities than $\mathbf{2 6 0} .^{174}$

Complexes $\mathbf{2 6 1}$ and $\mathbf{2 6 2}$ are active for three types of tandem reactions, dehalogenation/transfer hydrogenation (Scheme 35A), Suzuki coupling/transfer hydrogenation (Scheme 35B) and Suzuki coupling/ $\alpha$-alkylation (Scheme 35C). ${ }^{175}$ In this case, the palladium and iridium centres catalyse different processes in the tandem reaction; the palladium fragments catalyse the dehalogenation and Suzuki coupling reaction, while the iridium fragments catalyse the transfer hydrogenation and $\alpha$-alkylation reactions. These tandem reactions represent a substantial advance relative to previously developed processes, which required the use of a palladium and an iridium catalyst as well as the isolation of intermediate products. 


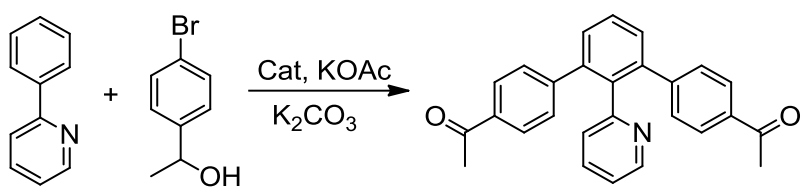

Scheme 34 Tandem oxidation of 1-(4-halophenyl)ethanol and arylation of arylpyridine by complex 252.

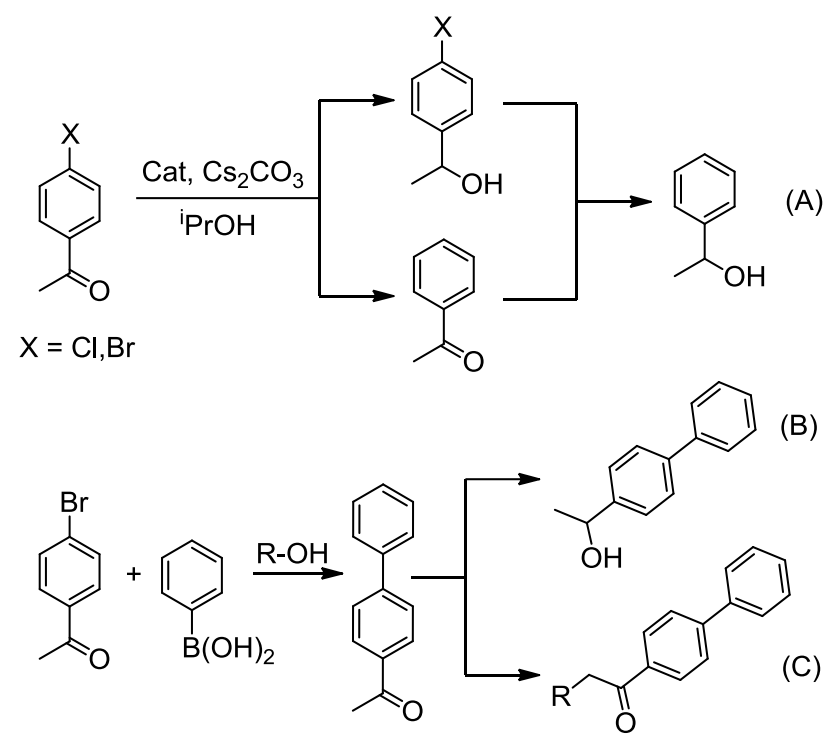

Scheme 35 Tandem dehalogenation/transfer hydrogenation (A), Suzuki coupling/transfer hydrogenation (B) and Suzuki coupling/ $\alpha$-alkylation (C).

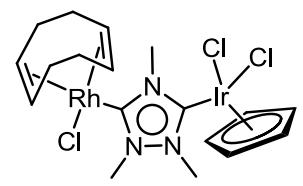

259

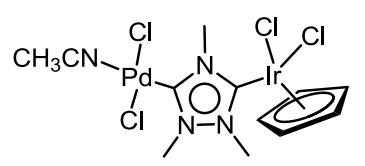

261

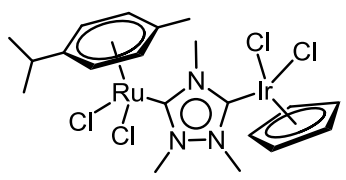

260

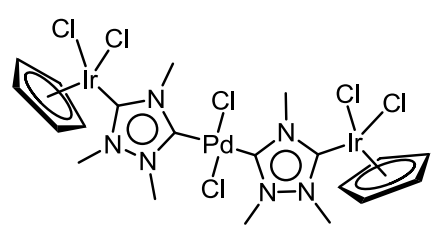

262
Figure 41 Heterometallic Ir-NHC catalysts.

It is noteworthy that, in all the cases presented above, the performances of the catalysts cannot the ascribed to individual metal fragments, since the intermetallic communication seems to alter the properties of the discrete metal centres.

\section{Thoughts on Ir-NHC catalysis}

The applications of iridium complexes in homogeneously catalysed processes, although undoubtedly important, have been less widespread than for other late transition metals, especially those of the noble triad ( $\mathrm{Ru}, \mathrm{Rh}$ and $\mathrm{Pd})$. Probably due to their comparatively higher stability, Ir(III) complexes have been traditionally used for the study of elementary steps and reaction mechanisms of their related rhodium catalysts. In fact, the low reactivity of certain Ir intermediates may hamper subsequent reactions, thus inhibiting the catalytic cycle or reducing, to some extent, the productivity of the process. However, the use of $\mathrm{N}$-heterocyclic carbenes as ancillary ligands seems to have triggered a new golden age in iridium catalysis. Why have NHC ligands had such an impact on iridium catalysis? In many instances, the well-stablished characteristics of NHC ligands may be customarily invoked: strong $\sigma$-donor ability (facilitates the oxidative addition step), stability of the $\mathrm{C}-\mathrm{M}$ bond (reduces the need for excess ligand and avoids catalyst decomposition) and steric protection (the NHCs fan-shaped structure has implications in the selectivity of the reaction and stabilises unsaturated intermediates). Nonetheless, a more indepth analysis of the behaviour of Ir-NHC catalysts may hint at certain reactivity trends that are specific to this type of complexes:

1) The presence of NHCs may trigger outer-sphere mechanisms due to the high electron density at the Ir centre, which increases its nucleophilic character. Furthermore, the steric hindrance added to the high trans effect of NHCs may hamper the access to $\operatorname{Ir}(\mathrm{V})$ species, especially when other encumbered moieties or ligands with high trans effect (e. g. hydrides) should be incorporated into the starting $\operatorname{Ir}(\mathrm{III})$ complex after oxidative addition. This favours alternative mechanistic pathways (bypassing classic mechanisms), which could result in novel selectivities and improved reactivities.

2) Oxidative addition to an $\operatorname{Ir}(\mathrm{I})$ centre to afford an $\operatorname{Ir}($ III) species is generally accepted to be less energy demanding than for their related rhodium complexes. The opposite occurs for the reductive elimination reaction from $\mathrm{Ir}(\mathrm{III})$ and $\mathrm{Rh}$ (III) complexes, which is easier for the latter. This results in $\operatorname{Ir}(\mathrm{III})$ species being excessively stable compared to Rh(III) for two reasons: (i) Ir(III) complexes undergo reductive elimination less straightforwardly than their $\mathrm{Rh}$ (III) analogues, and (ii) the access to $\operatorname{Ir}(\mathrm{V})$ intermediates may be difficult in some cases, e. g. encumbered hepta-coordinated iridium(V) species $^{176}$ or challenging oxidative additions. In the case of the latter, the $\operatorname{Ir}(I I I)-\operatorname{Ir}(\mathrm{V})$ oxidative addition has often been reported as the rate-limiting step of the catalytic cycle ${ }^{177}$ and, sometimes, alternative $\sigma$-bond metathesis steps need to be invoked. ${ }^{178,150,151}$

The presence of NHC ligands may ease the access to lower oxidation states since their large steric bulk may favour reductive elimination. Regarding the access to higher oxidation states, although $\mathrm{NHC}-\operatorname{Ir}(\mathrm{V})$ intermediates may be infrequent for the reasons commented above, they cannot be discarded because the presence of NHCs increases the electron density at the metal centre, which should ease the oxidative addition process. For example, theoretical calculations support the fact that $\mathrm{C}-\mathrm{H}$ bond activation may take place at room temperature through an $\operatorname{Ir}(\mathrm{V})$ intermediate when sufficiently strongly donating carbene ligands are employed. ${ }^{179}$

Perhaps more importantly, high electron density at an $\operatorname{Ir}(\mathrm{III})$ centre may trigger $\sigma$-CAM reactions, where the Ir centre at the transition state formally takes on an oxidation state between III and $V$, which would be, overall, the equivalent of an oxidative addition followed by reductive elimination.

3) As seen throughout the manuscript, $\operatorname{Ir}($ III) hydrides are ubiquitous intermediates in the postulated catalytic cycles. The high trans effect of NHCs and hydride ligands leads to the 
destabilisation of these intermediates and to the intrinsic lability of the hydride ligands, which is exacerbated by their pronounced nucleophilicity-due to the high electron density at the Ir centre.

4) The straightforward functionalisation and structural variability of NHCs permits the incorporation of moieties that may interact with the substrate, thus allowing the design of metal-ligand cooperation systems that trigger alternative reaction pathways. ${ }^{180}$

Summarising, the donor capabilities, steric bulk and high trans effect of NHCs seem to increase the reactivity of the, in principle, overstable Ir(III) intermediates. These features, added to the fact that functionalised NHCs may act as non-innocent ligands through metal-ligand cooperation processes opens up an abundant mechanistic diversity that may account for the prolific reactivity of Ir-NHC catalysts.

\section{Conclusions}

The broad range of catalytic reactions commented on in this review illustrate the versatility of Ir-NHC catalyst, which, in recent times, have expanded beyond the widely studied and successful (transfer) hydrogenation reactions. Among the large number of processes catalysed by Ir-NHC complexes we would like to highlight here those that, in our opinion, show more promise.

1) Water oxidation catalysis: Ir-NHC WOCs, especially those featuring highly electron donating mesoionic NHCs, have shown exceptionally good activities that in some cases surpass $\mathrm{Ru}$ catalysts. New advances on catalyst and ligand design offer great opportunities for further development thanks to the easily tuneable NHCs.

2) $\mathrm{C}-\mathrm{H}$ bond functionalisation: The use of Ir-NHCs in processes such as borylation and silylation are scarce, despite the unquestionable importance of these reactions in synthetic chemistry. However, the few examples so far reported show great promise for future expansion.

3) Dehydrogenation processes: Iridium catalysts have been widely explored in dehydrogenation reactions, which somewhat contrasts with the limited number of examples that employ NHCs as ancillary ligands. These types of processes include important reactions, such as, $\mathrm{H}_{2}$ production from methanol, aminoboranes or formic acid, and the valorisation of naturally occurring polyols such as glycerol.

4) Signal amplification by reversible exchange: The dramatic progress of the SABRE technique in the last few years has been intimately related to Ir-NHC catalysis. However, most SABRE IrNHC catalysts have been based on the same scaffold $\left(\left[\operatorname{Ir}(\mathrm{H})_{2}(\mathrm{NHC})(\mathrm{py})_{3}\right]^{+}\right)$. The use of new NHC-motifs and catalyst formulations may bring about interesting results.

The reaction mechanisms that we have gathered for this review show that Ir-NHC catalysts display a rich variety of catalytic cycles, from inner- to outer-sphere mechanisms, in which the metal centre may adopt a great diversity of oxidation states that include $\operatorname{Ir}(\mathrm{I}), \operatorname{Ir}(\mathrm{II}), \operatorname{Ir}(\mathrm{III}), \operatorname{Ir}(\mathrm{IV})$, and $\operatorname{Ir}(\mathrm{V})$.

The high reactivity that the coordination of one or more NHC ligand conveys into Ir complexes, and the straightforward derivatisation of these ligands, shows great potential for new catalytic applications and the development of those already known.

\section{Conflicts of interest}

There are no conflicts to declare.

\section{Acknowledgements}

This work was supported by the Spanish Ministry of Economy and Competitiveness (MINECO/FEDER) (CTQ-2015-67366-P, CTQ-2013-42532-P projects and "Ramón y Cajal" programme (M.I.)) and the DGA/FSE-E07. The support from the KFUPMUniversity of Zaragoza research agreement and the Centre of Research Excellence in Petroleum Refining \& KFUPM is gratefully acknowledged.

\section{Notes and references}

1 Iridium Complexes in Organic Synthesis (Eds. L. A. Oro and C. Claver), Wiley-VCH Verlag GmbH \& Co. KGaA, Weinheim, 2009.

2 a) R. H. Crabtree, H. Felkin, T. Fillebeen-Khan, and G.E. Morris, J. Organomet. Chem., 1979, 168, 183; b) R. H. Crabtree, Acc. Chem. Res., 1979, 12, 331.

3 a) A. Lightfoot, P. Schnider, and A. Pfaltz, Angew. Chem Int. Ed., 1998, 37, 2897; b) A. Pfaltz, Acc. Chem. Res., 2007, 40, 1402; c) S. Bell, B. Wüstenberg, S. Kaiser, F. Menges, T. Netscher, A. Pfaltz, Science, 2006, 311, 642.

4 J. H. Jones, Platinum Metals Rev., 2000, 44, 94.

5 a) H. U. Blaser, H. P. Buser, K. Coers, R. Hanreich, H. P. Jalett, E. Jeslch, B. Pugin, H. D. Schneider, F. Splinder, A. Wegmann, Chimia, 1999, 53, 275; b) H. U. Blaser, Adv. Synth. Catal., 2002, 344, 17; c) R. Hofer, Chimia 2005, 59, 10; d) R. Dorta, D. Broggini, R. Stoop, H. Rüegger,F. Spindler and A. Togni, Chem. Eur. J., 2004, 10, 267.

6 A. J. Arduengo III, R. L. Harlow and M. Klyne, J. Am. Chem. Soc., 1991, 113, 361.

7 W. A. Herrmann, M. Elison, J. Fischer, C. Köcher and G. R. J. Artus, Angew. Chem. Int. Ed., 1995, 34, 2371.

8 a) M. N. Hopkinson, C. Richter, M. Schedler and F. Glorius, Nature, 2014, 510, 485; b) W. A. Herrmann and C. Köcher, Angew. Chem. Int. Ed., 1997, 36, 2162; c) P. de Frémont, N. Marion and S. P. Nolan, Coord. Chem. Rev., 2009, 253, 862; d) M. C. Jahnke and F. E. Hahn, in $\mathrm{N}$-Heterocyclic Carbenes: From Laboratory Curiosities to Efficient Synthetic Tools, ed. S. Díez-González, RSC Publishing, Cambridge, 2011, Ch. 1, pp. 1-41; e) M. Poyatos, J. A. Mata and E. Peris, Chem. Rev., 2009, 109, 3677; f) F. E. Hahn and M. C. Jahnke, Angew. Chem. Int. Ed., 2008, 47, 3122; g) D. Bourissou, O. Guerret, F. P. Gabbaï and G.Bertrand, Chem. Rev., 2000, 100, 39; h) O. Schuster, L. Yang, H. G. Raubenheimer and M. Albrecht, Chem. Rev., 2009, 109, 3445; i) T. Dröge and F. Glorius, Angew. Chem. Int. Ed., 2010, 49, 6940.

9 a) G. C. Vougioukalakis and R. H. Grubbs, Chem. Rev., 2010, 110, 1746; b) C. Samojłowicz, M. Bieniek and K. Grela, Chem. Rev., 2009, 109, 3708; c) C. J. O'Brien, E. A. B. Kantchev, C. Valente, N. Hadei, G. A. Chass, A. Lough, A. C. Hopkinson and M. G. Organ, Chem. Eur. J., 2006, 12, 4743 . 
10 a) C. S. J. Cazin, N-Heterocyclic Carbenes in Transition Metal Catalysis and Organocatalysis, Springer Science+Business Media B.V., Dordrecht, 2011; b) S. Díez-González, N-Heterocyclic Carbenes: From Laboratory Curiosities to Efficient Synthetic Tools, $2^{\text {nd }}$ Edition, The Royal Society of Chemistry, London, 2017; c) V. César, L. H. Gade and S. Bellemin-Laponnaz, in $N$ Heterocyclic Carbenes: From Laboratory Curiosities to Efficient Synthetic Tools: Edition 2, ed. S. Díez-González, RSC Catalysis Series, London, Ch. 8, 2017, pp. 302-335.

11 a) R. H. Crabtree Platinum Metals Rev., 2006, 50, 171; b) M. Poyatos, G. Guisado-Barrios and E. Peris, in $N$ Heterocyclic Carbenes: Effective Tools for Organometallic Synthesis, ed. S. P. Nolan, Wiley-VCH Verlag GmbH \& Co. KGaA, Weinheim, Ch. 10, 2014, pp. 271-305.

12 E. Peris and R. H. Crabtree, in Iridium Complexes in organic Synthesis, (Eds. L. A. Oro and C. Claver), WileyVCH Verlag GmbH \& Co. KGaA, Weinheim, 2009, Ch.3, pp. 39-54.

13 H. M. Lee, T. Jiang, E. D. Stevens and S. P. Nolan Organometallics, 2001, 20, 1255

14 A. Binobaid, M. Iglesias, D. Beetstra, A. Dervisi, I. Fallis and K. J. Cavell, Eur. J. Inorg. Chem., 2010, 5426.

15 J. J. Dunsford, D. S. Tromp, K. J. Cavell, C. J. Elsevier and B. M. Kariuki, DaltonTrans., 2013, 42, 7318.

16 L. D. Vázquez-Serrano, B. T. Owens and J. M. Buriak, Chem. Commun., 2002, 2518.

17 a) R. H. Crabtree and M. W. Davis, Organometallics, 1983, 2, 682; b) R. H. Crabtree, P. C. Demou, D. Eden, J. M. Mihelcic, C. A. Parnell, J. M. Quirk, G. E. Morris, J. Am Chem. Soc., 1982, 104, 6994.

18 G. E. Dobereiner, A. Nova, N. D. Schley, N. Hazari, S. J. Miller, O. Eisenstein and R. H. Crabtree, J. Am. Chem. Soc., 2011, 133, 7547.

19 E. L. Kolychev, S. Kronig, K. Brandhorst, M. Freytag, P. G. Jones and M. Tamm, J. Am. Chem. Soc., 2013, 135 12448.

20 a) C. Valla and A. Pfaltz, Chim. Oggi 2004, 22, 4; b) F. Menges, M. Neuburger and A. Pfaltz, Org. Lett., 2002, 4, 4713; c) P. G. Cozzi, N. Zimmermann, R. Hilgraf, S Schaffner and A. Pfaltz, Adv. Synth. Catal., 2001, 343 450; d) W. Tang, W. Wang and X. Zhang, Angew. Chem., Int. Ed., 2003, 42, 943; e) D.-R. Hou, J. H. Reibenspies, T. J. Colacot and K. Burgess, Chem. Eur. J., 2000, 7, 5391; f) J. Blankenstein and A. Pfaltz, Angew. Chem., Int. Ed., 2001, 40, 4445

21 For significant reviews see: a) X. Cui and K. Burgess, Chem. Rev., 2005, 105, 3272; b) D. Zhao, Lisa Candish, D. Paul and F. Glorius, ACS Catal., 2016, 6, 5978; c) D. Janssen-Müller, C. Schlepphorst and F. Glorius, Chem. Soc. Rev., 2017,46, 4845

22 a) M. C. Perry, X. Cui, M. T. Powell, D.-R. Hou, J. H. Reibenspies and K. Burgess, J. Am. Chem. Soc., 2003 125, 113; b) D.-R. Hou and K. Burgess, Org. Lett., 1999, 1, 1745; c) D.-R. Hou, J. Reibenspies, K. Burgess, J. Org. Chem., 2001, 66, 206; d) M. T. Powell, D.-R. Hou, M. C. Perry, X. Cui and K. Burgess, J. Am. Chem. Soc., 2001 123, 8878 .

23 A. Schumacher, M. Bernasconi and A. Pfaltz, Angew Chem. Int. Ed., 2013, 52, 7422.

24 K. Källastrom and P. G. Andersson, Tetrahedron Lett. 2006, 47, 7477.

25 C. Bolm, T. Focken and G. Raabe, Tetrahedron: Asymmetry, 2003, 14, 1733.

26 T. Focken, G. Raabe and C. Bolm, Tetrahedron Asymmetry, 2004, 15, 1693.

27 W. A. Herrmann, D. Baskakov, E. Herdtweck, S. D. Hoffmann, T. Bunlaksananusorn, F. Rampf and L. Rodefeld, Organometallics, 2006, 25, 2449.
28 D. Baskakov, W. A. Herrmann, E. Herdtweck and S. D. Hoffmann, Organometallics, 2007, 26, 626.

29 C. Metallinos and X. Du, Organometallics, 2009, 28 1233.

30 J. John, C. Wilson-Konderka and C. Metallinos, Adv. Synth. Catal., 2015, 357, 2071.

31 a) W. W. N. O, A. J. Lough and R. H. Morris, Organometallics, 2013, 32, 380; b) W. W. N. O, A. J. Lough and R. H. Morris, Organometallics, 2012, 31 2152; c) E. Jansen, L. S. Jongbloed, D. S. Tromp, M. Lutz, B. de Bruin and C. J. Elsevier, ChemSusChem, 2013, 6, 1737.

32 R. Noyori, M. Yamakawa, and S. Hashiguchi, J. Org Chem., 2001, 66, 7931.

33 F. Aznarez, M. Iglesias, A. Hepp, B. Veit, P. J. Sanz Miguel, L. A. Oro, G.-X. Jin and F. E. Hahn, Eur. J. Inorg. Chem. 2016, 4598

34 H. Syska, W. A. Herrmann and F. E. Kühn, J. Organomet. Chem., 2012, 703, 56

35 H. Horvath, A. Katho, A. Udvardy, G, Papp, D. Szikszai and F. Joo, Organometallics, 2014, 33, 6330.

36 a) P. G. Jessop, T. Ikariya and R. Noyori, Nature, 1994 368, 231; b) F. J. Fernández-Alvarez, M. Iglesias, L. A. Oro and V. Polo, ChemCatChem, 2013, 5, 3481; c) A. Azua, S. Sanz, and E. Peris, Chem. Eur. J., 2011, 17, 3963.

37 G. H. Gunasekar, K. Park, V. Ganesan, K. Lee, N.-K. Kim K.-D. Jung and S. Yoon, Chem. Mater., 2017, 29, 6740.

38 P. Sánchez, M. Hernández-Juárez, E. Álvarez, M. Paneque, N. Rendón and A. Suárez, Dalton Trans., 2016, 45, 16997.

39 a) S. Gülcemal and B. Çetinkaya in N-Heterocyclic Carbenes: From Laboratory Curiosities to Efficient Synthetic Tools, $2^{\text {nd }}$ Edition, (Ed. S. Díez-González) The Royal Society of Chemistry, London, 2017, Ch. 13, pp. 484-533; b) D. Wang and D. Astruc, Chem. Rev., 2015, $115,6621$.

40 M. V. Jiménez, J. Fernández-Tornos, J. J. Pérez-Torrente, F. J. Modrego, S. Winterle, C. Cunchillos, F. J. Lahoz and Luis A. Oro, Organometallics, 2011, 30, 5493.

41 I. Kownacki, M. Kubicki, K. Szubert and B. Marciniec, J. Organomet. Chem., 2008, 693, 321.

42 K. Riener, M. J. Bitzer, A. Pöthig, A. Raba, M. Cokoja, W. A. Herrmann and E. Kühn, Inorg. Chem., 2014, 53, 12767

43 C.-Y. Wang, C.-F. Fu, Y.-H. Liu, S.-M. Peng and S.-T. Liu, Inorg. Chem., 2007, 46, 5779.

44 J.-F. Sun, F. Chen, B. A. Dougan, H.-J. Xu, Y. Cheng, Y.-Z Li, X.-T. Chen and Z.-L. Xue, J. Organomet. Chem., 2009 694, 2096.

45 H. Türkmen, T. Pape, F. E. Hahn and B. Çetinkaya, Organometallics, 2008, 27, 571.

46 F. E. Hahn, C. Holtgrewe, T. Pape, M. Martin, E. Sola and L. A. Oro, Organometallics, 2005, 24, 2203.

47 S. Gülcemal, A. G. Gökçe and B. Çetinkaya, Inorg. Chem. 2013, 52, 10601

48 D. Gülcemal, A. G. Gökçe, S. Gülcemal and B. Çetinkaya, RSC Adv., 2014, 4, 26222

49 S. C. Zinner, C. F. Rentzsch, E. Herdtweck, W. A Herrmann and F. E. Kühn, Dalton. Trans., 2009, 7055.

50 A. Azua, J. A. Mata, E. Peris, F. Lamaty, J. Martinez and E. Colacino, Organometallics, 2012, 31, 3911.

51 A. C. Hillier, H. M. Lee, E. D. Stevens and S. P. Nolan, Organometallics, 2001, 20, 4246.

52 X. Gong, H. Zhang and X. Li, Tett. Lett., 2011, 52, 5596.

53 D. Gnanamgari, A. Moores, E. Rajaseelan and R. H. Crabtree, Organometallics, 2007, 26, 1226.

54 a) A. Azua, J. A. Mata and E. Peris, Organometallics, 2011, 30, 5532; b) A. Azua, M. Finn, H. Yi, A. B. Dantas, and A. Voutchkova-Kostal, ACS Sustainable Chem. Eng., 2017, 5, 3963. 
55 M. V. Jiménez, J. Fernández-Tornos, J. J. Pérez-Torrente, F. J. Modrego, P. García-Orduña and L. A. Oro, Organometallics, 2015, 34, 926.

56 N. Sluijter and C. J. Elsevier, Organometallics, 2014, 33, 6389.

57 a) M. Blanco, P. Álvarez, C. Blanco, M. V. Jiménez, J. J. Pérez-Torrente, L. A. Oro, J. Blasco, V. Cuartero and R. Menéndez, Catal. Sci. Technol., 2016, 6, 5504; b) M Blanco, P. Álvarez, C. Blanco, M. V. Jiménez, J. Fernández-Tornos, J. J. Pérez-Torrente, L. A. Oro and R. Menéndez, ACS Catal., 2013, 3, 1307; c) M. Blanco, P. Álvarez, C. Blanco, M. V. Jiménez, J. Fernández-Tornos, J. J. Pérez-Torrente, J. Blasco, G. Subías, V. Cuartero, L. A. Oro, R. Menéndez, Carbon, 2016, 96, 66.

58 G. M. Pawara and M. R. Buchmeiser, Adv. Synth. Catal. 2010, 352, 917.

59 M. Albrecht, J. R. Miecznikowski, A. Samuel, J. W. Faller and R. H. Crabtree, Organometallics, 2002, 21, 3596.

60 J. R. Miecznikowski and R. H. Crabtree, Organometallics, 2004, 23, 629.

61 J. S. M. Samec, J.-E.Bäckvall, P. G. Andersson and P. Brandt, Chem. Soc. Rev., 2006, 35, 237.

62 N. García, E. A. Jaseer, J. Munárriz, P. J. Sanz Miguel, V. Polo, M. Iglesias and L. A. Oro, Eur. J. Inorg. Chem., 2015, 4388.

63 Z. Mazloomi, R. Pretorius, O. Pàmies, M. Albrecht and M. Diéguez, Inorg. Chem., 2017, 56, 11282

64 S. Sabater, M. Baya, and J. A. Mata, Organometallics, 2014, 33, 6830

65 a) U. Hintermair, J. Campos, T. P. Brewster, L. M. Pratt, N. D. Schley and R. H. Crabtree, ACS Catal., 2014, 4, 99; b) J. Campos, U. Hintermair, T. P. Brewster, M. K. Takase and R. H. Crabtree ACS Catal., 2014, 4, 973.

66 J. Holmes, C. M. Pask and C. E. Willans, Dalton Trans., 2016, 45, 15818.

67 R. Corberán, M. Sanaú and E. Peris, Organometallics, 2007, 26, 3492.

68 A. Pontes da Costa, M. Viciano, M. Sanaú, S. Merino, J. Tejeda, E. Peris and B. Royo, Organometallics, 2008, 27, 1305.

69 J. L. Gomez-Lopez, D. Chávez, M. Parra-Hake, A. T. Royappa, A. L. Rheingold, D. B. Grotjahn and V. MirandaSoto, Organometallics, 2016, 35, 3148.

70 D. Iglesias, S. Sabater, A. Azuaab and J. A. Mata, New J. Chem., 2015, 39, 6437.

71 X.-H. Zhu, L.-H. Cai, C.-X. Wang, Y.-N. Wang, X.-Q. Guo, X.-F. Hou, J. Molec. Catal. A, 2014, 393, 134.

72 D. Gnanamgari, E. L. O. Sauer, N. D. Schley, C. Butler, C. D. Incarvito and R. H. Crabtree, Organometallics, 2009, 28, 321.

73 a) R. Maity, A. Mekic, M. van der Meer, A. Verma and B. Sarkar, Chem. Commun., 2015, 51, 15106; b) R. Maity, M. van der Meer, S. Hohloch and B. Sarkar, Organometallics, 2015, 34, 3090.

74 A. Bolje, S. Hohloch, M. van der Meer, J. Košmrlj and B. Sarkar, Chem. Eur. J., 2015, 21, 6756.

75 R. Maity, S. Hohloch, C.-Y. Su, M. van der Meer and B. Sarkar, Chem. Eur. J., 2014, 20, 9952.

76 W. B. Cross, C. G. Daly, Y. Boutadla and K. Singh, Dalton Trans., 2011, 40, 9722.

77 S. Sabater, J. A. Mata and E. Peris, Chem. Eur. J., 2012, 18,6380 .

78 X.-Q. Guo, Y.-N. Wang, D. Wang, L.-H. Cai, Z.-X. Chen and Xiu-Feng Hou, Dalton Trans., 2012, 41, 14557.

79 S. Hohloch, L. Suntrup and B. Sarkar, Organometallics, 2013, 32, 7376

80 H. Seo, B. Y. Kim, J. H. Lee, H.-J. Park, S. U. Son, and Y. K. Chung, Organometallics, 2003, 22, 4783.
81 a) U. Nagel and C. Diez, Eur. J. Inorg. Chem., 2009, 1248; b) U. Nagel and C. Diez, Appl. Organomet. Chem., 2010, 24, 509 .

82 H. Chiyojima, S. Sakaguchi, Tet. Lett. 2011, 52, 6788.

83 G. Dyson, J.-C. Frison, A. C. Whitwood and R. E. Douthwaite, Dalton Trans., 2009, 7141.

84 K. Yoshida, T. Kamimura, H. Kuwabara and A. Yanagisawa, Chem. Commun., 2015, 51, 15442.

85 J.-Q. Lia and P. G. Andersson, Chem. Commun., 2013, 49 , 6131.

86 A. Bartoszewicz, R. Marcos, S. Sahoo, A. K. Inge, X. Zou and B. Martín-Matute, Chem. Eur. J., 2012, 18, 14510.

87 A. Prades, R. Corberán, M. Poyatos and E. Peris, Chem. Eur. J., 2008, 14, 11474.

88 J. Campos, L. S. Sharninghausen, M. G. Manas and Robert H. Crabtree Inorg. Chem., 2015, 54, 5079.

89 S. Kerdphon, X. Quan, V. S. Parihar and P. G. Andersson, J. Org. Chem., 2015, 80, 11529.

90 A. Rajaraman, A. R. Sahoo, F. Hild, C. Fischmeister, M. Achard and C. Bruneau, Dalton Trans., 2015, 44, 17467.

91 M. V. Jiménez, J. Fernández-Tornos, F. J. Modrego, J. J. Pérez-Torrente and L. A. Oro, Chem. Eur. J., 2015, 21 , 17877.

92 S. Ibañez, M. Poyatos and E. Peris, Dalton Trans., 2016, 45, 14154

93 S. Ruiz-Botella and E. Peris, Chem. Eur. J., 2015, 21 15263.

94 a) E. Mas-Marzá, M. Poyatos, M. Sanaú and E. Peris Inorg. Chem., 2004, 43, 2213; b) E. Mas-Marzá, M. Sanaú and E. Peris, Inorg. Chem., 2005, 44, 9961.

95 A. Zanardi, E. Peris and J. A. Mata, New J. Chem., 2008, 32, 120

96 a) M. Iglesias, M. Pérez-Nicolás, P. J. Sanz Miguel, V. Polo, F. J. Fernández-Alvarez, J. J. Pérez-Torrente and L. A. Oro, Chem. Commun., 2012, 48, 9480; b) M. Iglesias, P. J. Sanz Miguel, V. Polo, F. J. Fernández-Alvarez, J. J. Pérez-Torrente and L. A. Oro, Chem. Eur. J., 2013, 19, 17559.

97 a) A. J. Chalk and J. F. Harrod, J. Am. Chem. Soc., 1965 87, 16; b) I.Ojima, in The Chemistry of Organic Silicon Compounds (Eds.: S. Patai and Z. Rappoport), Wiley, New York, 1989, p. 1479.

98 a) J. Yang and M. Brookhart, J. Am. Chem. Soc., 2007, 129, 12656; b) S. Park and M. Brookhart, Organometallics, 2010, 29, 6057; c) S. Park and M. Brookhart, J. Am. Chem. Soc., 2012, 134, 640; d) T. T. Metsänen, P. Hrobárik, H. F. T. Klare, M. Kaupp and M. Oestreich, J. Am.Chem. Soc., 2014, 136, 6912.

99 K. Shinohara, S. Kawabata, H. Nakamura, Y. Manabe and S. Sakaguchi, Eur. J. Org. Chem., 2014, 5532.

100 a) X. Sala, I. Romero, M. Rodriguez, L. Escriche and A. Llobet, A. Angew. Chem. Int. Ed., 2009, 48, 2842; b) R. Brimblecombe, G. C. Dismukes, G. F. Swiegers and L. Spiccia, Dalton Trans., 2009, 9374.

101 a) N. D. McDaniel, F. J. Coughlin, L. L. Tinker and S. Bernhard, J. Am. Chem. Soc., 2008, 130, 210; b) J. F. Hull, D. Balcells, J. D. Blakemore, C. D. Incarvito, O. Eisenstein, G. W. Brudvig and R. H. Crabtree, J. Am. Chem. Soc. 2009, 131, 8730; c) J. D. Blakemore, N. D. Schley, D. Balcells, J. F. Hull, G. W. Olack, C. D. Incarvito, O. Eisenstein, G. W. Brudvig and R. H. Crabtree, J. Am. Chem. Soc., 2010, 132, 16017; d) A. Savini, G. Bellachioma, G. Ciancaleoni, C. Zuccaccia, D. Zuccaccia and A. Macchioni, Chem. Commun., 2010, 46, 9218; e) W. I. Dzik, S. E. Calvo, J. N. H. Reek, M. Lutz, M. A. Ciriano C. Tejel, D. G. H. Hetterscheid, and B. de Bruin, Organometallics, 2011, 30, 372; f) D. B. Grotjahn, D. B. Brown, J. K. Martin, D. C. Marelius, M.-C. Abadjian, H. N. 
Tran, G. Kalyuzhny, K. S. Vecchio, Z. G. Specht, S. A. Cortes-Llamas, V. Miranda-Soto, C. van Niekerk, C. E. Moore and Arnold L. Rheingold, J. Am. Chem. Soc., 2011, 133, 19024; g) H. Cao, J.-F. Zhang, Q. Zhou, S. Huang, X. Hong, X.-F. Hou, Molec. Catal., 2017, 434, 49.

102 R. Lalrempuia, N. D. McDaniel, H. Müller-Bunz, S. Bernhard and M. Albrecht, Angew. Chem. Int. Ed., 2010, 49, 9765.

103 a) A. Petronilho, M. Rahman, J. A. Woods, H. Al-Sayyed H. Müller-Bunz, J. M. D. MacElroy, S. Bernhard and M Albrecht, Dalton Trans., 2012, 41, 13074; b) I. Corbucci, A. Petronilho, H. Müller-Bunz, L. Rocchigiani, M Albrecht and A. Macchioni, ACS Catal., 2015, 5, 2714; c) A. Petronilho, J. A. Woods, H. Mueller-Bunz, S. Bernhard and M. Albrecht, Chem. Eur. J., 2014, 20, 15775; d) J. A Woods, R. Lalrempuia, A. Petronilho, N. D. McDaniel, H. Müller-Bunz, M. Albrecht and S. Bernhard, Energy Environ. Sci., 2014, 7, 2316; e) A. Petronilho, J. A. Woods, S. Bernhard and M. Albrecht, Eur. J. Inorg. Chem., 2014, 708

104 J. Graeupner, U. Hintermair, D. L. Huang, J. M. Thomsen, M. Takase, J. Campos, S. M. Hashmi, M. Elimelech, G. W. Brudvig and R. H. Crabtree, Organometallics, 2013, 32, 5384.

105 a) D. J. Wasylenko, R. D. Palmer, C. P. Berlinguette, Chem. Commun., 2013, 49, 218; b) D. G. H. Hetterscheid J. N. H. Reek, Angew. Chem. Int. Ed., 2012, 51, 9740; c) S. Romain, L. Vigara and A.i Llobet, Acc. Chem. Res. 2009, 42, 1944.

106 a) T. P. Brewster, J. D. Blakemore, N. D. Schley, C. D. Incarvito, N. Hazari, G. W. Brudvig and R. H. Crabtree, Organometallics, 2011, 30, 965; b) Z. Codolà, J. M. S. Cardoso, B. Royo, M. Costas and J. Lloret-Fillol, Chem. Eur. J. 2013, 19, 7203; c) D. G. H. Hetterscheid and J. N. H. Reek, Chem. Commun., 2011, 47, 2712.

107 a) U. Hintermair, S. M. Hashmi, M. Elimelech, R. H. Crabtree, J. Am. Chem. Soc., 2012, 134, 9785; b) H. Junge, N. Marquet, A. Kammer, S. Denurra, M. Bauer, S. Wohlrab, F. Gärtner, M.-M. Pohl, A. Spannenberg, S. Gladiali and M. Beller, Chem. Eur. J., 2012, 18, 12749.

108 a) J. L. Namy, J. Souppe, J. Collin and H. B. Kagan, J. Org. Chem., 1984, 49, 2045; b) Y. Ishii, T. Nakano, A. Inada, Y. Kishigami, K. Sakurai and M. Ogawa, J. Org. Chem., 1986 51, 240; c) K. Krohn, B. Knauer, J. Küpke, D. Seebach, A. K. Beck and M. Hayakawa, Synthesis, 1996, 1341; d) S. Hashiguchi, A. Fujii, K.-J. Haack, K. Matsumura, T. Ikariya and R. Noyori, Angew. Chem. Int. Ed. Engl., 1997, 36 288; e) G.-Z. Wang and J.-E. Bäckvall, J. Chem. Soc. Chem. Commun., 1992, 337; f) M. L. S. Almeida, M Beller, G.-Z. Wang and J.-E. Bäckvall, Chem. Eur. J., 1996 2, 1533; g) Y. Nishibayashi, A. Yamauchi, G. Onodera and S. J. Uemura, Org. Chem., 2003, 68, 5875; h) K. Fujita, S. Furukawa and R. Yamaguchi, J. Organomet. Chem. 2002, 649, 289. i) K. Fujita, K. Yamamoto and R. Yamaguchi, Org. Lett., 2002, 4, 2691; j) K. Fujita, Z. Li, N. Ozeki and R. Yamaguchi, Tetrahedron Lett., 2003, 44 2687; k) T. Suzuki, K. Morita, M. Tsuchida and K. Hiroi, J. Org. Chem., 2003, 68, 1601; k) C. Gunanathan, D Milstein, Science, 2013, 341, 1229712

109 a) G. A. Olah, A. Goeppert and S. G. K. Prakash, Beyond Oil and Gas: The Methanol Economy, Wiley-VCH: Weinheim, Germany, 2006; b) G. A. Olah, Angew. Chem. Int. Ed., 2013, 52, 104; c) G. A. Olah, Angew. Chem. Int. Ed., 2005, 44, 2636

$110 \mathrm{~F}$. Hanasaka, K. Fujita and R. Yamaguchi, Organometallics, 2004, 23, 1490.

111 S. Hohloch, L. Hettmanczyk and B. Sarkar, Eur. J. Inorg. Chem., 2014, 3164.

112 L. S. Sharninghausen, J. Campos, M. G. Manas and R. H. Crabtree, Nat. Commun., 2014, 5, 5084.
113 L. S. Sharninghausen, B. Q. Mercado, R. H. Crabtree, D. Balcells and J. Campos, Dalton Trans., 2015, 44, 18403.

114 Z. Sun, Y. Liu, J.o Chen, C. Huang and T. Tu, ACS Catal., 2015, 5, 6573.

115 a) J. J. Bozell and G. R. Petersen, Green Chem., 2010, 12 539; b) L. Vilcocq, R. Koerin, A. Cabiac, C. Especiel, S. Lacombeand D. Duprez, Appl. Catal., B, 2014, 27, 499; c) N. Li and G. W. Huber, J. Catal., 2010, 1, 48.

116 M. G. Manas, J. Campos, L. S. Sharninghausen, E. Lin and R. H. Crabtree, Green Chem., 2015, 17, 594.

117 a) M. Nielsen, E. Alberico, W. Baumann, H.-J. Drexler, H. Junge, S. Gladiali, M. Beller, Nature, 2013, 495, 85; b) R. E. Rodríguez-Lugo, M. Trincado, M. Vogt, F. Tewes, G. Santiso-Quinones, H. Grützmacher, Nat. Chem., 2013, 5, 342; c) E. Alberico, P. Sponholz, C. Cordes, M. Nielsen, H.-J. Drexler, W. Baumann, H. Junge, M. Beller, Angew. Chem. Int. Ed., 2013, 52, 14162; d) A. Monney, E. Barsch, P. Sponholz, H. Junge, R. Ludwig, M. Beller, Chem. Commun., 2014, 50, 707; e) P. Hu, Y. Diskin-Posner, Y. Ben-David, D. Milstein, ACSCatal., 2014, 4, 2649.

118 For representative examples see: a) M. Gupta, C. Hagen, R. J. Flesher, W. C. Kaska and C. M. Jensen, Chem. Commun., 1996, 2083; b) M. Gupta, C. Hagen, W. C. Kaska, R. E. Cramer and C. M. Jensen, J. Am. Chem. Soc., 1997, 119, 840; c) W. W. Xu, G. P. Rosini, M. Gupta, C. M. Jensen, W. C. Kaska, K. Krogh-Jespersen and A. S. Goldman, Chem. Commun., 1997, 2273; d) C. M. Jensen, Chem. Commun., 1999, 2443; e) F. C. Liu, A. S. Goldman, Chem. Commun., 1999, 655; f) F. C. Liu, E. B. Pak, B. Singh, C. M. Jensen, A. S. Goldman, J. Am. Chem. Soc., 1999, 121, 4086; g) K. Krogh-Jespersen, M. Czerw, N. Summa, K. B. Renkema, P. D. Achord and A. S. Goldman, J. Am. Chem. Soc., 2002, 124, 11404; h) K. B. Renkema, Y. V. Kissin and A. S. Goldman, J. Am. Chem. Soc., 2003, 125, 7770; i) I. Göttker-Schnetmann and M. Brookhart, J. Am. Chem. Soc., 2004, 126, 9330; j) I. GöttkerSchnetmann, P. White and M. Brookhart, J. Am. Chem. Soc., 2004, 126, 1804; k) I. Göttker-Schnetmann, P. S. White and M. Brookhart, Organometallics, 2004, 23, 1766; I) K. M. Zhu, P. D. Achord, X. W. Zhang, K. KroghJespersen and A. S. Goldman, J. Am. Chem. Soc., 2004, 126, 13044; m) S. Kundu, Y. Choliy, G. Zhuo, R. Ahuja, T. J. Emge, R. Warmuth, M. Brookhart, K. Krogh-Jespersen, A. S. Goldman, Organometallics, 2009, 28, 5432.

119 a) A. R. Chianese, A. Mo, N. L. Lampland, R. L. Swartz and P. T. Bremer, Organometallics, 2010, 29, 3019; b) A. R. Chianese, S. E. Shaner, J. A. Tendler, D. M. Pudalov, D. Y. Shopov, D. Kim, S. L. Rogers and A. Mo, Organometallics, 2012, 31, 7359; c) A. R. Chianese, M. J. Drance, K. H. Jensen, S. P. McCollom, N. Yusufova, S. E. Shaner, D. Y. Shopov and J. A. Tendler, Organometallics, 2014, 33, 457.

120 a) W. Zuo and P. Braunstein, Organometallics, 2012, 31, 2606; b) M. Raynal, R. Pattacini, C. S. J. Cazin, C. Vallée, H. Olivier-Bourbigou, P. Braunstein, Organometallics, 2009, 28, 4028.

121 M. Yadav, Q. Xu, Energy Environ. Sci., 2012, 5, 9698.

122 A. Rossin and M. Peruzzini, Chem. Rev., 2016, 116, 8848.

123 G. C. Fortman, A. M. Z. Slawin, and S. P. Nolan, Organometallics, 2011, 30, 5487.

124 D. J. Nelson, B. J. Truscott, J. D. Egbert and S. P. Nolan, Organometallics, 2013, 32, 3769.

125 a) C. Fellay, P. J. Dyson and G. Laurenczy, Angew. Chem. Int. Ed., 2008, 47, 3966; b) B. Loges, A. Boddien, H. Junge and M. Beller, Angew. Chem. Int. Ed., 2008, 47, 3962; c) J. F. Hull, Y. Himeda, W.-H. Wang, B. Hashiguchi, R. Periana,D. J. Szalda, J. T. Muckerman and E. Fujita, Nat. Chem., 2012, 4, 383; d) J. J.A. Celaje, Z. Lu, E. A. Kedzie, N. J. Terrile, J. N. Lo and T. J. Williams, Nat. Commun., 2016, 7, 11308; e) M. Grasemann and G. Laurenczy, 
Energy Environ. Sci., 2012, 5, 8171; f) S.-F. Hsu, S. Rommel, P. Eversfield, K. Muller, E. Klemm, W. R. Thiel and B. Plietker, Angew. Chem. Int. Ed., 2014, 53, 707; g) E. A. Bielinski, P. O. Lagaditis, Y. Zhang, B. Q. Mercado, C. Würtele, W. H. Bernskoetter, N. Hazari and S. Schneider, J. Am. Chem. Soc., 2014, 136, 10234.

126 H. Horväth, G. Papp, R. Szabolcsi, Ý. Kathó, and F. Joó, ChemSusChem, 2015, 8, 3036.

127 S. Siek, D. B. Burks, D. L. Gerlach, G. Liang, J. M. Tesh, C. R. Thompson, F. Qu, J. E. Shankwitz, R. M. Vasquez, N. Chambers, G. J. Szulczewski, D. B. Grotjahn, C. E. Webster and E. T. Papish, Organometallics, 2017, 36, 1091.

128 a) E. M. Isin, C. S. Elmore, G. N. Nilsson, R. A. Thompson and L. Weidolf, Chem. Res. Toxicol., 2012, 25, 532; b) J. Atzrodt, V. Derdau, T. Fey and J. Zimmermann, Angew. Chem. Int. Ed., 2007, 46, 7744; c) P. H. Allen, M. J. Hickey, L. P. Kingston, D. J. Wilkinson, J. Labelled Compd. Radiopharm., 2010, 53, 731.

129 a) J. A. Brown, A. R. Cochrane, S. Irvine, W. J. Kerr, B. Mondal, J. A. Parkinson, L. C. Paterson, M. Reid, T. Tuttle, S. Andersson and G. N. Nilsson, Adv. Synth. Catal., 2014, 356, 3551; b) P. W. C. Cross, J. M. Herbert, W. J. Kerr, A. H. McNeill and L. C. Paterson, Synlett, 2016, 27, 111; c) A. R. Cochrane, C. Idziak, W. J. Kerr, B. Mondal, L. C. Paterson, T. Tuttle, S. Andersson and G. N. Nilsson, Org. Biomol. Chem., 2014, 12, 3598; d) J. Atzrodt, V. Derdau, W. J. Kerr, M. Reid, P. Rojahn and R. Weck, Tetrahedron, 2015, 71, 1924.

130 W. J. Kerr, R. J. Mudd, P. K. Owens, M. Reid, J. A. Brown and S. Campos, J. Label Compd. Radiopharm., 2016, 59, 601

131 a) A. Y. L. Shu, W. Chen and J. R. Heys, J. Organomet. Chem., 1996, 524, 87; b) J. R. Heys, J. Label. Compd. Radiopharm., 2007, 50, 770.

132 G. C. Fortman, H. Jacobsen, L. Cavallo and S. P. Nolan, Chem. Commun., 2011, 47, 9723.

133 a) M. B. Skaddan, C. M. Yung and R. G. Bergman, Org. Lett., 2004, 6, 11; b) S. R. Klei, J. T. Golden, P. Burger and R. G. Bergman, J. Mol. Catal. A: Chem., 2002, 189, 79; c) S. R. Klei, T. D. Tilley and R. G. Bergman, Organometallics, 2002, 21, 4905; d) J. T. Golden, R. A Andersen and R. G. Bergman, J. Am. Chem. Soc., 2001, 123, 5837; e) C. M. Yung, M. B. Skaddan and R. G. Bergman, J. Am. Chem. Soc., 2004, 126, 13033.

134 R. Corberán, M. Sanaú and E. Peris, J. Am. Chem. Soc., 2006, 128, 3974.

135 M. C. Lehman, J. B. Gary, P.D. Boyle, M. S. Sanford and E. A. Ison, ACS Catal., 2013, 3, 2304.

136 a) A. Burhop, R. Prohaska, R. Weck, J. Atzrodt and V. Derdau, J. Label. Compd. Radiopharm., 2017, 60, 343; b) A. Burhop, R. Weck and V. Derdau, J., Eur. J. Org. Chem, 2017, 1418.

137 W. J. Kerr, M. Reid and T. Tuttle, Angew. Chem. Int. Ed. 2017, 56, 7808.

138 I. Romanenko, S. Norsic, L. Veyre, R. Sayah, F. D'Agosto, J. Raynaud, C. Boisson, E. Lacôte and C. Thieuleux, Adv. Synth. Catal., 2016, 358, 2317.

139 a) T. K. Maishal, J. Alauzun, J.-M. Basset, C. Copéret, R. J. P. Corriu, E. Jeanneau, A. Mehdi, C. Reyé, L. Veyre and C. Thieuleux, Angew. Chem. Int. Ed., 2008, 47, 8654; b) T. K. Maishal, M. Boualleg, M. Bouhrara, C. Copéret, E. Jeanneau, L. Veyre and C. Thieuleux, Eur. J. Inorg. Chem., 2010, 5005.

140 a) R. R. Ernst, Angew. Chem. Int. Ed. Engl., 1992, 31, 805; b) K. Wuthrich, Angew. Chem. Int. Ed., 2003, 42, 3340; c) P. G. Morris, Nuclear Magnetic Resonance Imaging in Medicine and Biology; Oxford Univ. Press, Oxford, 1986; d) S. B. Duckett and N. J. Wood, Coord. Chem. Rev., 2008, 252, 2278.

141 a) H. Johanneson, S. Macholl and J. H. Ardenkjaer Larsen, J. Magn. Reson., 2009, 197, 167; b) J. H. Ardenkjaer-Larsen, B. Fridlund, A. Gram, G. Hansson, L. Hansson, M. H. Lerche, R. Servin, M. Thaning and K. Golman, Proc. Natl. Acad. Sci. USA, 2003, 100, 10158.

142 a) C. R. Bowers and D. P. Weitekamp, Phys. Rev. Lett., 1986, 57, 2645; b) C. R. Bowers and D. P. Weitekamp, J. Am. Chem. Soc., 1987, 109, 5541; c) T. C. Eisenschmid, R. U. Kirss, P. P. Deutsch, S. I. Hommeltoft, R. Eisenberg, J. Bargon, R. G. Lawler and A. L. Balch, J. Am. Chem. Soc., 1987, 109, 8089; d) S. Glöggler, A. M. Grunfeld, Y. N. Ertas, J. McCormick, S. Wagner, P. P. M. Schleker and L. S. Bouchard, Angew. Chem. Int. Ed., 2015, 54, 2452.

143 R. W. Adams, J. A. Aguilar, K. D. Atkinson, M. J. Cowley, P. I. P. Elliott, S. B. Duckett, G. G. R. Green, I. G. Khazal, J. López-Serrano and D. C. Williamson, Science, 2009, 323, 1708.

144 K. D. Atkinson, M. J. Cowley, P. I. P. Elliott, S. B. Duckett, G. G. R. Green, J. Lopez-Serrano and A. C. Whitwood, J. Am. Chem. Soc., 2009, 131, 13362.

145 R. W. Adams, S. B. Duckett, R. A. Green, D. C. Williamson and G. G. R. Green, J. Chem. Phys., 2009, 131, 194505.

146 M. J. Cowley, R. W. Adams, K. D. Atkinson, M. C. R. Cockett, S. B. Duckett, G. G. R. Green, J. A. B. Lohman, R. Kerssebaum, D. Kilgour and R. E. Mewis, J. Am. Chem. Soc., 2011, 133, 6134.

147 L. S. Lloyd, R. W. Adams, M. Bernstein, S. Coombes, S. B. Duckett, G. G. R. Green, R. J. Lewis, R. E. Mewis and C. J. Sleigh, J. Am. Chem. Soc., 2012, 134, 12904; b) N. Eshuis, N. Hermkens, B. J. A. van Weerdenburg, M. C. Feiters, F. P. J. T. Rutjes, S. S. Wijmenga and M. Tessari, J. Am. Chem. Soc., 2014, 136, 2695; c) B. J. A. van Weerdenburg, S. Glöggler, N. Eshuis, A. H. J. (Ton) Engwerda, J. M. M. Smits, R. de Gelder, S. Appelt, S. S. Wymenga, M. Tessari, M. C. Feiters, B. Blümich and F. P. J. T. Rutjes, Chem. Commun., 2013, 49, 7388; d) L. S. Lloyd, A. Asghar, M. J. Burns, A. Charlton, S. Coombes, M. J. Cowley, G. J. Dear, S. B. Duckett, G. R. Genov, G. G. R. Green, L. A. R. Highton, A. J. J. Hooper, M. Khan, I. G. Khazal, R. J. Lewis, R. E. Mewis, A. D. Roberts and A. J. Ruddlesden, Catal. Sci. Technol., 2014, 4, 3544; e) R. E. Mewis, K. D. Atkinson, M. J. Cowley, S. B. Duckett, G. G. R. Green, R. A. Green, L. A. R. Highton, D. Kilgour, L. S. Lloyd, J. A. B. Lohmanc and D. C. Williamsona, Magn. Reson. Chem., 2014, 52, 358; f) H. Zeng, J. Xu, M. T. McMahon, J. A.B. Lohman, P. C. M. van Zijl, J. Magn. Reson., 2014, 246, 119; g) M. Fekete, C. Gibard, G. J. Dear, G. G. R. Green, A. J. J. Hooper, A. D. Roberts, F. Cisnetti and S. B. Duckett, Dalton Trans., 2015, 44, 7870; h) P. Spannring, I. Reile, M. Emondts, P. P. M. Schleker, N. K. J. Hermkens, N. G. J. van der Zwaluw, B. J. A. van Weerdenburg, P. Tinnemans, M. Tessari, B. Blümich, F. P. J. T. Rutjes and M. C. Feiters, Chem. Eur. J., 2016, 22, 9277 ; i) A. M. Olaru, M. J. Burns, G. G. R. Greenb and S. B. Duckett, Chem. Sci., 2017, 8, 2257; j) F. Shi, A. M. Coffey, K. W. Waddell, E. Y. Chekmenev and B. M. Goodson, Angew. Chem. Int. Ed., 2014, 53, 7495; k) F. Shi, A. M. Coffey, K. W. Waddell, E. Y. Chekmenev and and B. M. Goodson, J. Phys. Chem. C, 2015, 119, 7525; I) M. L. Truong, F. Shi, P. He, B. Yuan, K. N. Plunkett, A. M. Coffey, R. V. Shchepin, D. A. Barskiy, K.I V. Kovtunov, I. V. Koptyug, K. W. Waddell, B. M. Goodson and E. Y. Chekmenev, J. Phys. Chem. B, 2014, 118, 13882; m) S. L. kuhl, M. Emondts, L. Schubert, P. Spannring, J. Klankermayer, B. Blemich and P. P. M.Schleker, ChemPhysChem, 2017, 18, 2426; n) K. V. Kovtunov, L. M. 
Kovtunova, M. E. Gemeinhardt, A. V. Bukhtiyarov, J. Gesiorski, V. I. Bukhtiyarov, E. Y. Chekmenev, I. V. Koptyug and B. M. Goodson, Angew. Chem. Int. Ed., 2017, 56, 10433; o) Z. Zhou, J. Yu, J. F. P. Colell, R. Laasner, A. Logan, D. A. Barskiy, R. V. Shchepin, E. Y. Chekmenev, V. Blum, W. S. Warren and T. Theis, J. Phys. Chem. Lett., 2017, 8, 3008; p) W. Iali, A. M. Olaru, G. G. R. Green and S. B. Duckett, Chem. Eur. J., 2017, 23 10491; q) R. V. Shchepin, B. M. Goodson, T. Theis, W. S. Warren and E. Y. Chekmenev, ChemPhysChem, 2017, 18, 1961; r) D. A. Barskiy, R. V. Shchepin, C. P. N. Tanner, J. F. P. Colell, B. M. Goodson, T. Theis, W. S. Warren and E. Y. Chekmenev, ChemPhysChem, 2017, 18, 1493; s) P. J. Rayner, M. J. Burns, A. M. Olaru, P. Norcott, M. Fekete, G. G. R. Green, L. A. R. Highton, R. E. Mewis and S. B. Duckett, PNAS, 2017, 114, E3188.

148 a) F. J. Fernández-Alvarez, M. Iglesias, L. A. Oro and V. Passarelli in Comprehensive Inorganic Chemistry II, Vol 8 (Eds.: J. Reedijk, K. Poeppelmeier), Elsevier, Oxford, 2013, Chap. 8.9, pp. 399; c) J. A. Labinger and J. E. Bercaw, Nature, 2002, 417, 507; d) R. G. Bergman, Nature, 2007, 446, 391.

149 a) R. Azpíroz, A. Di Giuseppe, R. Castarlenas, J. J. PerezTorrente and L. A. Oro, Chem. Eur. J., 2013, 19, 3812; b) L. Rubio-Pérez, R. Azpíroz, A. Di Giuseppe, V. Polo, R. Castarlenas, J. J. Pérez-Torrente and L. A. Oro, Chem. Eur. J., 2013, 19, 15304; c) ; L. Rubio-Pérez, M. Iglesias, R. Castarlenas, V. Polo, J. J. Pérez-Torrente and L. A. Oro, ChemCatChem, 2014, 6, 3192; d) J. Kwak, M. Kim and S. Chang, J. Am. Chem. Soc., 2011, 133, 3780; e) M. Kim, J. Kwak and S. Chang, Angew. Chem. Int. Ed., 2009, 48, 8935.

150 G. Choi, H. Tsurugi and Kazushi Mashima, J. Am. Chem. Soc., 2013, 135, 13149.

151 L. Rubio-Pérez, M. Iglesias, J. Munárriz, V. Polo, V. Passarelli, J. J. Pérez-Torrente and L. A. Oro, Chem. Sci., 2017, 8, 4811.

152 G. D. Frey, C. F. Rentzsch, D. von Preysing, T. Scherg, M. Mühlhofer, E. Herdtweck and W. A. Herrmann, J. Organomet. Chem., 2006, 691, 5725.

153 C. F. Rentzsch, E. Tosh, W. A. Herrmann and F. E. Kühn, Green Chem., 2009, 11, 1610.

154 L. Rubio-Pérez, M. Iglesias, J. Munárriz, V. Polo, P. J. Sanz Miguel, J. J. Pérez-Torrentea and Luis A. Oro, Chem. Commun., 2015, 51, 9860.

155 Z. Hou, T.-A. Koizumi, A. Fujita, H. Yamazaki and Y. Wakatsuki, J. Am. Chem. Soc., 2001, 123, 5812.

156 T. E. Müller, K. C. Hultzsch, M. Yus, F. Foubelo and M. Tada, Chem. Rev., 2008, 108, 3795.

157 E. B. Bauer, G. T. S. Andavan, T. K. Hollis, R. J. Rubio, J. Cho, G. R. Kuchenbeiser, T. R. Helgert, C. S. Letko and F. S. Tham, Org. Lett., 2008, 10, 1175 .

158 Z. G. Specht, S. A. Cortes-Llamas, H. N. Tran, C. J. van Niekerk, K. T. Rancudo, J. A. Golen, C. E. Moore, A. L. Rheingold, T. J. Dwyer and D. B. Grotjahn, Chem. Eur. J., 2011, 17, 6606

159 a) G. Sipos, A. Ou, B. W. Skelton, L. Falivene, L. Cavallo and R. Dorta, Chem. Eur. J., 2016, 22, 6939; b) G. Sipos, P. Gao, D. Foster, B. W. Skelton, A. N. Sobolev and R. Dorta, Organometallics, 2017, 36, 801

160 L. D. Field, B. A. Messerle, K. Q. Vuong and Peter Turner, Organometallics, 2005, 24, 4241.

161 R. Corberán, V. Lillo, J. A. Mata, E. Fernández and E. Peris, Organometallics, 2007, 26, 4350.

162 M. Aliaga-Lavrijsen, M. Iglesias, A. Cebollada, K. Garcés, N. García, P. J. Sanz Miguel, F. J. Fernández-Alvarez, J. J. Pérez-Torrente and L. A. Oro, Organometallics, 2015, 34, 2378.

163 N. Imlinger, M. Mayr, D. Wang, K. Wurst, M. R. Buchmeisera, Adv. Synth. Catal., 2004, 346, 1836.
164 T. Iwai, T. Fujihara, J. Terao and Y. Tsuji, J. Am. Chem. Soc., 2012, 134, 1268.

165 a) H. Kim and C. Lee, Angew. Chem. Int. Ed., 2012, 51 12303; b) M. Majek, U. Faltermeier, B. Dick, R. PérezRuiz and A. Jacobi von Wangelin, Chem. Eur. J., 2015, 21, 15496.

166 C. Yang, F. Mehmood, T. L. Lam, S. L.-F. Chan, Y. Wu, C.S. Yeung, X. Guan, K. Li, C. Y.-S. Chung, C.-Y. Zhou, T. Zou and C.-M. Che, Chem. Sci., 2016, 7, 3123.

167 T. L. Lam, J. Lai, R. R. Annapureddy, M. Xue, C. Yang, Y. Guan, P. Zhou and S. L.-F. Chan, Inorg. Chem., 2017, 56, 10835.

168 S. L.-F. Chan, T. L. Lam, C. Yang, S.-C. Yan and N. M. A Cheng, Chem. Commun., 2015, 51, 7799.

169 A. R. Chianese, S. E. Shaner, J. A.Tendler, D. M. Pudalov, D. Y. Shopov, D. Kim, S. L. Rogers and A. Mo, Organometallics, 2012, 31, 7359.

170 S. M. M. Knapp, S. E. Shaner, D. Kim, D. Y. Shopov, J. A. Tendler, D. M. Pudalov and A. R. Chianese, Organometallics, 2014, 33, 473.

171 a) R.Weihofen, O. Tverskoy and G. Helmchen, Angew. Chem. Int. Ed., 2006, 45, 5546; b) C. Gnamm, C. M. Krauter, K. Brödner, G. Helmchen, Chem. Eur. J., 2009, 15, 2050; c) C. Gnamm, K. Brödner, C. M. Krauter and G. Helmchen, Chem. Eur. J., 2009, 15, 10514; d) J. F. Teichert, M. Fañanás-Mastral and B. L. Feringa, Angew. Chem. Int. Ed., 2011, 50, 688; d) M. Fañanás-Mastral, J. F. Teichert, J. A. Fernández-Salas, D. Heijnen and B. L. Feringa, Org. Biomol. Chem., 2013, 11, 4521; e) D. Zhao, M. Fañanás-Mastral, M.-C. Chang, E. Otten and B. L. Feringa, Chem. Sci., 2014, 5, 4216.

172 a) K.-Y. Ye, Q. Cheng, C.-X. Zhuo, L.-X. Dai and S.-L. You, Angew. Chem. Int. Ed., 2016, 55, 8113; b) K.-Y. Ye, K.-J. Wu, G.-T. Li, L.-X. Dai and S.-L. You, Heterocycles, 2017, 95, 304

173 A. Zanardi, R. Corberán, J. A. Mata and E. Peris, Organometallics, 2008, 27, 3570.

174 S. Sabater, J. A. Mata and E. Peris, Organometallics, 2012, 31, 6450.

175 A. Zanardi, J. A. Mata and E. Peris, J. Am. Chem. Soc., 2009, 131, 14531.

176 L. Zhu, X. Qi, Y. Li, M. Duan, L. Zou, R. Bai and Y. Lan, Organometallics, 2017, 36, 2107.

177 a) T. M. Boller, J. M. Murphy, M. Hapke, T. Ishiyama, N. Miyaura and J. F. Hartwig, J. Am. Chem. Soc., 2005, 127, 14263; (b) I. A. I. Mkhalid, J. H. Barnard, T. B. Marder, J. M. Murphy and J. F. Hartwig, Chem. Rev., 2010, 110, 890; c) H. Tamura, H. Yamazaki, H. Sato and S. Sakaki, J. Am. Chem. Soc., 2003, 125, 16114; d) K. T. Smith, S. Berritt, M. Gonzalez-Moreiras, S. Ahn, M. R. Smith, M. H. Baik and D. J. Mindiola, Science, 2016, 351, 1424; e) G. P. Huang, M. Kalek, R. Z. Liao, and F. Himo, Chem. Sci., 2015, 6, 1735.

178 B. E. Haines, Y. Saito, Y. Segawa, K. Itami and D. G. Musaev, ACS Catal., 2016, 6, 7536.

179 K. F. Donnelly, R. Lalrempuia, H. Müller-Bunz, E. Clot and M. Albrecht, Organometallics, 2015, 34, 858.

180 E. Peris, Chem. Rev., 2017, DOI:10.1021/acs.chemrev.6b00695. 